\title{
Structural interventions in invasive cardiology
}

Citation for published version (APA):

Nietlispach, F. (2014). Structural interventions in invasive cardiology. [Doctoral Thesis, Maastricht University]. Datawyse / Universitaire Pers Maastricht. https://doi.org/10.26481/dis.20140417fn

Document status and date:

Published: 01/01/2014

DOI:

10.26481/dis.20140417fn

Document Version:

Publisher's PDF, also known as Version of record

\section{Please check the document version of this publication:}

- A submitted manuscript is the version of the article upon submission and before peer-review. There can be important differences between the submitted version and the official published version of record.

People interested in the research are advised to contact the author for the final version of the publication, or visit the DOI to the publisher's website.

- The final author version and the galley proof are versions of the publication after peer review.

- The final published version features the final layout of the paper including the volume, issue and page numbers.

Link to publication

\footnotetext{
General rights rights.

- You may freely distribute the URL identifying the publication in the public portal. please follow below link for the End User Agreement:

www.umlib.nl/taverne-license

Take down policy

If you believe that this document breaches copyright please contact us at:

repository@maastrichtuniversity.nl

providing details and we will investigate your claim.
}

Copyright and moral rights for the publications made accessible in the public portal are retained by the authors and/or other copyright owners and it is a condition of accessing publications that users recognise and abide by the legal requirements associated with these

- Users may download and print one copy of any publication from the public portal for the purpose of private study or research.

- You may not further distribute the material or use it for any profit-making activity or commercial gain

If the publication is distributed under the terms of Article $25 \mathrm{fa}$ of the Dutch Copyright Act, indicated by the "Taverne" license above, 


\section{Structural Interventions in Invasive Cardiology}

Dr. Fabian Nietlispach 
(C) Copyright Fabian Nietlispach, Maastricht 2014

ISBN 9789461593153

Production: Datawyse | Universitaire Pers Maastricht 


\title{
Structural Interventions in Invasive Cardiology
}

\author{
DISSERTATION
}

To obtain the degree of Doctor at Maastricht University, on the authority of the Rector Magnificus, Prof. dr. L.L.G. Soete in accordance with the decision of the Board of Deans,

to be defended in public

on Thursday 17 April 2014 at 10.00 hours

door

\section{Fabian Nietlispach}

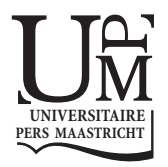




\section{Supervisor}

Prof. dr. HP. Brunner - La Rocca

\section{Assessment Committee}

Prof. dr. J. Maessen, chairman

Prof. dr. J. Hoorntje

Dr. V. van Ommen

Prof. dr. F.W. Prinzen 


\section{Contents}

$\begin{array}{lll}\text { 1. Introduction } & 7\end{array}$

1.1. Historical overview: From prototype valves to current 9 transcatheter aortic valves and delivery systems

1.2. From transfemoral to other access routes 11

1.2.1. Transapical 11

1.2.2. Subclavian 11

1.2.3. Transaortic 12

1.3. From high-risk to lower risk 12

2. Current problems and unsolved issues 17

2.1. The 'stroke issue' 17

2.1.1. An embolic deflection device for aortic valve interventions 19

2.1.2. Cerebral protection devices for transcatheter aortic valve 31 implantation: Is better the enemy of good?

2.2. Stroke prevention in patients with atrial fibrillation: left atrial $\quad 45$ appendage occlusion

2.2.1. Percutaneous Left Atrial Appendage Closure 47

2.2.2. Amplatzer Left Atrial Appendage Occlusion: Single Center 10-Year 59

Experience

$\begin{array}{lll}\text { 2.3. The transapical procedure } & 73\end{array}$

2.3.1. Closure of apical access site after transapical, transcatheter $\quad 75$ paravalvular leak closure

2.3.2. Transapical Access Closure - The TA PLUG Device 81

2.4. Pathology of Transcatheter Valve Therapy 91

$\begin{array}{lll}3 . & \text { Discussion } & 109\end{array}$

3.1. Current issues: wrap-up 111

3.1.1. Neurologic events 113

3.1.2. Ischemia during TAVR 115

3.1.3. The transapical procedure 116 
3.2. A glimpse into the future

3.2.1. Combined interventions

3.2.2. Ad-hoc TAVR: the future starts now

4. Summary

121

Samenvatting (Summary in Dutch)

129

5. Acknowledgment

137

6. Curriculum Vitae

141 
Part 1

Introduction 

Developing techniques that allow avoiding open-chest surgery for aortic valve replacement has been a field of research for many years. A less invasive approach has the potential to replace time-consuming surgery with significant impact on patients' physical integrity into a simpler procedure with faster recovery. Furthermore, it would leave the patient without visible scar apart from a minor inguinal incision.

What started with Andersen's successful series of transcatheter aortic valve implantations in seven swine in $1992^{1}$, has become a standard procedure in humans and so far has been performed in $>50^{\prime} 000$ patients worldwide.

\subsection{Historical overview: From prototype valves to current transcatheter aortic valves and delivery systems}

Andersens prototype transcatheter aortic valve consisted of a stent and a porcine valve. The stent was made of two folded and sutured stainless steel monofilaments. The porcine pig valve was sutured to the metallic stent. This stent-valve was then crimped onto an inflatable 12 French balloon catheter (see figure).
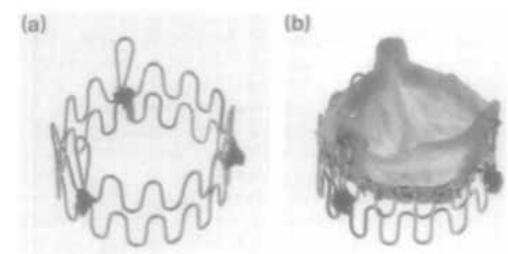

(d)
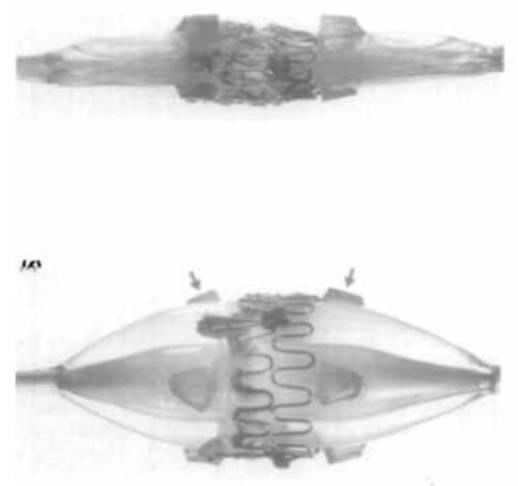

(g)

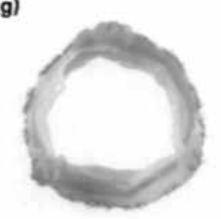

Figure 1. The stent was constructed with two $0.55 \mathrm{~mm}$ stainless steel wires folded in 15 loops (a). A three-leaflet porcine aortic valve was mounted inside the stent and fixed to the metal by sutures to form the stent-valve (b) and (c). Before implantation the stent-valve was mounted on a deflated threefoiled balloon dilatation catheter (d). The diameter of the collapsed stent-valve was $12 \mathrm{~mm}$ (d) and (e). Balloon inflation expanded the stent-valve to an external diameter of $32 \mathrm{~mm}$ (f) and (g). Each of the three balloons were mounted with two elastic blocks (indicated by arrows), to prevent migration of the stent-valve from the middle of the balloons. (European Heart Journal 1992;13:704-8) 
It took 10 years after Andersen's promising series until Cribier performed the firstin-human transcatheter aortic valve replacement (TAVR) ${ }^{2}$, using a valve and delivery system that looked similar to Andersen's prototype stent-valve: crimped onto an inflatable balloon was the Cribier-Edwards equine valve that could be delivered through a 24French delivery system. Using antegrade femoral venous access followed by a transseptal puncture and after crossing the left atrium and left ventricle, the valve was delivered in a sub-coronary annular aortic position. In a multimorbid, inoperable patient, the valve was successfully deployed and was functioning well for 17 weeks, until the patient passed away for non-cardiac reasons.

A breakthrough for broader use of the procedure was the introduction of the retrograde transfemoral arterial approach developed by Webb ${ }^{3}$. However, inability of crossing the stenotic and calcified aortic valve with a stent-valve mounted on a bulky balloon was a common reason for procedural failure in the early days. Further developments of the valve (which was now made out of the more commonly available bovine pericardium) and the delivery system (where a nose cone facilitated native valve crossing and a catheter flex mechanism allowed for easier crossing of the aortic arch) led to procedural success in $>95 \%$ of cases.

Developments and progresses in balloon-expandable valves were paralleled by the invention of a self-expandable stent-valve. The first generation self-expandable valve (CoreValve) was a bovine pericardial valve, sutured onto a self-expandable nitinol stent, delivered via a 25French catheter. The valve is sheathed and positioned in the aortic annulus. Withdrawal of the sheath leads to expansion and deployment of the valve. Replacing the bovine pericardial valve with thinner porcine pericardial tissue allowed reducing the diameter of the delivery system to 21French. The first larger series of 25 patients treated with the porcine pericardial CoreValve was published in $2006^{5}$.

While research and development of the bovine balloon-expandable valves focussed on enabling delivery through smaller sheaths, the research focus of self-expandable valves was on improving accuracy of positioning and delivery.

Both manufacturers succeeded in overcoming the Achilles heels of their products: The most recent commercially available valve systems of the two companies are the Edwards SAPIEN XT bovine pericardial valve delivered via the 16French Novaflex system and the porcine Medtronic CoreValve Evolut valve, delivered through the 18French delivery system.

Procedural complications occur and lead to temporary setbacks. The nature of the complications is different as compared to open-heart surgery (e.g. more vascular complications, less major bleddings). Despite these complications, the method established worldwide thanks to the convincing technique and steady improvements and refinements of the valve and the valve-systems (the different complications will be summarized and discussed in detail in the 'discussion section', Chapter 3). 


\subsection{From transfemoral to other access routes}

The first patient treated with TAVR suffered severe peripheral arterial disease (PAD). This led Dr Cribier to choose a venous, transseptal approach. Although successful, the transvenous access was too cumbersome to evolve as a standard approach for TAVR. While a retrograde transfemoral access proved to be reproducible with good results, it was limited to patients without significant PAD. Development of smaller delivery catheters and sheaths enabled the cardiologists to treat more and more patients with a transfemoral TAVR despite the presence of a certain degree of PAD.

Alternatives to a retrograde transfemoral arterial approach were developed for patients suffering severe PAD. All of them have in common, that they so far ask for a surgical cut-down (with a few exceptions), therefore procedures are typically performed in general anaesthesia and lead to longer postprocedural recovery.

\subsubsection{Transapical}

A left antero-lateral thoracotomy is used to expose the left ventricular apex. Pursestring sutures are placed at the apex lateral to the left anterior descending artery. Needle puncture of the left ventricle is followed by introduction of a stiff guide wire to the descending aorta, over which the valve delivery sheath is introduced to the ventricle. Feasibility of a transapical TAVR using the balloon-expandable Edwards valve was shown in $2006^{6}$, and subsequent publications proved safety and efficacy of the approach ${ }^{7}$. While the antegrade transapical approach enables a direct access to the valve, the procedure is hampered by the need for general anaesthesia and the more invasiveness of the procedure.

Except for a few centres, the transapical approach is only chosen, if the presence of severe PAD precludes a transfemoral procedure. Comparison of outcomes between transfemoral and transapical procedures showed in most publications worse outcome, when a transapical procedure was chosen. The higher risk population treated with a transapical procedure might in part explain these differences. However, in a risk-score matched comparison, better outcome with transfemoral as compared to transapical was found for the high and intermediate risk cohort ${ }^{8}$. A higher inflammatory stimulus when using a transapical approach ${ }^{9}$ might be one reason explaining the difference.

\subsubsection{Subclavian}

In case the axillary (and subclavian) artery is big enough in calibre, a surgical cutdown to the artery allows for introduction of the delivery system through the left or right axillary/subclavian artery. Since until recently, there was no transapical delivery system for the CoreValve prosthesis, the subclavian access enjoyed great popularity in 'CoreValve centres'. 
True percutaneous subclavian procedures (without surgical cut-down to the artery) have been performed, but potential vascular complications without the possibility of manually compressing the artery, bear a certain (unpredictable) risk.

An early series on subclavian TAVR in 3patients was published in 200910, showing feasibility of the method. The following year a series of 54 patients proved safety and efficacy of this access route with comparable results to a transfemoral approach $^{11}$. In the same line and as an alternative to a subclavian approach, some centers successfully used the carotid artery as an access route.

\subsubsection{Transaortic}

The most recent development is the transaortic approach. It is the most direct approach to the aortic valve and avoids crossing of the left ventricle. The first successful procedure was reported in 2009 using the CoreValve prosthesis ${ }^{12}$ and one year later the same procedure was reproduced using the Edwards valve ${ }^{13}$. In a patient with peripheral vascular disease precluding a transfemoral approach and chest deformity precluding a transapical approach, an upper partial sternotomy was performed. The ascending aorta was exposed and TAVR successfully performed, followed by sheath withdrawal and closure of the ascending aorta by tying purse strings sutures.

\subsection{From high-risk to lower risk}

Unlike percutaneous coronary intervention, which was first undertaken in low risk patients 14,15 , TAVR was performed in high-risk, inoperable patient populations. Currently, two randomized landmark trials on TAVR exist (PARTNER A and B) ${ }^{16,17}$. The first PARTNER trial (PARTNER B) proved superiority of TAVR over medical treatment in inoperable patients with a $20 \%$ absolute mortality reduction and an almost $25 \%$ absolute risk reduction for cardiovascular death at one year. Besides, the percentage of patients with no or mild symptoms was significantly higher after undergoing TAVR as compared to medical treatment ( $75 \%$ vs $42 \%$ ). Indication for TAVR in this patient population is generally accepted, except maybe for the very sick patients (e.g. very frail, dialysis patients with severe COPD), where meaningful symptomatic recovery after TAVR is doubtful and survival is severely impaired due to co-morbidities.

The second PARTNER trial (PARTNER A) randomized high-risk patients to either surgical aortic valve replacement (SAVR) or TAVR. Since the trial was mainly performed in the United States, most centres started their TAVR program only within the trial. Despite this disadvantage, TAVR proved to be non-inferior to SAVR with regard to survival. The subgroup of patients treated with transfemoral TAVR even showed a significantly better 30-day survival as compared to SAVR patients (as-treated analysis). 
Peri-procedural risks differed between the two treatment arms: while TAVR patients suffered more vascular complications and neurologic events, SAVR patients encountered more major bleedings and new-onset atrial fibrillation.

Although the PARTNER trials currently represent the best evidence in the TAVR field, they might not accurately reflect current outcomes in TAVR. The PARTNER trials were performed using the second generation Edwards device. Newer devices and delivery systems improved on accuracy of deployment and a markedly reduced sheath size lead to a reduction of vascular access complications ${ }^{18}$. Increased operator experience also improves outcomes in TAVR, as previously shown ${ }^{19}$. Registry data therefore probably more accurately reflect current outcomes and practice. The French registry (FRANCE 2) ${ }^{20}$ demonstrated equally good 1-year survival rates when using a frugal approach to TAVR: three quarters of procedures were performed in the catheterization laboratory (as opposed to a hybrid operating suite) and a transarterial approach was used in $>80 \%$. Of those, local anaesthesia was used in $>40 \%$ and fully percutaneous arterial access site closure was routine. In $>15 \%$ of patients, decision to undergo TAVR (as opposed to SAVR) was solely based on patients' preference (as opposed to high surgical risk).

The European SOURCE registry ${ }^{8}$ compared outcomes of transfemoral and transapical groups adjusted to their respective risk score, showing better outcomes with the transfemoral approach. Stroke rates were lower in this real-world registry (2.5\% at 30 days and $4.5 \%$ at 1 year), as compared to the PARTNER Trial.

The Canadian experience ${ }^{21}$ reported equal use of the transfemoral and transapical route with similar outcomes between the two. They defined high-risk subgroups with worse outcome to be patients suffering from chronic obstructive pulmonary disease and chronic kidney disease, while patients with porcelain aorta showed better long-term outcomes.

A subgroup of TAVI patients that are of particular concern are patients suffering from atrial fibrillation: outcome in those patients is worse as compared to patients in sinus rhythm, for reasons that are not fully understood ${ }^{22}$.

In summary, TAVR has established as an excellent alternative to SAVR with an at least comparable outcome. The focus has diverted away from reasonability to improving outcome and maybe moving towards lower risk populations. This bodes well for the new procedure. How can we try to further improve outcomes of TAVR? The most devastating complication is the occurrence of a major stroke: can we further reduce the stroke rate? In particular: what is the role of cerebral protection devices? Left atrial appendage occlusion (LAAO) is an attractive treatment option for TAVR patients in atrial fibrillation, typically being exposed to a high bleeding risk. What are the long-term outcomes after LAAO? Do long-term outcome data justify the combination of TAVR and LAAO to potentially improve outcomes in this high-risk population? And: what can we learn from pathology studies in TAVR patients? Can the transcatheter valves be expected to be as durable as bioprosthetic surgical valves? What are the mechanisms of heart-block and are 
there other - unexpected - pathology findings? Can we reduce invasiveness of the transapical procedure, thereby potentially improving outcomes? I will try to address some aspects of these important issues in the following chapters.

\section{References}

1. Andersen HR, Knudsen LL, Hasenkam JM. Transluminal implantation of artificial heart valves. Description of a new expandable aortic valve and initial results with implantation by catheter technique in closed chest pigs. Eur Heart J. 1992;13:704-708.

2. Cribier A, Eltchaninoff H, Bash A, Borenstein N, Tron C, Bauer F, Derumeaux G, Anselme F, Laborde F, Leon MB. Percutaneous transcatheter implantation of an aortic valve prosthesis for calcific aortic stenosis: first human case description. Circulation. 2002;106:3006-3008.

3. Webb JG, Chandavimol M, Thompson CR, Ricci DR, Carere RG, Munt BI, Buller CE, Pasupati S, Lichtenstein S. Percutaneous aortic valve implantation retrograde from the femoral artery. Circulation. 2006;113:842-850.

4. Grube E, Laborde JC, Zickmann B, Gerckens U, Felderhoff T, Sauren B, Bootsveld A, Buellesfeld L, Iversen S. First report on a human percutaneous transluminal implantation of a self-expanding valve prosthesis for interventional treatment of aortic valve stenosis. Catheter Cardiovasc Interv. 2005;66:465-469.

5. Grube E, Laborde JC, Gerckens U, Felderhoff T, Sauren B, Buellesfeld L, Mueller R, Menichelli M, Schmidt T, Zickmann B, Iversen S, Stone GW. Percutaneous implantation of the CoreValve selfexpanding valve prosthesis in high-risk patients with aortic valve disease: the Siegburg first-in-man study. Circulation. 2006;114:1616-1624.

6. Lichtenstein SV, Cheung A, Ye J, Thompson CR, Carere RG, Pasupati S, Webb JG. Transapical transcatheter aortic valve implantation in humans: initial clinical experience. Circulation. 2006;114:591-596.

7. Ye J, Cheung A, Lichtenstein SV, Nietlispach F, Albugami S, Masson JB, Thompson CR, Munt B, Moss R, Carere RG, Jamieson WR, Webb JG. Transapical transcatheter aortic valve implantation: follow-up to 3 years. J Thorac Cardiovasc Surg. 2010;139:1107-13, 1113.e1.

8. Thomas M, Schymik G, Walther T, Himbert D, Lefevre T, Treede H, Eggebrecht H, Rubino P, Colombo A, Lange R, Schwarz RR, Wendler O. One-year outcomes of cohort 1 in the Edwards SAPIEN Aortic Bioprosthesis European Outcome (SOURCE) registry: the European registry of transcatheter aortic valve implantation using the Edwards SAPIEN valve. Circulation. 2011;124:425-433.

9. Stahli BE, Grunenfelder J, Jacobs S, Falk V, Landmesser U, Wischnewsky MB, Luscher TF, Corti R, Maier W, Altwegg LA. Assessment of inflammatory response to transfemoral transcatheter aortic valve implantation compared to transapical and surgical procedures: a pilot study. J Invasive Cardiol. 2012;24:407-411.

10. Fraccaro C, Napodano M, Tarantini G, Gasparetto V, Gerosa G, Bianco R, Bonato R, Pittarello D, Isabella G, Iliceto S, Ramondo A. Expanding the eligibility for transcatheter aortic valve implantation the trans-subclavian retrograde approach using: the III generation CoreValve revalving system. JACC Cardiovasc Interv. 2009;2:828-833.

11. Petronio AS, De Carlo M, Bedogni F, Marzocchi A, Klugmann S, Maisano F, Ramondo A, Ussia GP, Ettori F, Poli A, Brambilla N, Saia F, De Marco F, Colombo A. Safety and efficacy of the subclavian approach for transcatheter aortic valve implantation with the CoreValve revalving system. Circ Cardiovasc Interv. 2010;3:359-366.

12. Bauernschmitt R, Schreiber C, Bleiziffer S, Ruge H, Mazzitelli D, Hutter A, Tassani P, Lange R. Transcatheter aortic valve implantation through the ascending aorta: an alternative option for noaccess patients. Heart Surg Forum. 2009;12:E63-4.

13. Bapat V, Thomas M, Hancock J, Wilson K. First successful trans-catheter aortic valve implantation through ascending aorta using Edwards SAPIEN THV system. Eur J Cardiothorac Surg. 2010;38:811813. 
14. Gruntzig A. Transluminal dilatation of coronary-artery stenosis. Lancet. 1978;1:263.

15. Gruntzig AR, Senning A, Siegenthaler WE. Nonoperative dilatation of coronary-artery stenosis: percutaneous transluminal coronary angioplasty. N Engl J Med. 1979;301:61-68.

16. Leon MB, Smith CR, Mack M, Miller DC, Moses JW, Svensson LG, Tuzcu EM, Webb JG, Fontana GP, Makkar RR, Brown DL, Block PC, Guyton RA, Pichard AD, Bavaria JE, Herrmann HC, Douglas PS, Petersen JL, Akin JJ, Anderson WN, Wang D, Pocock S. Transcatheter aortic-valve implantation for aortic stenosis in patients who cannot undergo surgery. N Engl J Med. 2010;363:1597-1607.

17. Smith CR, Leon MB, Mack MJ, Miller DC, Moses JW, Svensson LG, Tuzcu EM, Webb JG, Fontana GP, Makkar RR, Williams M, Dewey T, Kapadia S, Babaliaros V, Thourani VH, Corso P, Pichard AD, Bavaria JE, Herrmann HC, Akin JJ, Anderson WN, Wang D, Pocock SJ. Transcatheter versus surgical aorticvalve replacement in high-risk patients. N Engl J Med. 2011;364:2187-2198.

18. Toggweiler S, Gurvitch R, Leipsic J, Wood DA, Willson AB, Binder RK, Cheung A, Ye J, Webb JG. Percutaneous aortic valve replacement: vascular outcomes with a fully percutaneous procedure. J Am Coll Cardiol. 2012;59:113-118.

19. Gurvitch R, Tay EL, Wijesinghe N, Ye J, Nietlispach F, Wood DA, Lichtenstein S, Cheung A, Webb JG. Transcatheter aortic valve implantation: lessons from the learning curve of the first 270 high-risk patients. Catheter Cardiovasc Interv. 2011;78:977-984.

20. Gilard M, Eltchaninoff H, Iung B, Donzeau-Gouge P, Chevreul K, Fajadet J, Leprince P, Leguerrier A, Lievre M, Prat A, Teiger E, Lefevre T, Himbert D, Tchetche D, Carrie D, Albat B, Cribier A, Rioufol G, Sudre A, Blanchard D, Collet F, Dos Santos P, Meneveau N, Tirouvanziam A, Caussin C, Guyon P, Boschat J, Le Breton H, Collart F, Houel R, Delpine S, Souteyrand G, Favereau X, Ohlmann P, Doisy V, Grollier G, Gommeaux A, Claudel JP, Bourlon F, Bertrand B, Van Belle E, Laskar M. Registry of transcatheter aortic-valve implantation in high-risk patients. $N$ Engl J Med. 2012;366:1705-1715.

21. Rodes-Cabau J, Webb JG, Cheung A, Ye J, Dumont E, Feindel CM, Osten M, Natarajan MK, Velianou JL, Martucci G, DeVarennes B, Chisholm R, Peterson MD, Lichtenstein SV, Nietlispach F, Doyle D, DeLarochelliere R, Teoh K, Chu V, Dancea A, Lachapelle K, Cheema A, Latter D, Horlick E. Transcatheter aortic valve implantation for the treatment of severe symptomatic aortic stenosis in patients at very high or prohibitive surgical risk: acute and late outcomes of the multicenter Canadian experience. $J$ Am Coll Cardiol. 2010;55:1080-1090.

22. Stortecky S, Windecker S, Pilgrim T, Heg D, Buellesfeld L, Khattab AA, Huber C, Gloekler S, Nietlispach F, Mattle H, Juni P, Wenaweser P. Cerebrovascular accidents complicating transcatheter aortic valve implantation: frequency, timing and impact on outcomes. EuroIntervention. 2012;8(1):62-70. 



\section{Part 2}

Current problems and unsolved issues

\subsection{The 'stroke issue'}





\subsubsection{An embolic deflection device for aortic valve interventions}

Fabian Nietlispach MD, Namal Wijesinghe MD, Ronen Gurvitch MD, Edgar Tay MD, Jeffrey P. Carpenter, MD, Carol Burns, RN, John G. Webb MD

J Am Coll Cardiol Intv 2010;3:1133-8. 


\section{Abstract}

Objectives. We describe initial human experience with a novel cerebral embolic protection device.

Background. Cerebral emboli are the major cause of procedural stroke during percutaneous aortic valve interventions.

Methods. Utilizing right radial artery access the embolic protection device is advanced into the aortic arch. Once deployed a porous membrane shields the brachiocephic trunk and the left carotid artery deflecting emboli away from the cerebral circulation. Embolic material is not contained or removed by the device. The device was utilized in 4 patients (mean age 90 years) with severe aortic stenosis undergoing aortic balloon valvuloplasty $(n=1)$ or transcatheter aortic valve implantation (TAVI) $(n=3)$.

Results. Correct placement of the embolic protection device was achieved without difficulty in all patients. Continuous brachiocephalic and aortic pressure monitoring documented equal pressures without evidence of obstruction to cerebral perfusion. Additional procedural time due to the use of the device was $13 \mathrm{~min}$ (IQR 12-16). There were no procedural complications. Pre-discharge cerebral magnetic resonance imaging found no new defects in any of 3 patients undergoing TAVI and a new $5 \mathrm{~mm}$ acute cortical infarct in 1 asymptomatic patient following balloon valvuloplasty alone. No patient developed new neurological symptoms or clinical findings of stroke.

Conclusion. Embolic protection during transcatheter aortic valve intervention appears feasible and may have the potential to reduce the risk of cerebral embolism and stroke.
Abbreviations:
TAVI = Transarterial aortic valve implantation cMRI = Cranial magnetic resonance imaging 


\section{Introduction}

Transcatheter aortic valve interventions are associated with a risk of cerebral embolism and stroke. Atheroembolism may occur as a consequence of traumatic passage of wires and catheters around an atheromatous aortic arch ${ }^{1}$. Calcific embolism may occur when the endothelial covering of a degenerated aortic valve is disrupted. Thromboembolism may occur during any interventional procedure. Aortic balloon valvuloplasty has been associated with a stroke rate of 1 to $4 \% 2345$. Transcatheter aortic valve implantation (TAVI) has been associated with a stroke rate of 1.9$4.2 \% 67$.

Clinical stroke may represent one end of the spectrum of cerebral embolism. Recent studies suggest that subclinical cerebral embolic events are common ${ }^{89-11}$. Cranial magnetic resonance imaging (cMRI) has demonstrated an incidence of new cerebral lesions in $22 \%$ of elderly high risk patients undergoing diagnostic catheterization with crossing of the aortic valve ${ }^{12}$ and recent studies found that $73-84 \%$ of patients undergoing TAVI had new cerebral lesions on cMRI ${ }^{13}{ }^{14}$. The clinical importance of asymptomatic new cMRI lesions is unknown, but remains a concern 8,15 1617 .

Cerebral protection devices exist for carotid interventions ${ }^{18}$ and may lead to a $60 \%$ reduction of brain embolism. Other devices are currently under investigation for surgical aortic valve replacement ${ }^{19}$. We report our first-in-human experience with the Embrella Embolic Deflector ${ }^{\mathrm{TM}}$ (Embrella Cardiovascular Inc, Wayne, PA) device which is designed to reduce the number of cerebral emboli in percutaneous aortic valve interventions.

\section{Methods}

\section{Patients}

The device was used in 4 patients with severe symptomatic aortic stenosis. All patients underwent balloon aortic valvuloplasty and in 3 patients this was followed by TAVI. Pre- and postprocedural cMRI studies were performed. All patients were reviewed with a senior team of cardiologists and cardiac surgeons and had been declined for open aortic valve replacement due to age and co-morbidities. Procedures were approved by the Department of Health and Welfare, Canada and patients gave written informed consent for TAVI, balloon aortic valvuloplasty and the use of the Embrella Embolic Deflector ${ }^{\mathrm{TM}}$. 


\section{Embrella Embolic Deflector ${ }^{T M}$}

The device is designed to cover the ostia of the brachiocephalic trunk (and its right carotid branch) and the left carotid artery originating directly from the transverse aorta, thereby deflecting emboli away from the cerebral circulation. Deflecting petals consist of a heparin coated polyurethane membrane with 100 micron sized pores. This membrane is mounted on a Nitinol@ frame, which itself is attached to a $110 \mathrm{~cm}$ long $0.035 \mathrm{inch}(0.09 \mathrm{~cm})$ Nitinol $\AA$ shaft (Figure $1 \mathrm{~A})$. When deployed, the petals of the device extend over a length of $58 \mathrm{~mm}$ with a width of $25 \mathrm{~mm}$. Three radiopaque markers help for fluoroscopy-guided deployment: one at the outer point of each petal and one on the distal shaft (Figure 1B). The entire system can be delivered through a 6 French delivery sheath introduced from the right arm.
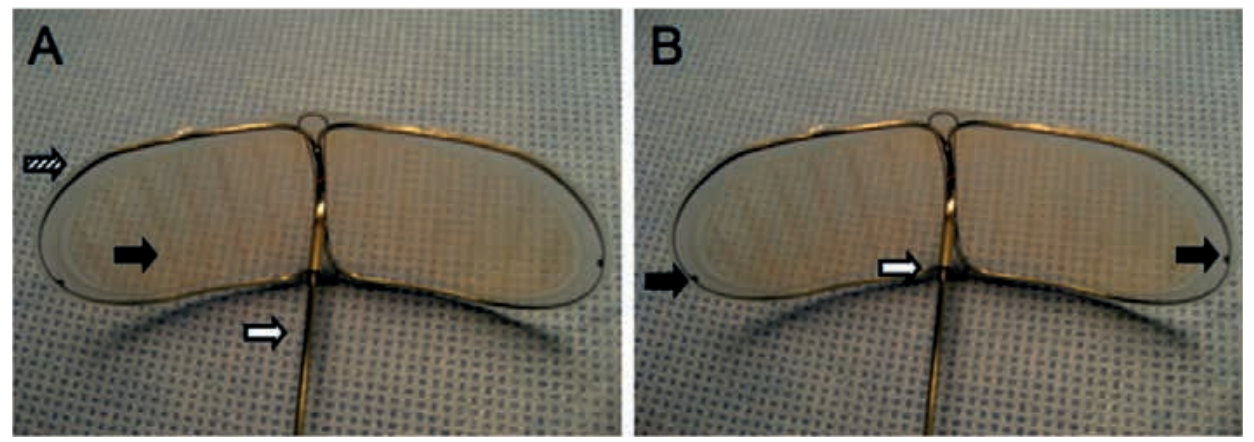

Figure 1. Embrella Embolic Deflector ${ }^{\mathrm{TM}}$

A. The device consists of a porous membrane (black arrow), a nitinol frame (striped arrow) and a nitinol shaft (white arrow). B. Two radiopaque markers indicate the end of each petal (black arrows) and one radiopaque marker at the end of the shaft help proper alignment of the device with the tip of the sheath (white arrow).

Patients were pre-treated with clopidogrel $600 \mathrm{mg}$ and aspirin $325 \mathrm{mg}$ at least 2 hours prior to commencement of the procedure. In all patients a standard $6 \mathrm{~F}$ sheath was placed in the right radial artery following which heparin was given so as to achieve an activated clotting time above $300 \mathrm{~ms}$. A 0.035 " J-tipped guidewire was advanced to the aortic arch over which was passed a $90 \mathrm{~cm}$ long 6 French Shuttle SL sheath (Cook Medical, Stouffville, ON, Canada). After confirming integrity of the devices' porous membrane by visual inspection, the device was retracted into a loading tool, flushed and subsequently introduced into the sheath. With the tip of the sheath in the aortic arch the device was slowly released under fluoroscopic guidance. Deployment of the two petals each in the opposite direction (one towards the ascending aorta, the other towards the distal aortic arch) without deformation of the petals was assured (Figure 2). The device was then retracted towards the sheath so that the distal marker on the sheath aligned with the radiopaque marker on the device shaft (Figure 3A and B). In this position the device and sheath were pulled back as to cover the ostia of the brachiocephalic trunk and the left common 
carotid artery, adjacent to the greater curvature of the aortic arch (Figure 3C). Correct device position was confirmed if contrast injections through the delivery sheath led to temporary dye pooling over the brachiocelphalic and left carotid ostia adjacent to the overlying device (Figure 3C). Pressure was measured continuously from the side port of the delivery sheath (representing brachiocephalic pressure distal to the Embrella device) and from a pigtail in the ascending aorta (representing pressure proximal to the Embrella device) to ensure that cerebral perfusion was maintained at all time (Figure 4).
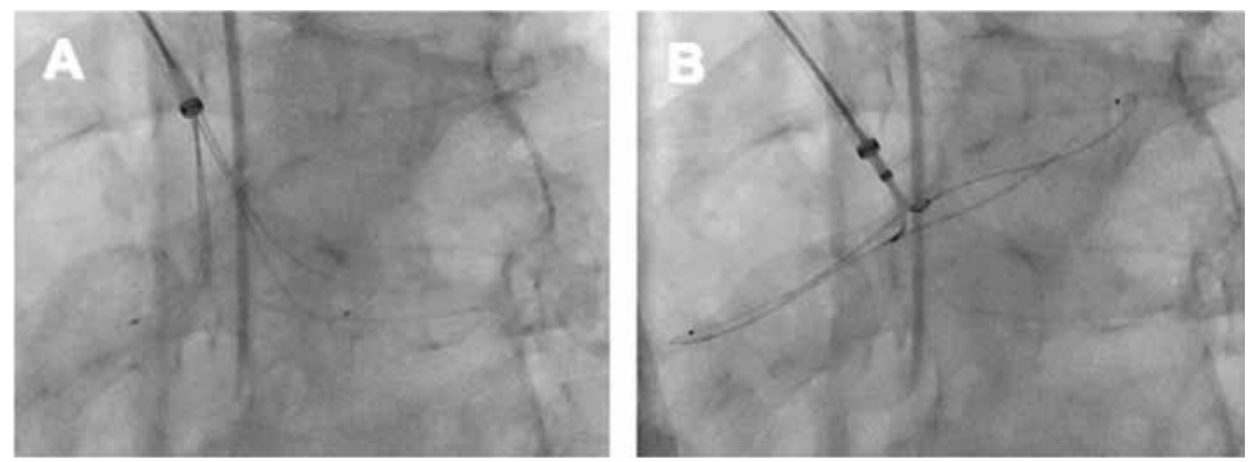

Figure 2. Deployment of the Embrella Embolic Deflector ${ }^{\mathrm{TM}}$

A. The two petals are oriented in the opposite direction. B. Further deployment with the two petals fully opened.
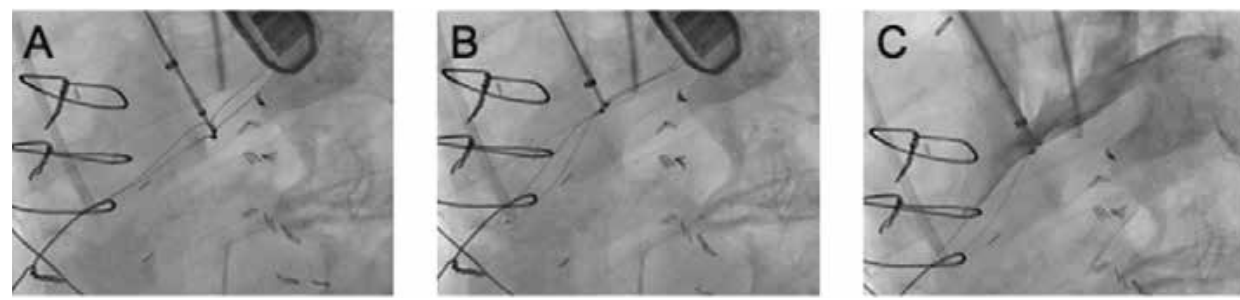

Figure 3. Final positioning of the Embrella Embolic Deflector ${ }^{\mathrm{TM}}$

$\mathbf{A}$ and $\mathbf{B}$. The radiopaque marker on the shaft has to be aligned with the radiopaque marker on the tip of the sheath. C. The sheath and the device are retracted to cover the ostia of the brachiocephalic trunk and the left common carotid. Contrast collects transiently on the distal side of the petals, indicating correct positioning. 


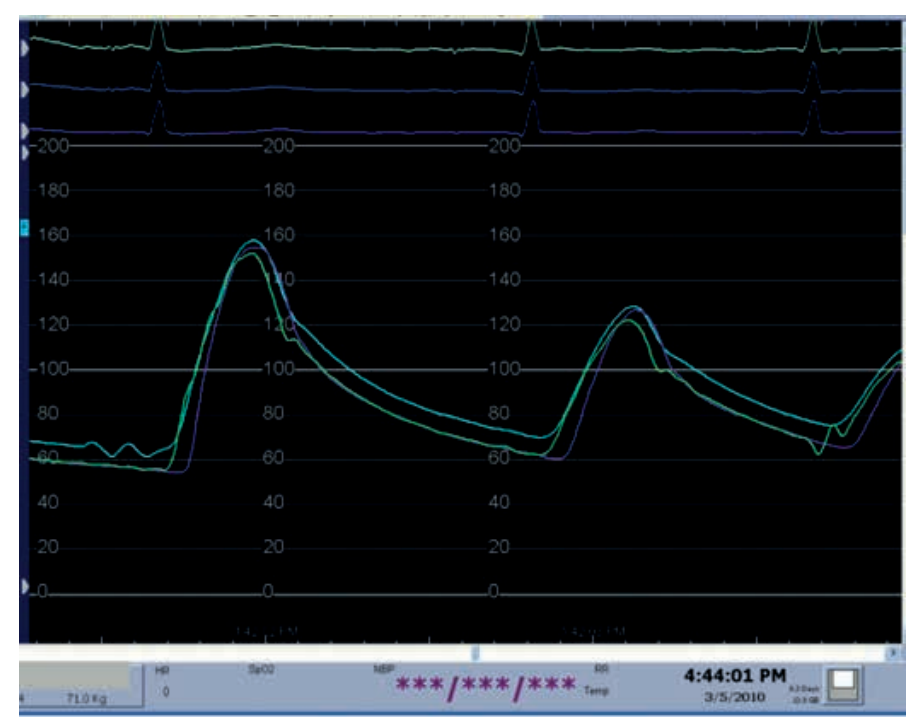

Figure 4. Continous pressure recording proximal and distal to the device Three pressure tracings were continuously recorded: aortic pressure (green), brachiocephalic pressure (blue) and femoral pressure (purple). There was no pressure gradient across the device.

\section{Aortic valve intervention}

Balloon valvuloplasty was performed utilizing a balloon (Nucleus ${ }^{\mathrm{TM}}$, NuMed Inc, London, ON, Canada) with a nominal diameter equal to the echocardiographic diameter of the aortic annulus. TAVI was performed in a standard manner utilizing an Edwards SAPIEN valve and Retroflex 3 delivery system (Edwards Lifescience Inc, Irvine, CA, USA) ${ }^{20}$. Percutaneous femoral access was utilized. A 14 French arterial sheath was utilized in the 1 patient undergoing valvuloplasty alone, a 24French sheath (for the $26 \mathrm{~mm}$ Edwards SAPIEN valve) was used in 2 patients and a 22French sheath (for the $23 \mathrm{~mm}$ Edwards SAPIEN valve) in 1 patient. Percutaneous puncture with pre-closure of the femoral access site (ProGlide, Abott Vascular, Abbott Park, IL, USA) was routine. Rapid pacing during balloon valvuloplasty and TAVI was routine. General anaesthesia with transesophageal echo-guidance was utilized in all TAVI procedures.

\section{Statistics}

Given the small study population all data are presented as median and interquartile ranges (IQR). No group comparisons were performed. 


\section{Results}

\section{Baseline characteristics}

Median age was 90years (IQR 87-92), 3 male and one female. Risk factors for stroke included peripheral vascular disease in 2 , prior stroke in 3 , hypertension in 3 , dyslipidemia in 2, none suffered diabetes or was a smoker and none had severe ascending aorta calcification ${ }^{21}$. Fluoroscopic calcification of the ascending aorta was graded mild in all and fluoroscopic valvular calcification was graded 3+ (dense circumferential calcification) in 3patients.

\section{Procedural outcome}

Correct placement of the Embrella Embolic Deflector ${ }^{\mathrm{TM}}$ with the deflecting petals covering the brachiocephalic and left carotid artery ostia was achieved in all 4 patients. The device appeared to be self-aligning within the transverse aorta and did not require manipulation beyond withdrawal so as to appose the outer curvature of the aortic arch. Contrast injection through the delivery sheath confirmed transient pooling in the arch vessels distal to the deflector. Radial and aortic monitoring showed no significant reduction in perfusion pressure and did not vary through the course of the procedure (Figure 4).

Advancement of wires, pigtail catheters, valvuloplasty balloons and the relatively bulky valve delivery system alongside the Embrella device was associated with minimal interaction without significant interference or dislodgement of the device (Figure 5). In one case a wire and pigtail catheter appeared to pass behind the deflector. This was corrected with further withdrawing the deflector so as to improve apposition of the device. At the end of the valve procedures, the deflector was easily withdrawn into the delivery sheath and removed. Hemostasis was accomplished with a standard radial compression band. Device inspection showed no evidence of visible damage or adherent thrombus or embolic material (Figure 6). The total procedural time was 91.5 min (IQR 83-97). Total time for insertion of the radial sheath, subsequent exchange for the Shuttle SL sheath and insertion, placement and finally retrieval of the Embrella device was 13min (IQR 12-16). The Embrella deflector was deployed ('device in patient') for a total of $42 \mathrm{~min}$ (IQR 39-50). 

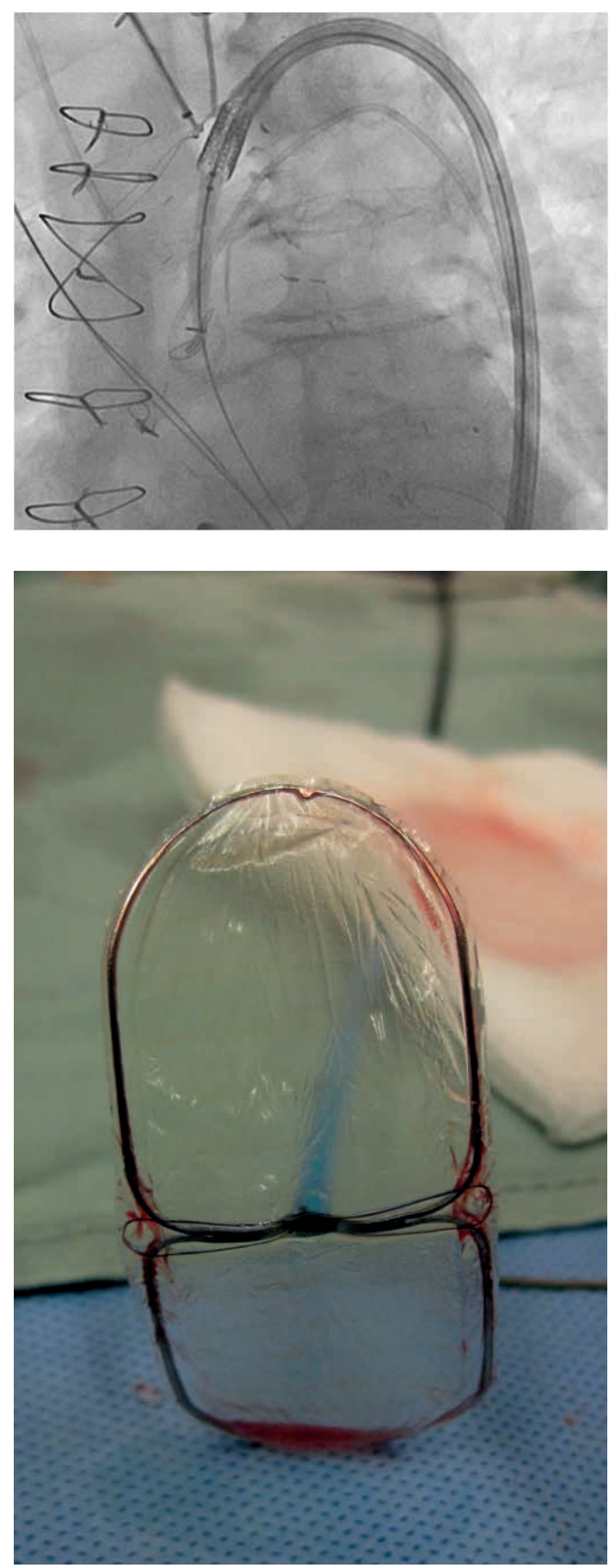

Figure 5. Minimal device interference No dislodgment or interference occurred during passage of the device with the valve delivery system.

\section{Figure 6. Device integrity}

No damage to the device was observed after retrieval. 


\section{Clinical outcome}

Clinical assessment before hospital discharge did not reveal any new neurologic symptoms. No procedural complications occurred, in particular there were no complications related to insertion of the Embrella device. Pre-discharge cMRI showed a $5 \mathrm{~mm}$ acute cortical infarct in the right temporal lobe in the patient that underwent balloon aortic valvuloplasty alone. No patient undergoing TAVI had a new finding on pre-discharge cMRI.

\section{Discussion}

Our first-in-human experience demonstrates that cerebral embolic protection during transcatheter aortic valve interventions is feasible and can be accomplished without significantly interfering with or prolonging what is an already complex procedure.

The Embrella device has a number of advantageous features. It can be introduced easily from the radial artery with minimal interference with the course of the TAVI procedure. Protection during the entire course of a TAVI procedure is feasible. A single device provides protection for the right carotid and right vertebral branches of the brachiocephalic artery and the left carotid artery. In some patients the device may also overlie the left subclavian ostium, providing protection for the left vertebral. As the device is not positioned within the cerebral vessels the risk of arterial spasm, injury, thrombosis or transiently impaired cerebral perfusion appears minimal.

Cerebral emboli originating from the aortic valve and proximal aorta are likely the major mechanism of stroke in the setting of aortic valve intervention ${ }^{12-14}$. Although stroke rates were relatively high in the early TAVI experience the reported risk of stroke seems to be falling, perhaps due to the development of less traumatic valve delivery catheters 22,23 , improved technique and patient selection. Nevertheless recent TAVI series continue to report a 1 to $4 \%$ risk of clinical stroke associated with significant morbidity and mortality 6,7,23.

Several lines of evidence suggest that reported stroke rates may underestimate the clinical importance of cerebral embolism. Early experience with transcranial Doppler and post-procedural cMRI ${ }^{13,}{ }^{14}$ suggest that cerebral embolism is more the norm than the exception with TAVI even in the absence of clinical deficits. Comparable experience with carotid stenting suggest microemboli play a role in memory loss and other neurocognitive syndromes 2425 . Several studies suggest that cerebral protection during carotid interventions may reduce cerebral embolism and improve outcomes 26271828 . 
The current study documents use of the Embrella device in the setting of TAVI. However other potential applications can be envisioned. Open heart or aortic surgery in the presence of aortic atheroma or intra-cardiac thrombus and mitral valvuloplasty or atrial appendage closure in the presence of left atrial thrombus may represent additional potential applications for cerebral protection.

\section{Limitations}

Given the small number of patients our experience can only be considered a proof of concept. Further studies will be required to document safety and efficacy. All our patients had type II aortic arch anatomy with the right subclavian and right carotid artery originating from the brachiocephalic trunk. The importance of variation in aortic arch anatomy is unknown as the applicability of this device in patients undergoing aortic valve interventions utilizing different interventional devices and routes of access (eg. transaxillary or transapical). The risk of device thrombosis in the presence of suboptimal anticoagulant and antiplatelet therapy and prolonged dwell time are unknown. An obvious concern is that this device does not trap emboli or allow for their removal. Instead emboli are deflected into the descending aorta. Although cerebral embolization may be reduced embolization to the periphery, kidneys and bowel may be correspondingly increased. Theoretically the clinical consequences are less with peripheral micro-embolism, however this remains to be demonstrated.

\section{Conclusion}

The use of an aortic embolic deflector system appears feasible and is compatible with clinical aortic valvuloplasty and transcatheter valve implantation. The procedure appears safe with minimal additional time requirements. The Embrella Embolic Deflector is a promising device that may improve the outcomes of TAVI. Further studies are required to further assess safety and efficacy.

\section{References}

1. Osranek M, Pilip A, Patel PR, Molisse T, Tunick PA, Kronzon I. Amounts of aortic atherosclerosis in patients with aortic stenosis as determined by transesophageal echocardiography. Am J Cardiol. 2009;103:713-717.

2. Grossetete R, Paris D, Crochet D, Le Menager H, Leurent B, Petitier H. [Aortic valvuloplasty in the elderly. Immediate and medium-term results]. Ann Radiol (Paris). 1989;32:97-102.

3. Pedersen WR, Klaassen PJ, Pedersen CW, et al. Comparison of outcomes in high-risk patients $>70$ years of age with aortic valvuloplasty and percutaneous coronary intervention versus aortic valvuloplasty alone. Am J Cardiol. 2008;101:1309-1314.

4. Eisenhauer AC, Hadjipetrou P, Piemonte TC. Balloon aortic valvuloplasty revisited: the role of the inoue balloon and transseptal antegrade approach. Catheter Cardiovasc Interv. 2000;50:484-491. 
5. Lewin RF, Dorros G, King JF, Mathiak L. Percutaneous transluminal aortic valvuloplasty: acute outcome and follow-up of 125 patients. J Am Coll Cardiol. 1989;14:1210-1217.

6. Webb JG, Altwegg L, Boone RH, et al. Transcatheter aortic valve implantation: impact on clinical and valve-related outcomes. Circulation. 2009;119:3009-3016.

7. Piazza N, Grube E, Gerckens U, et al. Procedural and 30-day outcomes following transcatheter aortic valve implantation using the third generation $(18 \mathrm{Fr})$ corevalve revalving system: results from the multicentre, expanded evaluation registry 1-year following CE mark approval. EuroIntervention: journal of EuroPCR in collaboration with the Working Group on Interventional Cardiology of the European Society of Cardiology. 2008;4:242.

8. Russell D. Cerebral microemboli and cognitive impairment. J Neurol Sci. 2002;203-204:211-214.

9. Hamon M, Gomes S, Oppenheim C, et al. Cerebral microembolism during cardiac catheterization and risk of acute brain injury: a prospective diffusion-weighted magnetic resonance imaging study. Stroke. 2006;37:2035-2038.

10. Dittrich R, Ringelstein EB. Occurrence and clinical impact of microembolic signals during or after cardiosurgical procedures. Stroke. 2008;39:503-511.

11. van Heesewijk HP, Vos JA, Louwerse ES, et al. New brain lesions at MR imaging after carotid angioplasty and stent placement. Radiology. 2002;224:361-365.

12. Omran H, Schmidt H, Hackenbroch M, et al. Silent and apparent cerebral embolism after retrograde catheterisation of the aortic valve in valvular stenosis: a prospective, randomised study. Lancet. 2003;361:1241-1246.

13. Ghanem A, Muller A, Nahle CP, et al. Risk and Fate of Cerebral Embolism After Transfemoral Aortic Valve Implantation A Prospective Pilot Study With Diffusion-Weighted Magnetic Resonance Imaging. J Am Coll Cardiol. 2010

14. Kahlert P, Knipp SC, Schlamann M, Thielmann M, F. Silent and apparent cerebral ischemia after percutaneous transfemoral aortic valve. Circulation. 2010

15. Mosley THJ, Knopman DS, Catellier DJ, et al. Cerebral MRI findings and cognitive functioning: the Atherosclerosis Risk in Communities study. Neurology. 2005;64:2056-2062.

16. Vermeer SE, Longstreth WTJ, Koudstaal PJ. Silent brain infarcts: a systematic review. Lancet Neurol. 2007;6:611-619.

17. Duffis EJ, Jones D, Tighe D, Moonis M. Neurological complications of coronary angiographic procedures. Expert Rev Cardiovasc Ther. 2007;5:1113-1121.

18. Henry M, Polydorou A, Henry I, Polydorou AD, Hugel M. Carotid angioplasty and stenting under protection: advantages and drawbacks. Expert Rev Med Devices. 2008;5:591-603.

19. Sauren LD, la Meir M, Bolotin G, et al. The EmBlocker: efficiency of a new ultrasonic embolic protection device adjunctive to heart valve surgery. Ann Thorac Surg. 2009;88:253-257.

20. Webb JG, Chandavimol M, Thompson CR, at al. Percutaneous aortic valve implantation retrograde from the femoral artery. Circulation. 2006;113:842-850.

21. Tanne D, Tenenbaum A, Shemesh J, et al. Calcification of the thoracic aorta by spiral computed tomography among hypertensive patients: associations and risk of ischemic cerebrovascular events. Int J Cardiol. 2007;120:32-37.

22. Nietlispach F, Wijesinghe N, Wood D, Carere RG, Webb JG. Current balloon-expandable transcatheter heart valve and delivery systems. Catheter Cardiovasc Interv. 2009

23. Grube E, Schuler G, Buellesfeld L, et al. Percutaneous aortic valve replacement for severe aortic stenosis in high-risk patients using the second- and current third-generation self-expanding CoreValve prosthesis: device success and 30-day clinical outcome. J Am Coll Cardiol. 2007;50:69-76.

24. Fearn SJ, Pole R, Wesnes K, Faragher EB, Hooper TL, McCollum CN. Cerebral injury during cardiopulmonary bypass: emboli impair memory. J Thorac Cardiovasc Surg. 2001;121:1150-1160.

25. Pugsley W, Klinger L, Paschalis C, Treasure T, Harrison M, Newman S. The impact of microemboli during cardiopulmonary bypass on neuropsychological functioning. Stroke. 1994;25:1393-1399.

26. Ringleb PA, Allenberg J, Bruckmann H, et al. 30 day results from the SPACE trial of stent-protected angioplasty versus carotid endarterectomy in symptomatic patients: a randomised non-inferiority trial. Lancet. 2006;368:1239-1247. 
27. Barbato JE, Dillavou E, Horowitz MB, et al. A randomized trial of carotid artery stenting with and without cerebral protection. J Vasc Surg. 2008;47:760-765.

28. Garg N, Karagiorgos N, Pisimisis GT, et al. Cerebral protection devices reduce periprocedural strokes during carotid angioplasty and stenting: a systematic review of the current literature. J Endovasc Ther. 2009;16:412-427. 


\subsubsection{Cerebral protection devices for transcatheter aortic valve implantation: Is better the enemy of good?}

Fabien Praz, MD, Fabian Nietlispach, MD

EuroIntervention 2013;9:S124-S128 


\section{Abstract}

Transcatheter aortic valve implantation is a widely performed procedure for treatment of symptomatic severe aortic stenosis.

According to the current literature, major stroke has been reported to occur in $3-6 \%$ of the patients during the first 30 days following valve implantation. Several pathological mechanisms may be involved in the development of periprocedural ischemic stroke with the majority being due to thrombo- and atheroembolism. One approach to reduce the incidence of procedural cerebral thromboembolic events is the use of cerebral protection devices, either deflecting (Embrella, TriGuard) or capturing (Claret, Embol-X) embolic material.

We sought to review the current evidence on this important issue focussing on the four cerebral protection devices currently available. 


\section{Introduction}

Since the publication of the randomized PARTNER trials in 2010 and 2011 transcatheter aortic valve implantation (TAVI) has become a widely performed treatment for patients suffering from symptomatic severe aortic stenosis (AS). The first published PARTNER B trial established the superiority of TAVI over medical treatment in inoperable patients showing a highly significant reduction of all-cause mortality at 1 year ( $43.3 \%$ vs. $68.0 \%$; $p<0.001$ ), paralleled by a markedly improved quality-of-life (1). However, there was a non-significant trend towards more major strokes in the transcatheter group (5\% vs. $1.1 \%$ in the medical group at 30 days; $\mathrm{p}=0.06$ ).

In the PARTNER A trial, patients with severe AS at high risk for surgery were randomized to either transfemoral / transapical TAVI or surgical aortic valve replacement (SAVR). TAVI proved to be non-inferior as compared to SAVR with regard to all-cause mortality. Thirty-day mortality was even significantly lower in the subgroup of patients undergoing transfemoral TAVI (3.7 vs $8.2 \%$, as-treatedanalysis)(2). Peri- and post-procedural morbidity differed considerably between the two treatment modalities: while neurologic events and vascular complications occurred more often in the TAVI group, the SAVR population suffered from more major bleedings and experienced more new-onset atrial fibrillation. The rate of major strokes did not differ between the treatment groups, and after 30 months(3), numerically more strokes had occurred in the SAVR population. According to a 2012 published meta-analysis including more than $10^{\prime} 000$ patients, 30-day neurologic event rate was $3.3 \pm 1.8 \%$ (range $0-6 \%$ ) with a 3.5 -fold increase in 30 -day mortality in patients experiencing a stroke $(25.5 \pm 21.9 \%$ vs. $6.9 \pm 4.2 \%)(4)$. Therefore, stroke prevention is an important issue.

\section{Pathogenesis of stroke in TAVI}

Cerebral imaging studies reported silent ischemic lesions (mostly multiple) in 68$91 \%$ of patients a few days after TAVI(5-7). These lesions were not associated with symptoms or measurable cognitive impairment and $80 \%$ of the detected lesions disappeared after 3 months(8).

Several mechanisms may be involved in the pathogenesis of periprocedural stroke in TAVI including embolization of calcified or atheromatous particles, thrombo- and air embolism, as well as prolonged hypotension and haemorrhage. Histopathological analyses of fragments captured during TAVI demonstrated thrombotic material (fibrin) and fragments compatible with aortic valve leaflet or aortic wall origin (amorphous calcium, and connective tissue) in the majority of cases(9). 
During TAVI procedural steps associated with manipulation of the aortic valve may cause most of the cerebral embolisms. Simple retrograde passage of the stenotic aortic valve with diagnostic catheters is associated with silent cerebral embolism in $22 \%$ of patients(10). Transcranial Doppler (TCD) studies during TAVI confirmed the majority of cerebral microembolisms occurring at the time of balloon valvuloplasty, deployment and positioning of the prosthetic valve $(11,12)$. This may explain why intra-procedural neurologic events are not more common in transfemoral procedures as compared to transapical TAVI, despite the theoretical advantage of sparing the aortic arch when a transpical approach is chosen $(6,13)$.

Only $40-50 \%$ of symptomatic strokes occur within 24 hours after TAVI $(14,15)$, resulting in more than half of the strokes not being directly procedure related.

Established risks factors for early stroke include small aortic valve area, prior history of cerebrovascular accidents, balloon postdilatation, multiple valve implantation attempts, and (new onset) atrial fibrillation(14-17). The incidence of stroke continues to be high, up to 60 days after valve implantation followed by a low but constant risk during long-term follow-up, mainly influenced by individual risk factors (e.g. BMI <20kg/m2, age $>80$ years, chronic atrial fibrillation and peripheral and cerebrovascular disease $)(17,18)$.

\section{Requirements for cerebral protection devices}

The goal of a cerebral protection device is to prevent clinical relevant intraprocedural strokes. As stroke is a rare complication, silent new cerebral lesions as assessed by diffusion-weighted MRI (DW-MRI) or high intensity transient signals (HITS) detected by transcranial Doppler are often used as endpoints in studies. The clinical meaning of new perfusion defects, however, remains a matter of controversy. According to surgical literature, the lesion "load" detected by MRI has been associated with postoperative cognitive decline(19) - a relation that has not been confirmed in patients undergoing TAVI $(8,20)$.

Evidence from carotid stenting and open-heart surgery suggests that mechanical cerebral protection has the potential to reduce stroke rate and to improve clinical outcome $(21,22)$.

Despite these theoretical advantages when using cerebral protection devices, positioning of the device in the aortic arch itself carries a certain risk of mobilizing atheromatous material and causing damage to the arterial wall, possibly resulting in a neurologic event. This makes an excellent safety profile and the use of antithrombogenic material the most important requirements for cerebral protection devices. Furthermore, protection devices are expected to warrant stable position, to fit anatomical variations of the aortic arch, to allow sufficient perfusion of the protected arterial territories, and to avoid interference with valve delivery. Deployment has to be simple and fast in order not to lengthen and complicating the TAVI 
procedure. There are currently four devices in investigational use potentially meeting these requirements (Table 1).

Table 1: Overview of the currently available cerebral protection devices

\begin{tabular}{lllll}
\hline & Access & Delivery & Principle & Studies (n) \\
\hline Embrella & radial/brachial & 6 French & deflection & $\begin{array}{l}\text { FIH (4) } \\
\text { PROTAVI-C Pilot Study (41)* }\end{array}$ \\
Triguard & femoral & 7/9 French & deflection & $\begin{array}{l}\text { FIH (15) } \\
\text { DEFLECT I (28)* }\end{array}$ \\
Montage & radial/brachial & 6 French & capture & $\begin{array}{l}\text { FIH (40) } \\
\text { Histopathological Study (40) }\end{array}$ \\
& & & & RT in surgical patients \\
Embol-X & transaortic (surgical) & 14 French & capture & \\
& & & & CR in TAVI (1) \\
\hline
\end{tabular}

n: number of patients included; FIH: first-in-human; RT: randomized trial; CR: case report; *: unpublished data

\section{Currently available cerebral protection devices}

\section{1) Embolic deflection devices}

The Embrella device (Edwards Lifesciences Ltd., Irvine, CA, USA), introduced via radial or brachial arterial access, deflects emboli from the innominate and the left carotid artery. In $60 \%$ of patients the device additionally covers the left subclavian artery. The device consists of two hydrophilic heparin-coated polyurethane membranes with $100 \mu \mathrm{m}$ pores. An oval umbrella-like nitinol frame holds the membranes and is attached to a 0.035 " $(0.89 \mathrm{~mm})$ nitinol cable (Figure 1). After introduction of a $6 \mathrm{~F}$ long delivery sheath through the radial or brachial artery to the aortic arch, the Embrella device is advanced under fluoroscopic guidance, exited the sheath in the aortic arch, where the two petals of the umbrella are stabilized at the outer curvature (Figure 2 ). 


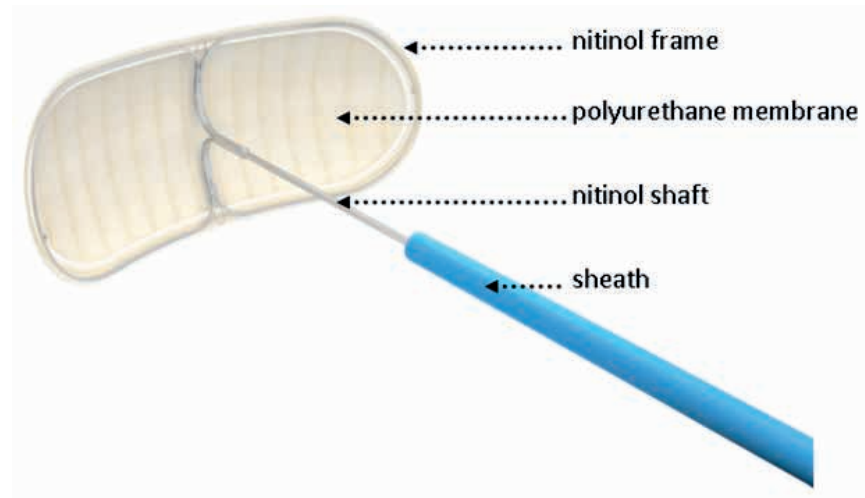

Figure 1. The Embrella device consists of an umbrella-like nitinol frame holding two polyurethane membranes (Courtesy of Edwards Lifesciences Ltd., Irvine, CA, USA.)

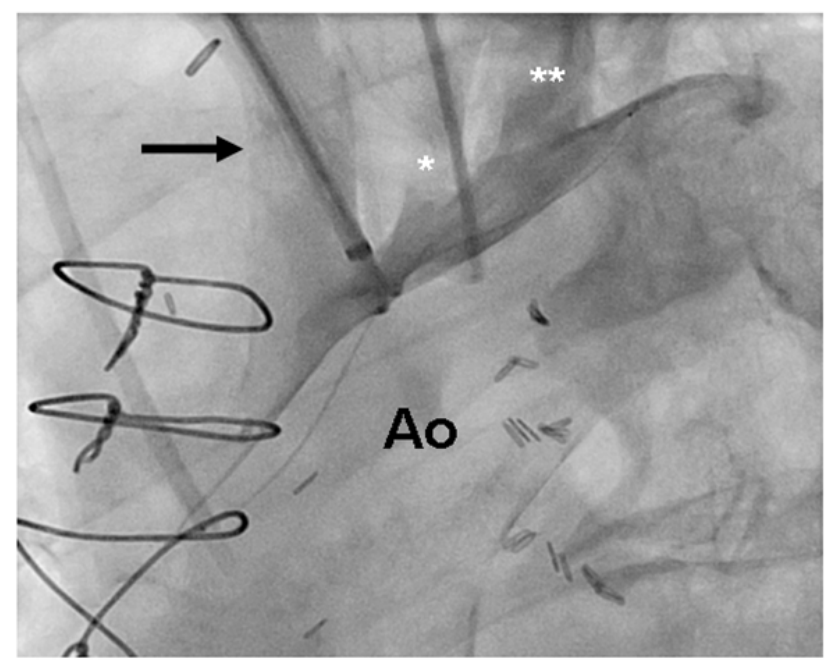

Figure 2. Embrella device positioned at the inner curvature of the aortic arch. The device fully covers the brachiocephalic trunk (arrow), the left carotid artery $\left({ }^{*}\right)$, and the left subclavian artery $\left({ }^{* *}\right)$; Ao: Aorta

A 2010 published first-in-human study in 4 patients confirmed feasibility of the device use(23). Currently, a double randomized trial is ongoing in Europe and Canada (PROTAVI-C for Prospective Randomized Outcome study in patients undergoing TAVI to Examine Cerebral Ischemia and Bleeding Complications). The study aims to investigate the efficacy of the Embrella device for prevention of new intraprocedural cerebral lesions (assessed by diffusion-weighted MRI) in 500 patients. In a second post-procedural phase, the patients will be randomly allocated to either single or dual antiplatelet therapy and followed for 1 year. The results of the PROTAVI-C Pilot Study were presented at EuroPCR 2013: in 41 patients the Em- 
brella device was successfully deployed and retracted. One patient suffered a nondevice related minor stroke on day two. On DW-MRI, all (100\%) patients showed new ischemic lesions. However, the lesion volume was markedly smaller as compared to patients where no cerebral protection was used. Intraprocedural transcranial doppler showed most HITS during valve crossing and prosthesis positioning, closely followed by a high number of HITS during deployment of the device.

The TriGuard Cerebral Protection Device (Keystone Heart Ltd, formerly SMT Research \& Development Ltd, Caesarea, Israel) is introduced via the femoral artery. The concept is similar to that of the Embrella device with some notable differences. A 9F sheath is usually used for delivery and retrieval and allows additional placement of a pigtail catheter for procedural guidance. The device itself consists of a nitinol mesh and a nitinol frame with two stabilizers that anchor the device in the brachiocephalic trunk and at the inner curvature of the aortic arch (Figure 3). The system was first designed as a permanent surgical implant for cerebral protection in patients at high risk for recurrent embolisms.
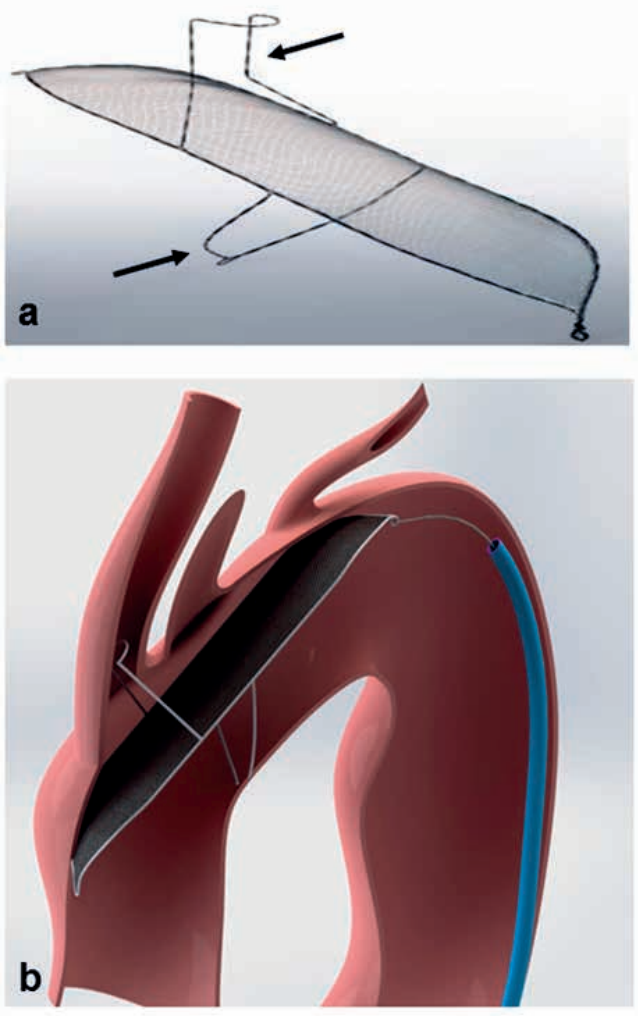

Figure 3. a: The TriGuard Cerebral Protection Device consists of a porous membrane and a nitinol frame with two stabilizers (arrows) (Courtesy of Keystone Heart Ltd, Caesarea, Israel)

b: Device anchored in the brachiocephalic trunk and at the inner curvature of the aortic arch. The design allows coverage of all three neck vessels (Courtesy of Keystone Heart Ltd, Caesarea, Israel) 
Initial experience in 15 patients proved feasibility(24) of the device use. At EuroPCR 2013 preliminary results from the prospective DEFLECT I Trial were presented: initial device positioning was successful in $100 \%$ of patients. However, after removal of the TAVI delivery system, only $79 \%$ of devices were still correctly positioned and only $68 \%$ of devices still covered all three neck vessels. Of the 28 study patients none had adverse clinical events associated with the device use, while 2 suffered a non-device related stroke on day 1 after TAVI. The total number of patients with new ischemic cerebral lesions on DW-MRI was not reduced significantly as compared to historical cohorts where no cerebral protection device was used (70\% vs. $76 \%$ ), while the total volume of the new lesions was reduced in patients where the TriGuard was used $(1.64 \mathrm{~cm} 3$ vs. $0.70 \mathrm{~cm} 3)$.

\section{2) Embolic capture devices}

The Montage Dual Filter System (Claret Medical Inc., Santa Rosa, CA, USA) is designed to capture embolic debris travelling to the brain in the brachiocephalic trunk and the left common carotid arteries (Figure 4). The catheter is delivered through a $6 \mathrm{~F}$ sheath via the radial or brachial artery. The conically shaped filters consist of a nitinol frame and polyurethane laser drilled filter membrane with $140 \mu \mathrm{m}$ diameter pores. The filter frames are radiopaque and once deployed seal against the vessel wall allowing filtered blood to pass to the brain while trapping debris. After positioning of the first filter in the brachiocephalic trunk, the catheter is advanced further in the aortic arch under fluoroscopic guidance and the tip of the delivery system is curved towards the left common carotid artery for placement of the second filter. Anatomical requirements are a diameter of the brachiocephalic trunk measuring between $9-16 \mathrm{~mm}$ and a left common carotid artery diameter between 6$10 \mathrm{~mm}$. Recent improvements over the first generation device include compatibility with 0.014 " standard coronary guidewires, a modified curve of the device tip to simplify antegrade intubation of the left carotid artery, hydro-coating, and implementation of an ergonomic handle. The safe use of the system has been demonstrated in a 2012 published first-in-man study, which included 40 patients ( 7 patients received the first generation device and 33 patients the second generation device). Successful placement of both filters was achieved in $60 \%$ of patients with the first generation and in $87 \%$ of patients with the second-generation device. Embolic debris was collected in $54 \%$ of patients at termination of the TAVI procedure. Complications directly related to device insertion occurred in 4 patients $(10 \%)$ requiring surgery in 3 patients (7.5\%) (1 dissection of the radial artery and 2 brachial pseudoaneurysms). Early stroke $(<24 \mathrm{~h})$ was reported in one patient $(2.5 \%)(25)$. In another study exclusively using the second-generation device, technical success was $100 \%$ without any device-related complications. Macroscopic debris was captured in at least one of the two filters in $75 \%$ of the cases(9). To date, no data exist on the potential reduction of cerebral embolisms when using the de- 
vice (e.g. by means of reduction of HITS on TCD or new -ischemic lesions on DWMRI). A larger multicentre randomized trial filling this gap is currently pending.
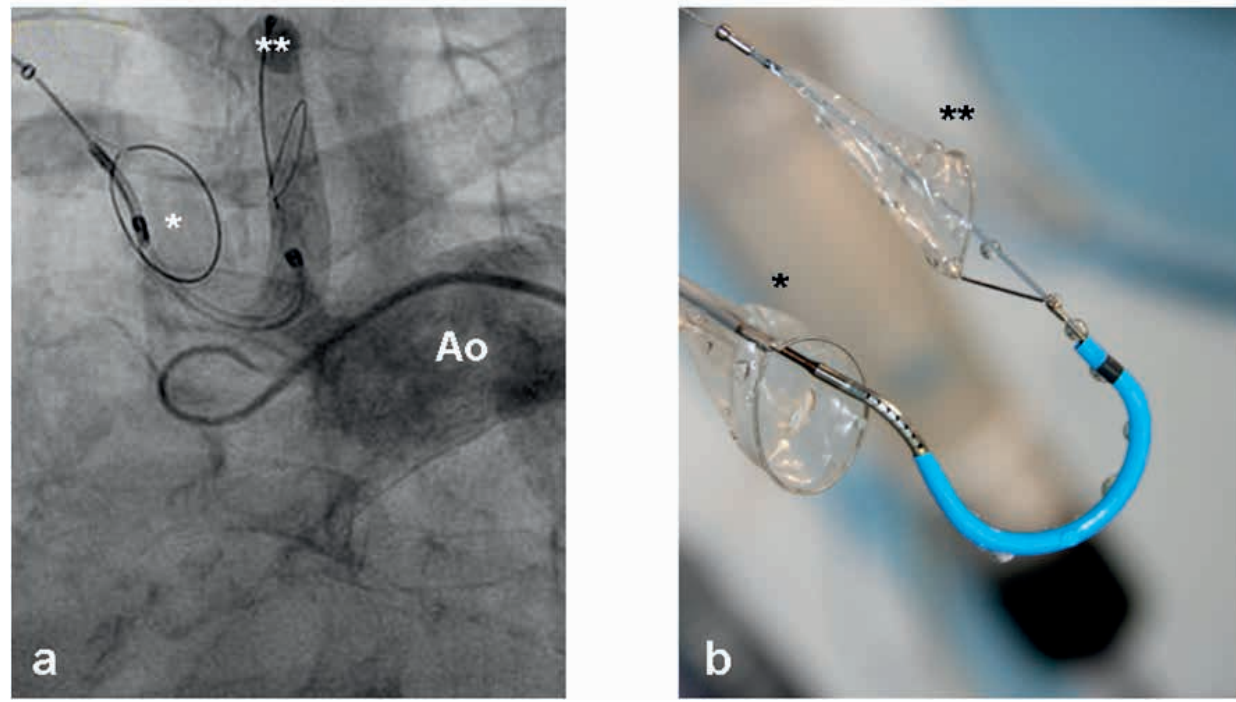

Figure 4. a: Angiographic view of the Montage Dual Filter System successfully positioned in the brachiocephalic trunk $\left({ }^{*}\right)$ and the left carotid artery ${ }^{* *}$ ) (Courtesy of Claret Medical Inc., Santa Rosa, CA, USA) b: The device consists of two conically shaped polyurethane filters and a nitinol frame. The proximal filter $(*)$ is deployed in the innominate artery and the distal filter in the left carotid artery ${ }^{* *}$ ); Ao: Aorta (Courtesy of Claret Medical Inc., Santa Rosa, CA, USA)

The Embol-X intra-aortic filter (Edwards Lifesciences Ltd., Irvine, CA, USA) was designed for surgical use. In surgical patients the device is introduced via a sidearm of a modified $24 \mathrm{~F}$ intra-aortic cannula and deployed in the ascending aorta before removal of the aortic clamp (Figure 5). It remains in place as long as the patient is on cardiopulmonary bypass. The filter consists of a polyester mesh capturing debris $>120 \mu \mathrm{m}$ and is currently available in 5 different sizes fitting internal aortic diameters of 2.2 to $4.0 \mathrm{~cm}$. In a randomized trial including almost 1'300 patients undergoing open heart surgery the device demonstrated capture of debris in up to $97 \%$ of patients. No particular safety concerns were raised. However, no significant differences in the rate of apparent strokes between the two study groups $(2.6 \%$ in the filter group vs. $2.2 \%$ in the control group; $p=0.59$ ) were seen. The occurrence of silent cerebral lesions has not been investigated. Overall, better outcome was observed in patients with a low body mass index $(<25 \mathrm{~kg} / \mathrm{m} 2)$, low ejection fraction $(\leq 25 \%)$ or previous history of cerebrovascular disease. These differences were mainly driven by a reduction in postoperative renal failure in the filter group(22).

In TAVI, the device can exclusively be introduced through an upper ministernotomy providing direct visualization of the ascending aorta. In 2011, the filter was successfully deployed over a $14 \mathrm{~F}$ sheath in one patient during transaortic TAVI(26). At follow-up (48h) the patient developed no silent or apparent cerebral 
complication. Since the transaortic access is the only TAVI access allowing insertion of the Embol-X device, the use in its current design will remain limited in TAVI.

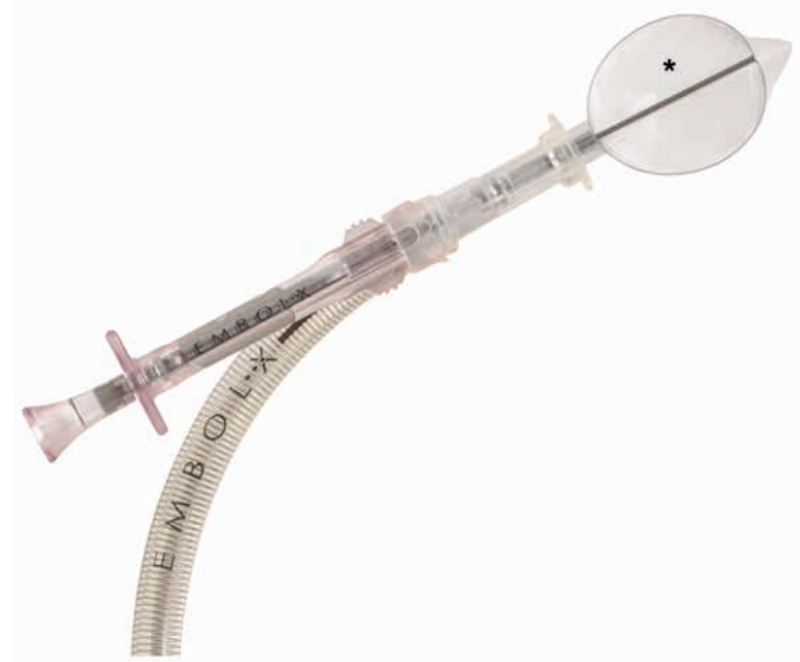

Figure 5. The Embol-X device is introduced via a sidearm of a modified $24 \mathrm{~F}$ intraaortic cannula. The polyester mesh $\left(^{*}\right)$ captures debris with a diameter $>120 \mu \mathrm{m}$.

\section{Conclusions}

Prevention of stroke is an important issue to further improve outcome in TAVI. This is particularly true in light of expansion of TAVI from high-risk to intermediate risk patients. As an established risk factor for the occurrence of early post-procedural neurological events, new-onset atrial fibrillation requires timely diagnosis and adequate treatment. Left atrial appendage closure is a very attractive alternative to oral anticoagulation in these patients $(27,28)$.

Further, smaller delivery catheters have the potential to further reduce stroke rate $(29,30)$. If a self-expandable valve prosthesis is used, avoiding balloon aortic valvuloplasty, eliminates an important source of microembolism during TAVI(31). The development of a true percutaneous transapical approach with percutaneous apical closure(32) may be less traumatic and improve outcome of the transapical TAVI.

It is of note, that only about $50 \%$ of the cerebrovascular events observed during the 30-days period following TAVI are believed to occur during the procedure itself, while the reminder of strokes occurred weeks to months after implantation. As a consequence, defining the most appropriate antiplatelet or anticoagulation regimen and its duration following TAVI may have a significant impact on stroke rate what makes medical therapy an important pillar of stroke prevention after TAVI. Me- 
chanical cerebral protection has the theoretical potential to reduce procedural stroke rate at most by $50 \%$. Besides local complications at the insertion site, results from the PROTAVI-C Pilot Study confirms that placement of the device itself carries a risk of causing cerebral embolism. From preliminary results of the DEFLECT I trial we learn, that there is a risk of device-interference with the valve delivery system. Whether a reduction in lesion volume justifies the risk of causing potential harm will hopefully be answered at termination of the studies.

At this stage, broad use of cerebral protection devices during TAVI cannot be recommended and their use should - outside of a clinical trial - be restricted to patients at very high-risk for embolic events (e.g. patients with mobile structures on the aortic valve).

\section{References}

1. Leon MB, Smith CR, Mack M, Miller DC, Moses JW, Svensson LG, Tuzcu EM, Webb JG, Fontana GP, Makkar RR, Brown DL, Block PC, Guyton RA, Pichard AD, Bavaria JE, Herrmann HC, Douglas PS, Petersen JL, Akin JJ, Anderson WN, Wang D, Pocock S. Transcatheter aortic-valve implantation for aortic stenosis in patients who cannot undergo surgery. N Engl J Med. 2010;363(17):1597-607.

2. Smith CR, Leon MB, Mack MJ, Miller DC, Moses JW, Svensson LG, Tuzcu EM, Webb JG, Fontana GP, Makkar RR, Williams M, Dewey T, Kapadia S, Babaliaros V, Thourani VH, Corso P, Pichard AD, Bavaria JE, Herrmann HC, Akin JJ, Anderson WN, Wang D, Pocock SJ. Transcatheter versus surgical aorticvalve replacement in high-risk patients. N Engl J Med. 2011;364(23):2187-98.

3. Kodali SK, Williams MR, Smith CR, Svensson LG, Webb JG, Makkar RR, Fontana GP, Dewey TM, Thourani VH, Pichard AD, Fischbein M, Szeto WY, Lim S, Greason KL, Teirstein PS, Malaisrie SC, Douglas PS, Hahn RT, Whisenant B, Zajarias A, Wang D, Akin JJ, Anderson WN, Leon MB. Two-year outcomes after transcatheter or surgical aortic-valve replacement. N Engl J Med. 2012;366(18): 1686-95.

4. Eggebrecht H, Schmermund A, Voigtlander T, Kahlert P, Erbel R, Mehta RH. Risk of stroke after transcatheter aortic valve implantation (TAVI): a meta-analysis of 10,037 published patients. EuroIntervention. 2012;8(1):129-38.

5. Fairbairn TA, Mather AN, Bijsterveld P, Worthy G, Currie S, Goddard AJ, Blackman DJ, Plein S, Greenwood JP. Diffusion-weighted MRI determined cerebral embolic infarction following transcatheter aortic valve implantation: assessment of predictive risk factors and the relationship to subsequent health status. Heart. 2012;98(1):18-23.

6. Astarci P, Glineur D, Kefer J, D'Hoore W, Renkin J, Vanoverschelde JL, El Khoury G, Grandin C. Magnetic resonance imaging evaluation of cerebral embolization during percutaneous aortic valve implantation: comparison of transfemoral and trans-apical approaches using Edwards Sapiens valve. Eur J Cardiothorac Surg. 2011;40(2):475-9.

7. Ghanem A, Muller A, Nahle CP, Kocurek J, Werner N, Hammerstingl C, Schild HH, Schwab JO, Mellert F, Fimmers R, Nickenig G, Thomas D. Risk and fate of cerebral embolism after transfemoral aortic valve implantation: a prospective pilot study with diffusion-weighted magnetic resonance imaging. J Am Coll Cardiol. 2010;55(14):1427-32.

8. Kahlert P, Knipp SC, Schlamann M, Thielmann M, Al-Rashid F, Weber M, Johansson U, Wendt D, Jakob HG, Forsting M, Sack S, Erbel R, Eggebrecht H. Silent and apparent cerebral ischemia after percutaneous transfemoral aortic valve implantation: a diffusion-weighted magnetic resonance imaging study. Circulation. 2010;121(7):870-8.

9. Van Mieghem NM, Schipper ME, Ladich E, Faqiri E, van der Boon R, Randjgari A, Schultz C, Moelker A, van Geuns RJ, Otsuka F, Serruys PW, Virmani R, de Jaegere PP. Histopathology of Embolic Debris Captured During Transcatheter Aortic Valve Replacement. Circulation. 2013. 
10. Omran H, Schmidt H, Hackenbroch M, Illien S, Bernhardt P, von der Recke G, Fimmers R, Flacke S, Layer G, Pohl C, Luderitz B, Schild H, Sommer T. Silent and apparent cerebral embolism after retrograde catheterisation of the aortic valve in valvular stenosis: a prospective, randomised study. Lancet. 2003;361(9365):1241-6.

11. Erdoes G, Basciani R, Huber C, Stortecky S, Wenaweser P, Windecker S, Carrel T, Eberle B. Transcranial Doppler-detected cerebral embolic load during transcatheter aortic valve implantation. Eur J Cardiothorac Surg. 2012;41(4):778-83; discussion 83-4.

12. Drews T, Pasic M, Buz S, Unbehaun A, Dreysse S, Kukucka M, Mladenow A, Hetzer R. Transcranial Doppler sound detection of cerebral microembolism during transapical aortic valve implantation. Thorac Cardiovasc Surg. 2011;59(4):237-42.

13. Rodes-Cabau J, Dumont E, Boone RH, Larose E, Bagur R, Gurvitch R, Bedard F, Doyle D, De Larochelliere R, Jayasuria C, Villeneuve J, Marrero A, Cote M, Pibarot P, Webb JG. Cerebral embolism following transcatheter aortic valve implantation: comparison of transfemoral and transapical approaches. J Am Coll Cardiol. 2011;57(1):18-28.

14. Miller DC, Blackstone EH, Mack MJ, Svensson LG, Kodali SK, Kapadia S, Rajeswaran J, Anderson WN, Moses JW, Tuzcu EM, Webb JG, Leon MB, Smith CR. Transcatheter (TAVR) versus surgical (AVR) aortic valve replacement: occurrence, hazard, risk factors, and consequences of neurologic events in the PARTNER trial. J Thorac Cardiovasc Surg. 2012;143(4):832-43 e13.

15. Tay EL, Gurvitch R, Wijesinghe N, Nietlispach F, Wood D, Cheung A, Ye J, Lichtenstein SV, Carere R, Thompson C, Webb JG. A high-risk period for cerebrovascular events exists after transcatheter aortic valve implantation. JACC Cardiovasc Interv. 2011;4(12):1290-7.

16. Stortecky S, Windecker S, Pilgrim T, Heg D, Buellesfeld L, Khattab AA, Huber C, Gloekler S, Nietlispach F, Mattle H, Juni P, Wenaweser P. Cerebrovascular accidents complicating transcatheter aortic valve implantation: frequency, timing and impact on outcomes. EuroIntervention. 2012;8(1):62-70.

17. Nombela-Franco L, Webb JG, de Jaegere PP, Toggweiler S, Nuis RJ, Dager AE, Amat-Santos IJ, Cheung A, Ye J, Binder RK, van der Boon RM, Van Mieghem N, Benitez LM, Perez S, Lopez J, San Roman JA, Doyle D, Delarochelliere R, Urena M, Leipsic J, Dumont E, Rodes-Cabau J. Timing, predictive factors, and prognostic value of cerebrovascular events in a large cohort of patients undergoing transcatheter aortic valve implantation. Circulation. 2012;126(25):3041-53.

18. Pilgrim T, Kalesan B, Wenaweser P, Huber C, Stortecky S, Buellesfeld L, Khattab AA, Eberle B, Gloekler S, Gsponer T, Meier B, Juni P, Carrel T, Windecker S. Predictors of clinical outcomes in patients with severe aortic stenosis undergoing TAVI: a multistate analysis. Circ Cardiovasc Interv. 2012;5(6):856-61.

19. Barber PA, Hach S, Tippett LJ, Ross L, Merry AF, Milsom P. Cerebral ischemic lesions on diffusionweighted imaging are associated with neurocognitive decline after cardiac surgery. Stroke. 2008;39(5):1427-33.

20. Ghanem A, Muller A, Sinning JM, Kocurek J, Becker BV, Vogel M, Vasa-Nicotera M, Hammerstingl C, Schwab JO, Nahle CP, Thomas D, Wagner M, Grube E, Werner N, Nickenig G. Prognostic value of cerebral injury following transfemoral aortic valve implantation. EuroIntervention. 2013;8(11):1296306.

21. Garg N, Karagiorgos N, Pisimisis GT, Sohal DP, Longo GM, Johanning JM, Lynch TG, Pipinos, II. Cerebral protection devices reduce periprocedural strokes during carotid angioplasty and stenting: a systematic review of the current literature. J Endovasc Ther. 2009;16(4):412-27.

22. Banbury MK, Kouchoukos NT, Allen KB, Slaughter MS, Weissman NJ, Berry GJ, Horvath KA. Emboli capture using the Embol-X intraaortic filter in cardiac surgery: a multicentered randomized trial of 1,289 patients. Ann Thorac Surg. 2003;76(2):508-15; discussion 15.

23. Nietlispach F, Wijesinghe N, Gurvitch R, Tay E, Carpenter JP, Burns C, Wood DA, Webb JG. An embolic deflection device for aortic valve interventions. JACC Cardiovasc Interv. 2010;3(11):1133-8.

24. Onsea K, Agostoni P, Samim M, Voskuil M, Kluin J, Budde R, Hendrikse J, Ramjankhan F, van Klarenbosch J, Doesburg P, Sieswerda G, Stella P. First-in-man experience with a new embolic deflection device in transcatheter aortic valve interventions. EuroIntervention. 2012;8(1):51-6. 
25. Naber CK, Ghanem A, Abizaid AA, Wolf A, Sinning JM, Werner N, Nickenig G, Schmitz T, Grube E. First-in-man use of a novel embolic protection device for patients undergoing transcatheter aortic valve implantation. EuroIntervention. 2012;8(1):43-50.

26. Etienne PY, Papadatos S, Pieters D, El Khoury E, Alexis F, Price J, Glineur D. Embol-X intraaortic filter and transaortic approach for improved cerebral protection in transcatheter aortic valve implantation. Ann Thorac Surg. 2011;92(5):e95-6.

27. Nietlispach F, Gloekler S, Krause R, Shakir S, Schmid M, Khattab AA, Wenaweser P, Windecker S, Meier B. Amplatzer left atrial appendage occlusion: Single center 10-year experience. Catheter Cardiovasc Interv. 2013.

28. Reddy VY, Doshi SK, Sievert H, Buchbinder M, Neuzil P, Huber K, Halperin JL, Holmes D. Percutaneous left atrial appendage closure for stroke prophylaxis in patients with atrial fibrillation: 2.3-Year Follow-up of the PROTECT AF (Watchman Left Atrial Appendage System for Embolic Protection in Patients with Atrial Fibrillation) Trial. Circulation. 2013;127(6):720-9.

29. Nietlispach F, Wijesinghe N, Wood D, Carere RG, Webb JG. Current balloon-expandable transcatheter heart valve and delivery systems. Catheter Cardiovasc Interv. 2010;75(2):295-300.

30. Binder RK, Rodes-Cabau J, Wood DA, Mok M, Leipsic J, De Larochelliere R, Toggweiler S, Dumont E, Freeman M, Willson AB, Webb JG. Transcatheter aortic valve replacement with the SAPIEN 3: a new balloon-expandable transcatheter heart valve. JACC Cardiovasc Interv. 2013;6(3):293-300.

31. Grube E, Naber C, Abizaid A, Sousa E, Mendiz O, Lemos P, Kalil Filho R, Mangione J, Buellesfeld L. Feasibility of transcatheter aortic valve implantation without balloon pre-dilation: a pilot study. JACC Cardiovasc Interv. 2011;4(7):751-7.

32. Nietlispach F, Eckstein F, Seeberger M, Osswald S, Kaufmann BA, Reuthebuch O. Closure of apical access site after transapical, transcatheter paravalvular leak closure. Can J Cardiol. 2012;28(4):516 e5-7. 



\section{Part 2}

Current problems and unsolved issues

2.2. Stroke prevention in patients with atrial fibrillation: left atrial appendage occlusion 



\subsubsection{Percutaneous Left Atrial Appendage Closure}

Fabian Nietlispach, MD, Steffen Gloekler, MD, Ahmed Khattab, MD, Thomas Pilgrim, MD, Michael Schmid, MD, Peter Wenaweser, MD, Stephan Windecker, MD, Bernhard Meier, MD

European Geriatric Medicine 2012;3(5):308-11 


\section{Abstract}

Introduction. Atrial fibrillation is a growing epidemic in the western world. Stroke as the most dreaded complication is effectively prevented by oral anticoagulation. Although effective in preventing stroke, they come at a price of bleeding complications. Concerns about bleeding lead to a high rate of drug discontinuation and is the reason many patients are not put on oral anticoagulants at all. Percutaneous left atrial appendage (LAA) closure is an excellent option for patients who cannot or who do not want to be on blood thinners, since the left atrial appendage is the origin of $>90 \%$ of clots arising from the left atrium.

Methods. Using femoral venous access, a plug is placed in the left atrial appendage, thereby excluding this embryologic remnant from the circulation. The procedure can be performed on an outpatient basis. We report our own experience in 100 patients using the Amplatzer Cardiac Plug.

Results. 100 patients $(72 \pm 10$ years) underwent LAA closure using only local anesthesia without transesophageal guidance. Imaging and sizing of the LAA was performed by contrast injections through the 13 French TorqVue delivery sheath, followed by device implantation. Clopidogrel was prescribed for 1 month and acetylsalicylic acid for 3-6 months. The procedure was successful in $98 \%$ of patients and was often performed in conjunction with other interventional procedures. Periprocedural complication rate was $6 \%$ (2\% pericardial effusion, $2 \%$ device embolization, $2 \%$ transient neurologic symptoms) with no long-term sequelae.

Conclusion. LAA closure is an attractive alternative to oral anticoagulation in patients suffering from atrial fibrillation. 


\section{Introduction}

Left atrial appendage closure is the latest achievement in stroke prevention in interventional cardiology. It joins carotid stenting ${ }^{1}$ and the patent foramen ovale (PFO) occlusion².

\section{Atrial fibrillation}

Atrial fibrillation (AF) is the most common arrhythmia and a growing epidemic in the aging western population: while its prevalence is $0.1 \%$ in patients $<55$ years, it increases to $9 \%$ in patients aged 80 years or older ${ }^{3}$ and it is predicted that by the year 2050, the prevalence will be more than doubled ${ }^{4}$.

AF can be asymptomatic, come along with symptoms such as palpitations or dyspnea, cause heart failure, and reduce quality of life. The main concern in patients suffering atrial fibrillation is, however, a 5-fold increased risk of thromboembolic stroke ${ }^{5}$. The individual annual stroke risk in patients suffering atrial fibrillation varies from $0.7 \%$ to $14.2 \%$, as reflected in the CHA2DS2-VASc Score, a scoring system based on the refined 2006 Birmingham stroke risk schema ${ }^{6}$.

$\mathrm{AF}$ associated stroke is the most devastating stroke subtype. It has a high 30day mortality (25\%) and is associated with significant permanent disability in $60 \%$ of patients.

\section{Oral anticoagulation}

Oral anticoagulation using vitamin $\mathrm{K}$ antagonists is a highly effective treatment with a relative risk reduction (RRR) for stroke of around 64\% as compared to placebo, and of $22 \%$ as compared to acetylsalicylic acid 7 . The advantage of oral anticoagulation is more pronounced in the elderly population ${ }^{8}$.

With the introduction of the CHA2DS2-VASc Score, which accounts for atherosclerotic disease as a stroke risk factor and puts more weight on advanced age than the former CHADS2 score, more patients qualify for oral anticoagulation: $91.5 \%$ of $\mathrm{AF}$ patients are in the intermediate or high risk group for stroke, warranting oral anticoagulation (as compared to 79.6\% when using the CHADS2-Score)6.

Although effective, oral anticoagulation has limitations and drawbacks: the small therapeutic window leaves us with an increased risk for stroke or intracranial hemorrhage in case of sub- or supratherapeutic doses (incidence up to 9.4/100 patient years) ${ }^{9}$. In a study setting, the predefined therapeutic International Normalized Ratio (INR) of $2.0-3.0$ was achieved in only $60 \%-77 \%$ of the time ${ }^{10}$. In the real world, this percentage is even lower. 
Besides intracranial hemorrhages, gastrointestinal (GI) bleeding is another serious side effect of oral anticoagulants. Mortality from GI bleeding ranges from 1$13 \% 11,12$, while oral anticoagulation not only serves as a risk factor for bleeding, but further increases bleeding related morbidity ${ }^{13}$.

To assess the risk of bleeding in a patient on vitamin $\mathrm{K}$ antagonists the HAS-BLED score $^{14}$ was developed. It defines risk factors for bleeding to be hypertension, abnormal renal or liver function, age $>65$ years, stroke or bleeding in the past, labile INRs, alcohol or drug intake (e.g. non-steroidal antirheumatic drugs). Each of these account for one point. A score of 3 or more puts a patient in the high-risk population. Other risk factors are diabetes, heart failure, decreased left ventricular function, or concurrent use of acetylsalicylic acid ${ }^{15}$. On average, in patients on vitamin $\mathrm{K}$ antagonists the annual risk for major bleeding is 3\% with the annual incidence of overall bleeding complications summing up to $10 \%{ }^{16}$.

New oral anticoagulants. The new oral anticoagulants recently introduced may improve on that. They are rivaroxaban, apixaban (oral factor Xa inhibitors), and dabigatran (direct thrombin inhibitor).

The three landmark studies compared the new oral anticoagulants to vitamin $\mathrm{K}$ antagonists and included each 14.000 to 18.000 patients suffering from atrial fibrillation ${ }^{10,17,18}$. They were able to show a relative risk reduction for the combined endpoint of stroke or systemic embolism of 21 - 34\%/year. The absolute risk reduction was rather modest ( $0.16-0.6 \%$ /year), pointing out that it had indeed been necessary to include such large numbers of patients to show an advantage over vitamin $\mathrm{K}$ antagonists.

The higher efficacy came at a price: Major gastrointestinal bleeding was significantly more frequent in patients treated with rivaroxaban, as compared to vitamin $\mathrm{K}$ antagonists (3.2\% vs $2.2 \%$ ). The same was found in patients treated with higher doses of dabigatran (1.5\% vs $1.02 \%$ ), but not with the lower dose of dabigatran or with apixaban. The higher, but not the lower dose of dabigatran was more efficient in reducing stroke and embolism when compared to vitamin $\mathrm{K}$ antagonists. Overall major bleeding was not more common neither in patients on high dose dabigatran, nor in patients on rivaroxaban or apixaban as compared to vitamin $\mathrm{K}$ antagonists. With apixaban and the lower dose of dabigatran it was even significantly less common. Moreover, cerebral bleeds were significantly reduced by all new oral anticoagulants. Thus, it is the gastrointestinal tract but fortunately not the head that seems prone to bleeding when the more efficacious newer drugs are used.

Even with the newer anticoagulants, bleeding remains a concern: major or clinically relevant non-major bleeding occurred in 4.1 to $6.0 \%$ in patients in the ARISTOTLEtrial18 and in 14.5 to $14.9 \%$ in the ROCKET-AF trial17, while major bleeding occurred in 2.7-3.4\% in the RE-LY trial10. The ROCKET-AF Trial included high-risk 
patients with a mean CHADS2 score of 3.5 and a very high prevalence of bleeding risk factors as mentioned above, reflecting a less selected population as compared to the two other studies (each with a mean CHADS2 score of 2.1).

Furthermore, even in the trial setting there was a high rate of drug discontinuation, ranging from $17 \%$ to $27 \% 10,18$.

\section{Left atrial appendage closure}

Rationale and evidence. As described, $>90 \%$ of patients in atrial fibrillation are at high risk for stroke. While vitamin $\mathrm{K}$ antagonists and newer oral anticoagulants are effective in reducing the stroke risk, they come at a price of relevant bleeding complications up to $15 \%$ /year.

Therefore an alternative treatment to reduce stroke risk is and remains necessary and welcome. Acetylsalicylic acid alone or in combination with clopidogrel is less effective for stroke prevention in patients with atrial fibrillation than vitamin $\mathrm{K}$ antagonists. The reason may be that thrombus formation in atrial fibrillation is thrombin, rather than platelet mediated. Therefore, the Virchow triad applies: hypercoagulability, stasis, and endothelial dysfunction. Besides absence of contractility in the left atrial appendage (LAA) in patients with atrial fibrillation, the LAA undergoes remodeling leading to dilation, a known risk factor for thrombus formation ${ }^{19}$ and endothelial dysfunction with a locally prothrombotic and hypercoagulable environment ${ }^{20,21}$. Not surprisingly, $91 \%$ of thrombi in patients with nonrheumatic atrial fibrillation are therefore found in the LAA ${ }^{22}$ (Figure 1).

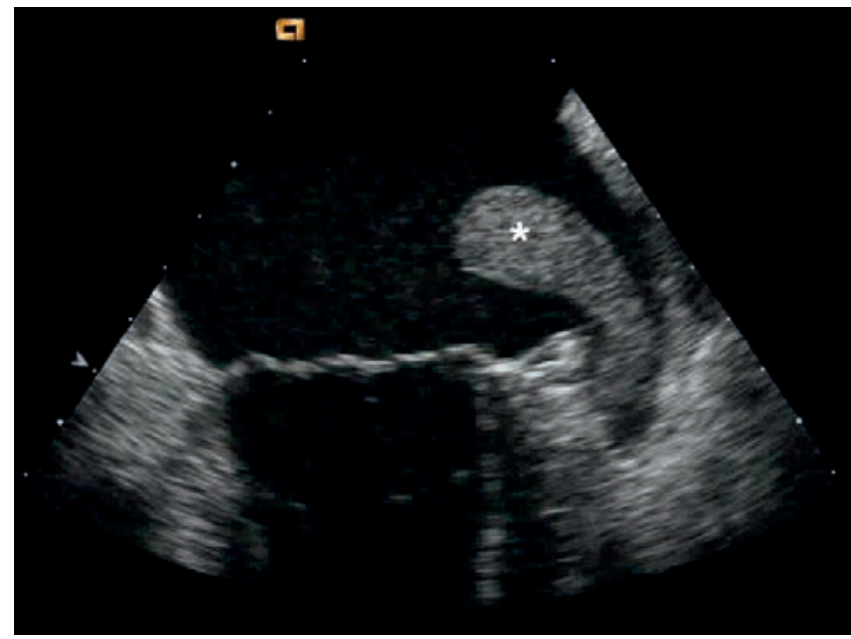

Figure 1. Thrombus in the left atrial appendage

Thrombus $\left({ }^{*}\right)$ in the LAA - the predilection site for thrombus formation in patients suffering from atrial fibrillation. 
The LAA is an embryologic remnant with no known important function. It has a variable anatomy with a single or multiple trabeculated lobules and is located anterior and inferior to the left superior pulmonary vein. Given its predilection for thrombus formation, exclusion of the LAA from the bloodstream seems a promising treatment.

While feasibility of surgical LAA obliteration during open-heart surgery was demonstrated $^{23}$, no study showed non-inferiority of the surgical approach as compared to vitamin $\mathrm{K}$ antagonists. The main concern of surgical closure was incomplete obliteration, potentially reducing its effectiveness ${ }^{24}$. As most surgical LAA closures were performed in the realm of metallic mitral valve replacement, oral anticoagulation had to be continued anyway, precluding a meaningful assessment of the preventive affect of LAA closure.

Different devices for percutaneous closure of the LAA were subsequently evaluated (Figure 2). The first was the PLAATO device (EV3 Inc, Plymouth, MN) ${ }^{25}$ in 2001, followed by Amplatzer devices (St. Jude Medical, St. Paul, MN) ${ }^{26}$ and the Watchman device (Artritech, Plymouth, MN)27 in 2002. Amplatzer devices have so far been the only ones implanted without echocardiographic guidance and hence without the compelling need for intubation ${ }^{28}$.

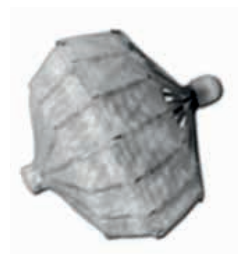

A

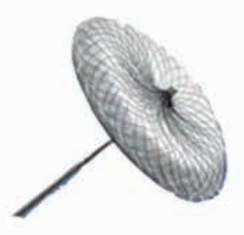

B

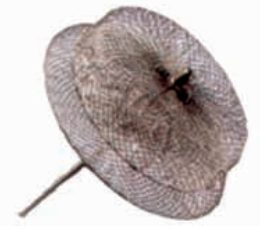

B

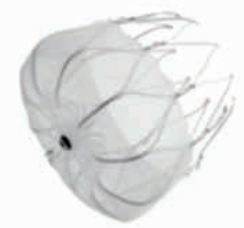

C

Figure 2. Percutaneous devices for LAA occlusion Devices used for LAA occlusion: A: PLAATO device (not longer available), B: Amplatzer ASD Occluder (left) and Amplatzer Cardiac Plug (right), C: Watchman device.

The secondary prevention trial PLAAT025 was using the PLAATO system in 111 patients with a contraindication to vitamin $\mathrm{K}$ antagonists and a previous history of stroke. After an average follow-up of 10 months, 2 strokes had occurred. Given the high-risk population, this was a theoretical $50 \%$ relative risk reduction as compared to no therapy.

The PROTECT AF trial ${ }^{27}$ randomized 707 patients 1:2 to LAA closure with the Watchman device and discontinuation of vitamin $\mathrm{K}$ antagonists after 90 days. Noninferiority in reducing stroke, systemic embolism, and cardiovascular death of the device therapy group after an average of 18 months follow-up (3.0 vs 4.9/100 patient-years) was demonstrated. The initial safety concerns were hushed to a great 
deal with the same authors publishing combined data on the PROTECT AF trial and the ongoing registry ${ }^{29}$. They showed improving results along the operator learning curve. Implant success could be improved with growing experience ( $91 \%$ vs 95\%) and safety events were reduced (e.g. serious pericardial effusion (4.1\% vs $2.2 \%$ ) and procedure related stroke $(0.5$ vs $0 \%)$.

The functional impact (sustained disability) of the adverse events was significantly lower in the intervention group than that of the bleeding complications in the vitamin $\mathrm{K}$ antagonist group.

\section{Devices and technique}

The current percutaneous LAA occluders are deployed using right femoral venous access (Figure 3). The right atrium is accessed, followed by a transseptal puncture (Figure 3A) or passage through a PFO or atrial septal defect (ASD) to enter the left atrium. A delivery sheath is positioned in the LAA and the occluder attached to a delivery cable is advanced through the sheath and properly positioned in the LAA. Once a stable position is achieved, the delivery cable is detached from the device and the delivery system removed.

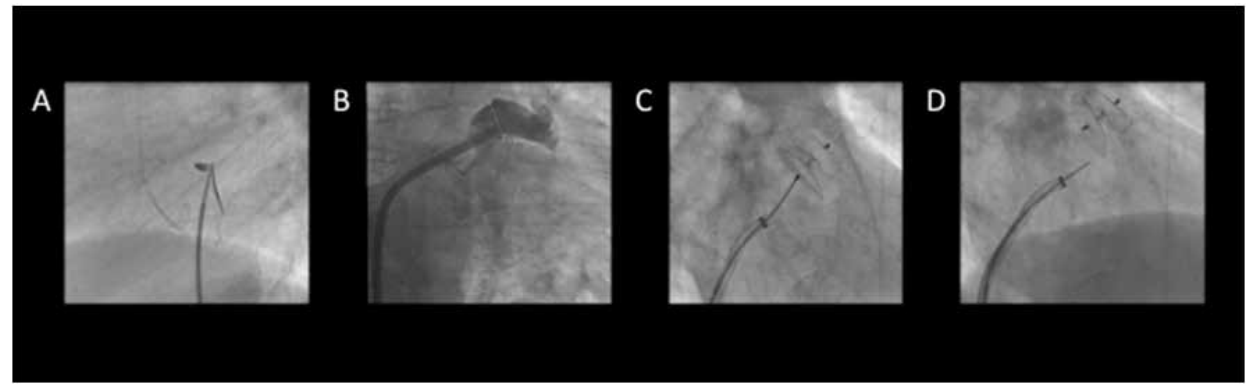

Figure 3. Procedural steps

A: transseptal puncture to gain access to the left atrium; B: depicting the LAA to exclude presence of thrombus and assess anatomy for device selection; C: deployment of the device in the LAA; D: Release of the device by unscrewing it from the delivery cable.

The procedure can be done either under general anesthesia, conscious sedation, or with local anesthesia. The latter considerably simplifies the entire procedure but hardly permits procedure guidance by transesophageal echocardiography (TEE) without significant discomfort for the supine patient and a risk of aspiration. However, fluoroscopy guidance is sufficient and saves time and cost.

Follow-up imaging needs to be done to ensure a long-term stable device position and sufficient exclusion of the LAA from bloodstream. It is also instrumental to rule out mobile thrombus on the device. Our own routine is to perform a transthoracic 
echocardiogram before discharge, which may be the day of the procedure to ensure the device is still in place. At 3-6 months post-procedure a TEE is performed at which time the platelet inhibition therapy can be stopped if complete exclusion of the LAA and freedom of thrombus are documented. Patients are generally discharged on vitamin $\mathrm{K}$ antagonists for a limited time or as at our center on acetylsalicylic acid and clopidogrel. Clopidrogrel is stopped after 1 month. Endocarditis prophylaxis is recommended for a few months until the device is assumed to be fully covered by endocardium.

The initial but no longer available PLAATO device was a self-expanding, polytetrafluoroethylene (PTFE)-covered nitinol cage with stabilizing anchors. The PTFE covering prevented further blood flow into the LAA. The device came in diameters ranging from 15-32 mm. The Amplatzer Cardiac Plug (ACP) it is a nitinol mesh, consisting of a lobe with tiny hooks (anchors), and a sealing disc towards the left atrium ('pacifier principle'). The 2 parts are connected with an extensible and flexible thin waist and filled with polyester to enhance endotheliazation and preventing blood flow into the LAA. It comes in sizes ranging from $16-30 \mathrm{~mm}$.

The Watchman device is a jellyfish-like self-expandable nitinol device with barbs as anchors, a covering PTFE-membrane and sizes ranging from 21-33 mm. As with the PLAATO device, the PTFE-membrane is meant to seal the LAA entry towards the left atrium, preventing blood flow into the LAA.

The main differences between the ACP and the Watchman device are the presence of an occluder disc towards the LAA in the ACP designed to facilitate complete exclusion of the LAA. The Watchman device needs to be fit precisely into the LAA orifice in order to effectively seal off the LAA without creating too much of a cul-desac while at the same time avoiding device protrusion into the left atrium.

\section{Bern experience with left atrial appendage closure using the Amplatzer Cardiac Plug}

Of the initial 100 patients undergoing LAA closure using the ACP and only local anesthesia without transesophageal guidance, the mean age was 72 \pm 10 (range 3592) years and the CHA2DS2-VASc Score was 3.7 \pm 1.7 (range 1-8). Indications stretched from repeated bleeding under vitamin $\mathrm{K}$ antagonists to patient preference.

We typically use the described double-curved TorqVue 13 French delivery sheath of St. Jude Medical (Figure 3). The delivery sheath is placed close to the LAA ostium and angiographic imaging is done using contrast injections through the sheath to exclude the presence of an LAA thrombus (usually confirming what was seen in a preliminary TEE) and assess the topography. The landing zone is estimated using the sheath's outer diameter $(5.1 \mathrm{~mm})$ as a reference and a device with a lobe diame- 
ter several mm larger is selected. After ACP implantation no vitamin K antagonists are used. Dual antiplatelet therapy (acetylsalicylic acid and clopidogrel) is prescribed for 1 month, followed by acetylsalicylic acid alone for 3-6 months, at which time a TEE is performed to confirm stable device position of the device, proper sealing of the LAA, and freedom of mobile clots.

Reasons for LAA closures were history of major bleeding in $46 \%$, high risk for bleeding in $25 \%$, history of falls in $8 \%$, labile INRs in $4 \%$, and patient preference in $16 \%$. The procedure was successful in $98 \%$ of our patients. Despite the fact that LAA closure was often performed in conjunction with other interventional procedures (coronary angiography in $65 \%$, PFO or ASD closure in $34 \%$, percutaneous coronary intervention in $25 \%$, transcatheter aortic valve replacement in $10 \%$, and atrial fibrillation ablation in 7\%), the periprocedural complication rate was acceptable $(6 \%)$ with no deaths, myocardial infarctions, or long-term disabilities. Two patients suffered pericardial effusions, whereof one required pericardiocentesis. Device embolization occurred twice with one device being successfully, snared and extracted, and reimplanted. The other embolized device made semi-elective surgery necessary. Transient neurologic symptoms were discovered in two patients, both fully recovered on the following day.

Our data demonstrate that LAA closure can be successfully performed under local anesthesia and without TEE. A risk for complication remains but most are minor. None of our patients experienced complications with long-term health impact.

Patients undergoing transcatheter aortic valve replacement (TAVR) often have AF and a high HAS-BLED score including atherosclerosis. Some additionally receive coronary stents mandating antiplatelet therapy ${ }^{30}$. This engenders a high bleeding risk. The future will show whether such patients benefit from a combined intervention (TAVR, LAA closure, and, perhaps, coronary stenting), as done in $10 \%$ of our cohort.

\section{Conclusions}

LAA closure has become an established and proven therapeutic alternative to oral anticoagulants for patients in atrial fibrillation. Serious complications are rare. All patients with an indication for anticoagulation that are for any reasons no or poor candidates for oral anticoagulation therapy should undergo LAA closure, provided no clot has formed yet in the LAA. In the remaining patients where medical therapy with oral anticoagulants is an option, LAA closure can be offered as an alternative or complementary treatment. Undergoing LAA closure means trading the life-long risk of bleeding complications under oral anticoagulants against an early risk for complications during the intervention. With the new oral anticoagulants, the long- 
term risk of serious bleeding complications will likely be reduced but the above balance is still valid.

\section{References}

1. Meier P, Knapp G, Tamhane U, Chaturvedi S, Gurm HS. Short term and intermediate term comparison of endarterectomy versus stenting for carotid artery stenosis: systematic review and metaanalysis of randomised controlled clinical trials. BMJ. 2010;340:c467.

2. Wahl A, Juni P, Mono ML, Kalesan B, Praz F, Geister L et al. Long-term propensity score-matched comparison of percutaneous closure of patent foramen ovale with medical treatment after paradoxical embolism. Circulation. 2012;125:803-812.

3. Go AS, Hylek EM, Phillips KA, Chang Y, Henault LE, Selby JV et al. Prevalence of diagnosed atrial fibrillation in adults: national implications for rhythm management and stroke prevention: the AnTicoagulation and Risk Factors in Atrial Fibrillation (ATRIA) Study. JAMA. 2001;285:2370-2375.

4. Roger VL, Go AS, Lloyd-Jones DM, Adams RJ, Berry JD, Brown TM et al. Heart disease and stroke statistics--2011 update: a report from the American Heart Association. Circulation. 2011;123:e18e209.

5. Singh IM, Holmes DRJ. Left atrial appendage closure. Curr Cardiol Rep. 2010;12:413-421.

6. Lip GY, Nieuwlaat R, Pisters R, Lane DA, Crijns HJ. Refining clinical risk stratification for predicting stroke and thromboembolism in atrial fibrillation using a novel risk factor-based approach: the euro heart survey on atrial fibrillation. Chest. 2010;137:263-272.

7. Hart RG, Pearce LA, Aguilar MI. Meta-analysis: antithrombotic therapy to prevent stroke in patients who have nonvalvular atrial fibrillation. Ann Intern Med. 2007;146:857-867.

8. Mant J, Hobbs FD, Fletcher K, Roalfe A, Fitzmaurice D, Lip GY et al. Warfarin versus aspirin for stroke prevention in an elderly community population with atrial fibrillation (the Birmingham Atrial Fibrillation Treatment of the Aged Study, BAFTA): a randomised controlled trial. Lancet. 2007;370:493503.

9. Hylek EM, Go AS, Chang Y, Jensvold NG, Henault LE, Selby JV et al. Effect of intensity of oral anticoagulation on stroke severity and mortality in atrial fibrillation. N Engl J Med. 2003;349:1019-1026.

10. Connolly SJ, Ezekowitz MD, Yusuf S, Eikelboom J, Oldgren J, Parekh A et al. Dabigatran versus warfarin in patients with atrial fibrillation. Engl J Med. 2009;361:1139-1151.

11. van Leerdam ME, Vreeburg EM, Rauws EA, Geraedts AA, Tijssen JG, Reitsma JB et al. Acute upper GI bleeding: did anything change? Time trend analysis of incidence and outcome of acute upper GI bleeding between 1993/1994 and 2000. Am J Gastroenterol. 2003;98:1494-1499.

12. Strate LL. Lower GI bleeding: epidemiology and diagnosis. Gastroenterol Clin North Am. 2005;34:643-664.

13. Hashash JG, Shamseddeen W, Skoury A, Aoun N, Barada K. Gross lower gastrointestinal bleeding in patients on anticoagulant and/or antiplatelet therapy: endoscopic findings, management, and clinical outcomes. J Clin Gastroenterol. 2009;43:36-42.

14. Pisters R, Lane DA, Nieuwlaat R, de Vos CB, Crijns HJ, Lip GY. A novel user-friendly score (HAS-BLED) to assess 1-year risk of major bleeding in patients with atrial fibrillation: the Euro Heart Survey. Chest. 2010;138:1093-1100.

15. Lip GY, Frison L, Halperin JL, Lane DA. Comparative validation of a novel risk score for predicting bleeding risk in anticoagulated patients with atrial fibrillation: the HAS-BLED (Hypertension, Abnormal Renal/Liver Function, Stroke, Bleeding History or Predisposition, Labile INR, Elderly, Drugs/Alcohol Concomitantly) score. J Am Coll Cardiol. 2011;57:173-180.

16. Wysowski DK, Nourjah P, Swartz L. Bleeding complications with warfarin use: a prevalent adverse effect resulting in regulatory action. Arch Intern Med. 2007;167:1414-1419.

17. Patel MR, Mahaffey KW, Garg J, Pan G, Singer DE, Hacke W et al. Rivaroxaban versus warfarin in nonvalvular atrial fibrillation. N Engl J Med. 2011;365:883-891. 
18. Granger CB, Alexander JH, McMurray JJ, Lopes RD, Hylek EM, Hanna M et al. Apixaban versus warfarin in patients with atrial fibrillation. $N$ Engl J Med.2011;365:981-992.

19. Pollick C, Taylor D. Assessment of left atrial appendage function by transesophageal echocardiography. Implications for the development of thrombus. Circulation. 1991;84:223-231.

20. Lip GY. Does paroxysmal atrial fibrillation confer a paroxysmal thromboembolic risk? Lancet. 1997;349:1565-1566.

21. Shirani J, Alaeddini J. Structural remodeling of the left atrial appendage in patients with chronic nonvalvular atrial fibrillation: Implications for thrombus formation, systemic embolism, and assessment by transesophageal echocardiography. Cardiovasc Pathol. 2000;9:95-101.

22. Blackshear JL, Odell JA. Appendage obliteration to reduce stroke in cardiac surgical patients with atrial fibrillation. Ann Thorac Surg. 1996;61:755-759.

23. Healey JS, Crystal E, Lamy A, Teoh K, Semelhago L, Hohnloser SH et al. Left Atrial Appendage Occlusion Study (LAAOS): results of a randomized controlled pilot study of left atrial appendage occlusion during coronary bypass surgery in patients at risk for stroke. Am Heart J. 2005;150:288-293.

24. Schneider B, Stollberger C, Sievers HH. Surgical closure of the left atrial appendage - a beneficial procedure? Cardiology. 2005;104:127-132.

25. Ostermayer SH, Reisman M, Kramer PH, Matthews RV, Gray WA, Block PC et al. Percutaneous left atrial appendage transcatheter occlusion (PLAATO system) to prevent stroke in high-risk patients with non-rheumatic atrial fibrillation: results from the international multi-center feasibility trials. $J$ Am Coll Cardiol. 2005;46:9-14.

26. Meier B, Palacios I, Windecker S, Rotter M, Cao QL, Keane D et al. Transcatheter left atrial appendage occlusion with Amplatzer devices to obviate anticoagulation in patients with atrial fibrillation. Catheter Cardiovasc Interv. 2003;60:417-422.

27. Holmes DR, Reddy VY, Turi ZG, Doshi SK, Sievert H, Buchbinder M et al. Percutaneous closure of the left atrial appendage versus warfarin therapy for prevention of stroke in patients with atrial fibrillation: a randomised non-inferiority trial. Lancet. 2009;374:534-542.

28. Park JW, Bethencourt A, Sievert H, Santoro G, Meier B, Walsh K et al. Left atrial appendage closure with Amplatzer cardiac plug in atrial fibrillation: initial European experience. Catheter Cardiovasc Interv. 2011;77:700-706.

29. Reddy VY, Holmes D, Doshi SK, Neuzil P, Kar S. Safety of percutaneous left atrial appendage closure: results from the Watchman Left Atrial Appendage System for Embolic Protection in Patients with AF (PROTECT AF) clinical trial and the Continued Access Registry. Circulation. 2011;123:417-424.

30. Pilgrim T, Wenaweser P, Windecker S, Meier B. Comprehensive „one stop-shop“ percutaneous cardiac intervention. Cardiovasc Med 2010;13:171-173 



\subsubsection{Amplatzer Left Atrial Appendage Occlusion: Single Center 10-Year Experience}

Fabian Nietlispach, MD, Steffen Gloekler, MD, René Krause, MD, Samera Shakir, MD, Michael Schmid, MD, Ahmed A. Khattab, MD, Peter Wenaweser, MD, Stephan Windecker, MD, Bernhard Meier, MD

Catheter Cardiovasc Interv. 2013;82(2):283-9 


\section{Abstract}

Objectives. To report a 10-year single center experience with Amplatzer devices for left atrial appendage (LAA) occlusion.

Background. Intermediate-term outcome data following LAA occlusion is scarce.

Methods. Short and intermediate-term outcome of patients who underwent LAA occlusion was assessed. All procedures were performed under local anesthesia without transesophageal echocardiography. Patients were discharged on acetylsalicylic acid and clopidogrel for 1 to 6 months.

Results. LAA occlusion was attempted in 152patients (105males, age $72 \pm$ 10years, CHA2DS2-Vasc-score 3.4 \pm 1.7 , HAS-BLED-score 2.4 \pm 1.2 ). Non-dedicated devices were used in 32patients (21\%, ND group) and dedicated Amplatzer Cardiac Plugs were used in 120patients (79\%, ACP group). A patent foramen ovale or atrial septal defect was used for left atrial access and closed at the end of LAA occlusion in 40patients. The short-term safety endpoints (procedural complications, bleeds) occurred in 15 (9.8\%) and the efficacy endpoints (death, stroke, systemic embolization) in 0 patients. Device embolization occurred more frequently in the ND as compared to the ACP group (5patients or $12 \%$ vs 2 patients or $2 \%$ ).

Mean intermediate-term follow up of the study population was 32months (range 1-120). Late deaths occurred in 15patients (5 cardiovascular, 7 non-cardiac, 3 unexplained). Neurologic events occurred in 2, peripheral embolism in 1, and major bleeding in 4patients.

The composite efficacy and safety endpoint occurred in $7 \%$ and $12 \%$ of patients.

Conclusion. LAA closure may be a good alternative to oral anticoagulation. This hypothesis needs to be tested in a randomized clinical trial to ensure that all potential biases of this observational study are accounted for. 


\section{Introduction}

Percutaneous left atrial appendage (LAA) occlusion is an alternative treatment option to oral anticoagulation (OAC) in patients with atrial fibrillation ${ }^{1-7}$. A variety of dedicated and non-dedicated devices were or are currently used for LAA occlusion: after the PLAATO-device ${ }^{3}$ was taken off the market due to economic reasons, the devices most often used were non-dedicated Amplatzer devices ${ }^{2}$, such as patent foramen ovale (PFO), atrial septal defect (ASD), and ventricular septal defect (VSD) occluders (St. Jude Medical, Plymouth, MN), the dedicated Watchman device (Artritech, Plymouth, MN) ${ }^{4}$, and since 2008 the dedicated Amplatzer Cardiac Plug (ACP) (St. Jude Medical, St. Paul, MN) ${ }^{5-7}$.

Operator experience is an important determinant for success, as LAA occlusion has to be considered a complex procedure ${ }^{8}$ with a considerable learning curve. Dedicated devices were designed and further adapted to offer better procedural outcome with lesser risk for device embolization.

In the randomized PROTECT-AF trial ${ }^{4}$, more early complications in patients treated with LAA occlusion were overcome by more late events in the warfarin group. The majority of primary safety endpoints (procedure complications, bleeds) in the LAA occlusion group occurred at the day of the procedure, whereas in successfully treated patients, the 2-year safety endpoint was significantly less frequent in the LAA occlusion group as compared to patients on warfarin. On the other hand, in the per protocol analysis, the primary efficacy event rate (death, stroke, peripheral embolization) was twice as high in the warfarin group as compared to the LAA occlusion group.

It can thus be speculated that a mechanical solution (by means of LAA occlusion) becomes more favorable over OAC the longer the follow-up. The early procedural hazard is overcome by continuous late events in the control group.

The goal of the present study was to fill in the gap of intermediate-term outcome data of patients that underwent LAA occlusion. Furthermore, we compared the outcome of dedicated versus non-dedicated devices to investigate whether dedicated devices in fact lead to better procedural outcome. This report is an observational study and can only be used to support the concept that occlusion of the LAA with the ACP device is preferable to OAC.

\section{Methods}

\section{Patients}

All patients with non-valvular atrial fibrillation and an indication for long-term oral anticoagulation (CHA2DS2-Vasc Score of $\geq 1$ ) were eligible for LAA occlusion. Indi- 
cations included a history of previous bleeding, patients at high-risk of bleeding, or patient preference.

All patients gave written informed consent before the procedure according to the stipulations and approval of the institutional Internal Review Board. This was a retrospective analysis of prospectively collected data, but not a randomized clinical trial.

\section{Non-dedicated Amplatzer devices and Amplatzer Cardiac Plug}

During the years 2002-2008, non-dedicated LAA occlusion devices were used (offlabel use of Amplatzer PFO, ASD and VSD occluders, Figure 1A). After 2008, the dedicated Amplatzer Cardiac Plug (ACP, Figure 1B) was utilized almost exclusively.

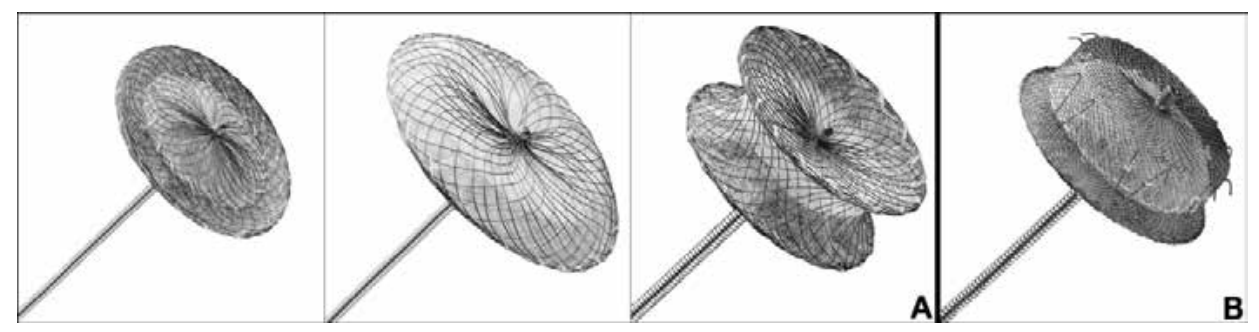

Figure 1. Non-dedicated and dedicated LAA occlusion devices

A: non-dedicated devices (from left to right): PFO, ASD, and VSD occluders.

B: ACP. Note the hooks on the lobe for anchoring of the device.

The devices are made of a nitinol mesh and polyester filling to enhance endothelialization and prevent blood flow through the device. The non-dedicated devices consist of 2 disks with a connecting waist of variable diameter depending on the device chosen. The ACP is composed of a lobe with tiny hooks for device anchoring and a sealing disk towards the left atrium. A thin, stretchable waist connects the lobe and the disk.

The Amplatzer TorqueVue $180^{\circ}$ delivery sheaths (for the non-dedicated devices) or the dedicated Amplatzer ACP delivery sheaths were used (both by St. Jude Medical, Plymouth, MN).

\section{Procedure}

Procedures were performed in the catheterization laboratory using local anesthesia and fluoroscopic guidance only. LAA occlusion was performed either alone or in conjunction with coronary angiography, coronary angioplasty, transcatheter valve implantation, PFO or ASD closure, or pulmonary vein isolation.

At the beginning of the procedure, 5000 units of heparin were given. In case a PFO or ASD was present, they were used for left atrial access. Otherwise a transseptal puncture was performed using an 8 French transseptal kit (Mullins ${ }^{\mathrm{TM}}$ transsep- 
tal sheath and Brockenbrough needle, Medtronic Inc., Minneapolis, MN). The obturator of this sheath accepts a stiff-shaft 0.035 inch Backup wire (Boston Scientific, Natick, MA, USA) used to introduce the Amplatzer delivery sheath. The LAA was visualized using contrast injections through this sheath in different angulations in order to identify the neck and the lobes of the LAA.

Given the known outer diameter of the delivery sheath $(3.0-5.5 \mathrm{~mm})$, the diameter of the landing zone was estimated, aiming for a device with a diameter at least $20 \%$ oversized compared with the LAA dimension (Figure 2A). The device was deployed in the LAA and a stable device position was confirmed by a tug test and contrast injections at imaging planes perpendicular to the device in the lobe (both parts of the device fully separated) to ensure circumferential anchoring in the LAA. Since 2006 a pusher cable with a moveable core was preferentially used ${ }^{9}, 10$. It afforded to pull back the sleeve around the core-wire to which the screw is attached. This revealed the stability of the device largely uninfluenced by the attached safety tether. Then, the device was released (Figure 2B and C). A transthoracic echocardiogram confirmed stable device position either the day of the procedure (in case the procedure was performed on an outpatient basis), or the following day.
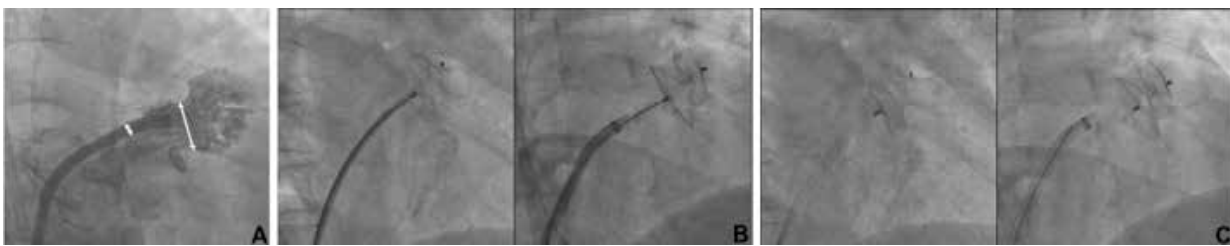

Figure 2. Device deployment

A: Contrast injections to the LAA through he delivery sheath with a known outer diameter (double arrow on the right: $13 \mathrm{~F}$ ACP delivery sheath corresponding to $5.5 \mathrm{~mm}$ ). The diameter of the landing zone is estimated and a device is chosen aiming for at least $20 \%$ oversizing.

B: An Amplatzer ASD device (left) and an ACP device (right) are depicted.

C: Once a stable device position is confirmed, the device is released (left: ASD device; right: ACP).

Patients were discharged on acetylsalicylic acid (100mg) and clopidogrel $(75 \mathrm{mg})$ for 1 to 6 months (except for patients who underwent concomitant left atrial ablation who remained on OAC for 3 months), at which time a follow-up transesophageal echocardiography (TEE) was performed to confirm proper seating of the LAA and to look for residual leaks or thrombi on the device. In addition, a neurology consult was performed at the time of the TEE.

Procedural success was defined as a device in the LAA after 6 months irrespective of residual leaks, the time point where transesophageal echocardiography was performed. 


\section{Follow-up}

A follow-up of all patients who had attempted percutaneous LAA occlusion was performed in the summer of 2012. Bleeding events, neurologic events, deaths (cardiovascular, other or unknown), current antithrombotic therapy, and hospitalizations were assessed. In case of an event, the treating family doctor or cardiologist were contacted, or hospital chart reviews were performed if necessary.

\section{Endpoints and Statistics}

Endpoints were divided into safety and efficacy endpoints. The safety endpoint was defined as the composite of procedure related complications (pericardial effusion, device embolization, and procedure related stroke) and major bleeds (according to TIMI Bleeding Criteria for classification of Non-CABG related bleeding). The efficacy endpoint was defined as the composite of cardiovascular and unexplained deaths, neurologic events (ischemic and hemorrhagic stroke, transient ischemic attacks), and systemic embolism.

Short-term outcome included the first six months of follow-up with subgroup analyses including comparison of patients treated with non-dedicated versus dedicated devices. If after 6 months a device was in place (start of intermediate-term follow-up), no difference between non-dedicated and dedicated devices was expected. Therefore, subgroup analyses for intermediate-term follow-up ( $>6$ months) compared patients with a device in place versus patients with no LAA occlusion device.

Data are presented as mean and standard deviation (SD). Between groups comparisons were done using paired t-test for numerical, Mann-Whitney test for ordinal and Fishers exact test for nominal data. A p-value of $\leq 0.05$ was considered statistically significant.

\section{Results}

\section{Patient characteristics}

LAA occlusion was attempted in 152 patients (105 males, age $72 \pm 10$ years) in atrial fibrillation (persistent or permanent in 72, paroxysmal in 80). Mean CHA2DS2-Vasc score was $3.4 \pm 1.7$ and mean HAS-BLED score was $2.4 \pm 1.2$. Heart failure was present in 29 (19\%), arterial hypertension in 114 (75\%), diabetes mellitus in 35 (23\%), and a history of prior stroke in 47 patients (31\%).

Reasons for LAA occlusion were prior relevant bleeding in 38 (25\%), high-risk of bleeding in 68 (45\%), high-risk of falls or prior falls in 11 (7\%), and patient preference in 37 patients (24\%).

In 21 patients (14\%), the procedure was performed on an outpatient basis. 
Baseline characteristics are presented in Table 1.

Table 1. Baseline characteristics

Baseline characteristics in the overall population, the population treated with a non-dedicated device and the population treated with the ACP device. Between group comparison was done using unpaired ttest.

\begin{tabular}{llllc}
\hline Baseline characteristics & $\begin{array}{l}\text { Overall population } \\
(\mathrm{n}=152)\end{array}$ & $\begin{array}{l}\text { ND group } \\
(\mathrm{n}=32)\end{array}$ & $\begin{array}{l}\text { ACP group } \\
(\mathrm{n}=120)\end{array}$ & p-value \\
\hline Age (years) & $72 \pm 10$ & $64 \pm 8$ & $74 \pm 10$ & $<0.0001$ \\
Male & $105(69 \%)$ & $23(72 \%)$ & $82(68 \%)$ & 0.83 \\
CHA2DS2-Vasc & $3.4 \pm 1.7$ & $2.6 \pm 1.6$ & $3.7 \pm 1.6$ & 0.0013 \\
HAS-BLED & $2.4 \pm 1.2$ & $1.7 \pm 1.1$ & $2.6 \pm 1.2$ & 0.0004 \\
Hypertension & $114(75 \%)$ & $16(50 \%)$ & $98(82 \%)$ & 0.0005 \\
Diabetes mellitus & $35(23 \%)$ & $2(6 \%)$ & $33(28 \%)$ & 0.009 \\
History of stroke & $47(31 \%)$ & $7(22 \%)$ & $40(33 \%)$ & 0.28 \\
\hline
\end{tabular}

\section{Procedural and short term outcome}

Non-dedicated devices were used in 32 patients (21\%, ND group), and a PFO, ASD, or VSD occluder was used in $2(6 \%), 20(63 \%)$, and $6(19 \%)$ of them, respectively. The dedicated ACP was used in 120 (79\%) patients (ACP group). In the remaining 4 patients prototype Amplatzer devices were used.

In 4 patients, 2 devices were implanted in the LAA, in 3 patients during the initial procedure and in 1 patient during follow-up. Reasons for implanting a second device were a large residual shunt or a specific LAA anatomy. Devices implanted were an ACP and PFO-device, 2 ACP devices and 2 PFO occluders in 1 patient each, and an ACP and Vascular Plug in the remaining patient.

LAA occlusion was performed in conjunction with coronary angiography in 105 (69\%), percutaneous coronary intervention in 29 (19\%), left atrial ablation in 10 (7\%), and transcatheter aortic valve implantation in 11 patients (7\%). A PFO or ASD was used for left atrial access and was closed at the end of the LAA closure procedure in 40 patients $(26 \%)$.

LAA occlusion was attempted in all 152 patients. Procedural complications occurred in 13 patients, which consisted of neurologic events in 3, cardiac tamponade in 4 , and device embolization in 6 patients. Short-term complications occurred in 2 patients: 6 days after the procedure, 1 patient died of gastrointestinal bleeding that was the indication for LAA occlusion. At 6 months follow-up 1 device embolization was detected on transesophageal echocardiogram that had apparently occurred before hospital discharge but was missed. 
The composite procedural and short-term safety endpoint occurred in 15 (ND 7, ACP 8) and the efficacy endpoint in none of the patients. Three procedural neurologic events occurred ( 2 transient ischemic attacks and 1 minor stroke with complete recovery after 3 months; ND 0 , ACP 3). None of the patients had persisting neurologic deficits. Cardiac tamponade occurred in 4 patients (ND 2, ACP 2) and was treated with pericardiocentesis in 3 and emergent surgical intervention (including surgical ligation of the LAA) in 1 patient. In 1 patient where tamponade was treated with pericardiocentesis, the procedure was abandoned and the patient did not have the LAA occluded. This was the only patient without device placement. No patient with procedural cardiac tamponade suffered long-term sequelae.

Device embolization occurred more frequently in the ND as compared to the ACP group ( 5 or $12 \%$ vs 2 or $1.6 \%$, p=0.0048). Six embolizations occurred during the procedure, while 1 occurred later and was detected at routine follow-up at 6 months. Embolized devices were snared and externalized in 3 patients and 2 underwent successful implantation of another device at the same sitting. The patient with late detection had the device snared and removed through an inguinal cutdown but did not receive another device. One patient had surgical removal of the device from the femoral artery after successful occlusion of the LAA with another device. Cardiac surgery with surgical ligation of the LAA was performed in 3 patients.

Overall, 6 patients remained without a percutaneous LAA occlusion device in place ( 3 in the ND group and 3 in the ACP group) due to embolization in 4 and cardiac tamponade in 2. Four of the 6 patients underwent cardiac surgery and had surgical ligation of the LAA. Two patients did not have their LAA occluded.

Procedural outcomes are summarized in Table 2. 
Table 2. Outcome of LAA occlusion:

Short-term outcome is divided into patients treated with the ACP device versus patients treated with non-dedicated devices.

Longterm outcome is divided into patients that underwent successful percutaneous LAA occlusion (pts $\mathrm{w}$ / perc LAAO) and patients that were treated either by surgical LAA occlusion or had their LAA not occluded (pts w/o perc LAAO).

LAAO related outcome comprises of events directly and causally related to LAA occlusion.

\begin{tabular}{|c|c|c|c|c|}
\hline Short-term outcome & $\begin{array}{l}\text { Overall population } \\
(n=152)\end{array}$ & $\begin{array}{l}\text { ND group } \\
(n=32)\end{array}$ & $\begin{array}{l}\text { ACP group } \\
(n=120)\end{array}$ & p-value \\
\hline Neurologic events & $3(2 \%)$ & 0 & $3(2.5 \%)$ & 0.37 \\
\hline Cardiac tamponade & $4(2.6 \%)$ & $2(2.5 \%)$ & $2(1.6 \%)$ & 0.15 \\
\hline Device embolization & $7(4.6 \%)$ & $5(12 \%)$ & $2(1.6 \%)$ & 0.0048 \\
\hline $\begin{array}{l}\text { Death } \\
\text { - cardiovascular } \\
\text { - non-cardiac }\end{array}$ & $\begin{array}{l}0 \\
1(0.6 \%) \\
\text { (d/t GI bleed) }\end{array}$ & $\begin{array}{l}0 \\
0\end{array}$ & $\begin{array}{l}0 \\
1(0.8 \%)\end{array}$ & 0.60 \\
\hline Safety endpoint & $15(9.8 \%)$ & $7(22 \%)$ & $8(6.7 \%)$ & 0.0061 \\
\hline Efficacy endpoint & 0 & 0 & 0 & $\mathrm{~N} / \mathrm{A}$ \\
\hline Bailout surgery & $\begin{array}{l}5(3.3 \%) \\
\text { (card. surgery in } 4)\end{array}$ & $3(9 \%)$ & $2(1.6 \%)$ & 0.063 \\
\hline
\end{tabular}

\begin{tabular}{lllll}
\hline Long-term outcome & Overall & $\begin{array}{l}\text { Pts w/o perc } \\
\text { LAAO (n=6) }\end{array}$ & $\begin{array}{l}\text { Pts w/perc } \\
\text { LAAO (n=145) }\end{array}$ \\
\hline $\begin{array}{l}\text { Cardiovascular death } \\
\text { Death }\end{array}$ & $5(3.3 \%)$ & 0 & $5(3.4 \%)$ & 0.64 \\
- Noncardiac & $7(4.6 \%)$ & 0 & $7(4.8 \%)$ & 0.58 \\
- Unexplained & $3(2 \%)$ & $3(50 \%)$ & 0 & 0.72 \\
Neurologic events & $2(1.3 \%)$ & $1(16.6 \%)$ & $1(0.7 \%)$ & 0.83 \\
Systemic embolism & $1(0.7 \%)$ & 0 & $1(0.7 \%)$ & 0.84 \\
Major bleed & $4(2.6 \%)$ & $1(16.6 \%)$ & $3(2.1 \%)$ & 0.029 \\
Safety endpoint & $4(2.6 \%)$ & $1(17 \%)$ & $3(2 \%)$ & 0.029 \\
Efficacy endpoint & $11(7.2 \%)$ & $1(17 \%)$ & $10(6.9 \%)$ & 0.037 \\
\hline
\end{tabular}

\begin{tabular}{ll}
\hline Overall outcome & \\
\hline Safety endpoint & $19(12.5 \%)$ \\
Efficacy endpoint & $11(7.2 \%)$ \\
\hline
\end{tabular}

\begin{tabular}{llll}
\hline $\begin{array}{l}\text { LAA occlusion related } \\
\text { outcome }\end{array}$ & Short-term & Long-term & Overall \\
\hline Safety endpoint & $14(9.2 \%)$ & $2(1.3 \%)$ & $16(10.5 \%)$ \\
Efficacy endpoint & 0 & $2(1.3 \%)$ & $2(1.3 \%)$ \\
\hline
\end{tabular}




\section{Follow-up}

Follow-up was complete in all but 1 patient (99\%). Mean intermediate-term follow up of the study population was 32 months (range 0.4-120 months).

135 patients were alive. Deaths occurred in 16 patients, of which 15 were late deaths ( $>6$ months after the initial procedure). Of those, 5 were cardiovascular, 7 non-cardiovascular, and 3 unexplained deaths. The cardiovascular deaths included 1 patient with progressive heart failure, 3 myocardial infarctions (where 2 presented as sudden cardiac deaths), and 1 patient who underwent LAA occlusion and transcatheter aortic valve implantation at the same session and died of progressive heart and renal failure after 33 days.

Of the cohort, 15 patients (10\%) were still taking OAC. The reasons for continued OAC were a history of pulmonary embolism in 2 , incomplete LAA closure in 4 and thrombus on the device in 2 patients. Two patients did not undergo percutaneous or surgical LAA occlusion and therefore were still on OAC. In the remaining 5 patients (all in the ND group) there was no obvious reason why they were still on OAC.

One patient, in whom a thrombus on the device was found during routine follow-up TEE refused to to take OAC. He developped a systemic embolism to his leg 30 months after LAA occlusion which required a surgical intervention.

During follow-up, neurologic events occurred in 2 patients. Both were ischemic strokes, 1 was minor and 1 major (Rankin 4). Both patients were in the ND group, but 1 patient had had surgical ligation of his LAA (due to procedural embolization of the device). Therefore, in percutaneously treated patients only 1 neurologic event and 1 systemic embolism occurred.

Bleeding complications occurred in 13 patients (9\%). Of those, 4 were major bleeds ( 2 intracerebral bleeds and 2 subdural hematoma). One of the patients with subdural bleeding did have a successful initial procedure with implantation of a small ASD occluder. On routine echocardiography after 6 months device embolization was discovered that apparently had been missed at discharge. The device was found in the femoral artery and was subsequently snared and externalized. He did not undergo another LAA occlusion attempt and was therefore on longterm OAC. The second subdural hematoma occurred in a patient on acetylsalicylic acid alone with a mesothelioma and frequent falls. One of the intracerebral bleeds occurred in a patient who was on dual antiplatelet therapy for 12 months due to previous coronary stenting and transcatheter aortic valve replacement. The second patient with an intracerebral bleed was found to have a thrombus on the ACP during follow-up and was subsequently put on OAC for a limited period of time during which the bleeding occurred. Minor bleeding occurred in 9 patients.

Overall, the composite efficacy and safety endpoint (intention-to-treat analysis) including procedural events occurred in 11 and 19 patients. Excluding short-term events for better appreciation of the protection provided by LAA closure, the efficacy and safety endpoints occurred in 11 (7.2\%) and 4 (2.6\%) patients, respectively. 
Follow-up outcome is summarized in Table 2.

In successfully treated patients, short-term follow-up transesophageal echocardiography was performed after 3 to 6 months, and showed residual shunt into the LAA in 9 patients $(5$ or $17 \%$ in the ND group and 4 or $3 \%$ in the ACP group, $\mathrm{p}=0.009)$. Thrombus on the device was present in 14 patients $(16 \%)$, which was treated with OAC for at least 3 months. In all 14 patients the thrombus resolved, except in 1 patient who refused to undergo repeat transesophageal echocardiography.

\section{Discussion}

We report a single center experience over 10 years with percutaneous LAA occlusion. To our knowledge, this is the longest follow-up of LAA closure reported.

There are 4 main findings in our study:

There was (1) improved short-term outcome with the dedicated ACP as compared to non-dedicated devices as already shown in a retrospective pilot-study9. Despite the improvements, (2) safety events occur in approximately 7\% of patients. Thus, LAA occlusion remains a technically demanding procedure. Once the procedural risk is overcome, (3) intermediate-term outcome is excellent. (4) Device thrombus is a relatively frequent finding on routine follow-up TEE, entailing therapeutic consequences.

Our study is different than previous studies1: Although most patients underwent transesophageal echocardiography during preliminary work-up, no echocardiographic guidance was used during the procedure, which were performed under local anaesthesia only. Secondly, most patients underwent LAA occlusion in conjunction with other interventional procedures.

Since the withdrawal of the Plaato system (ev3 Inc., Plymouth, MN), the Amplatzer devices are the longest-used devices for LAA closure (10 years). Our data confirm the promising results when using these devices. We observed significantly less device embolizations in the ACP group, indicating that the design of the ACP and the special LAA sheath enhance proper anchoring in the LAA. We experienced less cardiac tamponade, but more embolizations with the ACP as compared to previous studies using the Watchman device4. This finding warrants further investigation. Interestingly, two-thirds of the embolizations in the Watchman trial occurred during follow-up, while in our study no late embolization occurred. This may be a misinterpretation of the time of events in the Watchman papers that defined the time of documentation of a missing device as the time of embolization. 
As with the ongoing continued access protocol of the Watchman device8, procedural outcome in our study with the ACP compares favorably to the initial PROTECTAF Trial, most likely largely due to growing center and operator experience.

Thrombus formation on the device remains a concern. Most patients are started on OAC or low-molecular weight heparin for a limited period of time ${ }^{11,12}$. While thrombi typically resolve after a few months, in 1 of our patients an intracerebral bleed occurred during this time. This again indicates that OAC is not a benign treatment option in these patients. Our data further suggest, that it is indeed worthwhile to perform a follow-up TEE a few months after device implantation for exclusion of device thrombus. On the other hand, incomplete LAA occlusion seems not to predispose to a higher risk of stroke and therefore does not warrant further treatment ${ }^{13,14}$.

Our study comprised a high-risk population, as reflected by a mean CHA2DS2-VascScore of 3.4. This corresponds to an annual stroke risk of $3.5 \%$ without warfarin ${ }^{15}$. In a study that assessed the stroke and bleeding risk stratified according to the CHA2DS2-Vasc-Score in patients taking warfarin, an annual stroke risk of $1.5 \%$ and an annual major bleeding risk of $>3 \%$ was found in patients with a comparable CHA2DS2-Vasc-Score as in our population ${ }^{16}$. In light of these results, the outcome after LAA Occlusion in our study is promising: we encountered an annual stroke risk of $1.2 \%$ (total of 5 events in 152 patients; average follow-up 2.6 years) and an annual major bleeding risk of $1 \%$ (total of 4 events in 152 patients). Of the 7 major complications during follow-up (2 strokes, 1 peripheral embolism and 4 major bleedings), 3 occurred in patients that did not have a percutaneous LAA occlusion. Thus, in successfully treated patients, the annual incidence of stroke and major bleeding was $0.8 \%$.

Although this is not a randomized trial, our results of LAA occlusion compare favorably to treatment with OAC. Although LAA occlusion bears a certain procedural risk, the longer the follow-up, the more favorable LAA occlusion becomes.

\section{Conclusions}

Left atrial appendage closure is a valuable alternative to oral anticoagulation. The benefit of the procedure increases with longer follow-up. With new dedicated devices, procedural outcome was significantly improved. This observational study invites for a randomized trial of OAC versus the ACP for LAA occlusion to demonstrate efficacy and safety. 


\section{References}

1. Sievert H, Lesh MD, Trepels T, Omran H, Bartorelli A, Della Bella P, Nakai T, Reisman M, DiMario C, Block P, Kramer P, Fleschenberg D, Krumsdorf U, Scherer D. Percutaneous left atrial appendage transcatheter occlusion to prevent stroke in high-risk patients with atrial fibrillation: early clinical experience. Circulation. 2002;105:1887-1889.

2. Meier B, Palacios I, Windecker S, Rotter M, Cao QL, Keane D, Ruiz CE, Hijazi ZM. Transcatheter left atrial appendage occlusion with Amplatzer devices to obviate anticoagulation in patients with atrial fibrillation. Catheter Cardiovasc Interv. 2003;60:417-422.

3. Ostermayer SH, Reisman M, Kramer PH, Matthews RV, Gray WA, Block PC, Omran H, Bartorelli AL, Della Bella P, Di Mario C, Pappone C, Casale PN, Moses JW, Poppas A, Williams DO, Meier B, Skanes A, Teirstein PS, Lesh MD, Nakai T, Bayard Y, Billinger K, Trepels T, Krumsdorf U, Sievert H. Percutaneous left atrial appendage transcatheter occlusion (PLAATO system) to prevent stroke in high-risk patients with non-rheumatic atrial fibrillation: results from the international multi-center feasibility trials. J Am Coll Cardiol. 2005;46:9-14.

4. Holmes DR, Reddy VY, Turi ZG, Doshi SK, Sievert H, Buchbinder M, Mullin CM, Sick P. Percutaneous closure of the left atrial appendage versus warfarin therapy for prevention of stroke in patients with atrial fibrillation: a randomised non-inferiority trial. Lancet. 2009;374:534-542

5. Park JW, Bethencourt A, Sievert H, Santoro G, Meier B, Walsh K, Lopez-Minquez JR, Meerkin D, Valdes M, Ormerod O, Leithauser B. Left atrial appendage closure with Amplatzer cardiac plug in atrial fibrillation: initial European experience. Catheter Cardiovasc Interv. 2011;77:700-706.

6. Lam YY, Yip GW, Yu CM, Chan WW, Cheng BC, Yan BP, Clugston R, Yong G, Gattorna T, Paul V. Left atrial appendage closure with AMPLATZER cardiac plug for stroke prevention in atrial fibrillation: initial Asia-Pacific experience. Catheter Cardiovasc Interv. 2012;79:794-800.

7. Nietlispach F, Gloekler S, Khattab A, Pilgrim T, Schmid M, Wenaweser P, Windecker S, Meier B. Percutaneous left atrial appendage closure. European Geriatric Medicine 2012, in press.

8. Reddy VY, Holmes D, Doshi SK, Neuzil P, Kar S. Safety of percutaneous left atrial appendage closure: results from the Watchman Left Atrial Appendage System for Embolic Protection in Patients with AF (PROTECT AF) clinical trial and the Continued Access Registry. Circulation. 2011;123:417-424.

9. Schmid M, Gloekler S, Saguner AM, et al. Transcatheter left atrial appendage closure in patients with atrial fibrillation: comparison between non-dedicated and dedicated Amplatzer devices. Cardiovasc Med. 2012, in press.

10. Meier B. Catheter-based atrial shunt occlusion, when the going gets even tougher. Catheter Cardiovasc Interv. 2007;69:21-22.

11. Cruz-Gonzalez I, Martin Moreiras J, Garcia E. Thrombus formation after left atrial appendage exclusion using an Amplatzer cardiac plug device. Catheter Cardiovasc Interv. 2011;78:970-973.

12. Cardona L, Ana G, Luisa B, Leal A, Antonio F, Lidia S, Cruz FR. Thrombus formation on a left atrial appendage closure device. Circulation. 2011;124:1595-1596.

13. Viles-Gonzalez JF, Kar S, Douglas P, Dukkipati S, Feldman T, Horton R, Holmes D, Reddy VY. The clinical impact of incomplete left atrial appendage closure with the Watchman Device in patients with atrial fibrillation: a PROTECT AF (Percutaneous Closure of the Left Atrial Appendage Versus Warfarin Therapy for Prevention of Stroke in Patients With Atrial Fibrillation) substudy. J Am Coll Cardiol. 2012;59:923-929.

14. Viles-Gonzalez JF, Reddy VY, Petru J, Mraz T, Grossova Z, Kralovec S, Neuzil P. Incomplete occlusion of the left atrial appendage with the percutaneous left atrial appendage transcatheter occlusion device is not associated with increased risk of stroke. J Interv Card Electrophysiol. 2012;33:69-75.

15. Camm AJ, Kirchhof P, Lip GY, Schotten U, Savelieva I, Ernst S, Van Gelder IC, Al-Attar N, Hindricks G, Prendergast B, Heidbuchel H, Alfieri O, Angelini A, Atar D, Colonna P, De Caterina R, De Sutter J, Goette A, Gorenek B, Heldal M, Hohloser SH, Kolh P, Le Heuzey JY, Ponikowski P, Rutten FH. Guidelines for the management of atrial fibrillation: the Task Force for the Management of Atrial Fibrillation of the European Society of Cardiology (ESC). Eur Heart J. 2010;31:2369-2429. 
16. Jover E, Roldan V, Gallego P, Hernandez-Romero D, Valdes M, Vicente V, Lip GY, Marin F. Predictive value of the CHA2DS2-VASc score in atrial fibrillation patients at high risk for stroke despite oral anticoagulation. Rev Esp Cardiol (Engl). 2012;65:627-633. 


\title{
Part 2
}

Current problems and unsolved issues

\author{
2.3. The transapical procedure
}





\subsubsection{Closure of apical access site after transapical, transcatheter paravalvular leak closure}

Fabian Nietlispach, MD, Friedrich Eckstein, MD, Manfred Seeberger, MD, Stefan Osswald, MD, Beat A. Kaufmann, MD, Oliver Reuthebuch, MD

Can J Cardiol. 2012;28(4):526.e5-7 
Abstract

Background. The safety of percutaneous transapical mitral paravalvular leak (PVL) closure could potentially be enhanced by device closure of the ventricular access site.

Methods. Percutaneous transapical PVL closure was performed. The 9 French delivery sheath was pulled back and a $6 \mathrm{~mm}$ muscular Ventricular Septal Defect Occluder (mVSD) was deployed at the apical puncture site.

Results. Immediate hemostasis was achieved. Total hospitalization was 9 days. NYHA functional class was improved, hemoglobin and haptoglobin rose, while LDH fell. Follow-up fluoroscopy and TTE revealed a good functional result.

Conclusion. Closure of the apical access site using an Amplatzer mVSD Occluder is feasible. 


\section{Introduction}

The feasibility of transapical, transcatheter mitral paravalvular leak (PVL) closure has recently been shown ${ }^{1}$. However, bleeding complications are the Achilles heel of the procedure. The left ventricular apex can be accessed either through a small intercostal incision or by direct percutaneous puncture. While the former technique has potentially a lower risk of bleeding, the latter technique is a simpler and less traumatic approach.

Here we report the percutaneous device closure of the apical puncture site following transapical PVL closure.

\section{Methods}

\section{Patient}

A 56 year-old woman with previous aortic and mitral mechanical valve replacements in 1986 and redo double valve replacements in 2006 underwent On-X mechanical prostheses (On-X Life Technologies Inc, Austin, TX) implantation. The postoperative course was complicated by major bleeding requiring a re-thoracotomy and cardiopulmonary resuscitation. In addition, worsening symptoms of heart failure (NYHA class III) despite maximal medical therapy, and significant hemolysis in the context of a moderate mitral PVL, led to the decision to proceed with PVL closure. Owing to the patients high surgical risk (frailty, prior complicated postoperative course, renal failure, polyneuropathy, chronic immunosuppressive therapy), a percutaneous transapical access was decided upon, despite the lack of long term data supporting such an approach.

\section{Investigations}

Blood analysis revealed a low hemoglobin $(84 \mathrm{~g} / \mathrm{l})$ and haptoglobin $(<0.0583 \mathrm{~g} / \mathrm{l})$, and an elevated LDH (431 U/l). Transesophageal echocardiography located the leak on the medial aspect of the mitral valve ring with a transvalvular gradient of 16/4mmHg ( $\mathrm{max} / \mathrm{mean})$, and revealed a normal left ventricular systolic function.

\section{Procedure}

Following informed consent, the procedure was performed under general anaesthesia in a hybrid operating room (OR). It was guided by fluoroscopy, TEE and TTE.

PVL closure was performed as previously described ${ }^{1}$, using a direct transcutaneous needle puncture of the ventricular apex. A $12 \mathrm{~mm}$ Amplatzer Muscular 
VSD Occluder was used. This device resulted in complete closure of the PVL (Figure 1). The sheath was pulled back into the mid-ventricle.

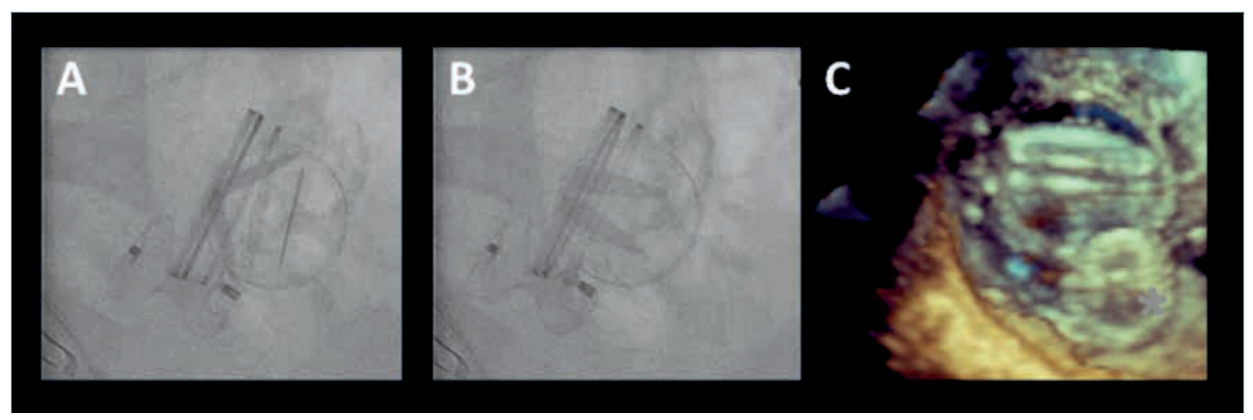

Figure 1. A: mitral leaflets fully open. B: leaflets in closed position. C: 3-D-TEE left atrial view on the mitral prosthesis and the Amplatzer device $(*)$ occluding the paravalvular leak.

Protamine (50mg) was given to reverse the previously administered 5000 units of heparine. A $6 \mathrm{~mm}$ Muscular VSD Occluder was then advanced using the same 9 French Amplatzer delivery sheath, and the distal disc was released into the midventricle. The sheath was subsequently pulled back into the myocardium. The second disc was released while pulling on the sheath. After a stable device position was achieved and hemostasis at the puncture site was confirmed by TTE, the device was released.

\section{Results}

Procedural time was $55 \mathrm{~min}$ and the volume of contrast dye used was $35 \mathrm{ml}$. Repetitive TTE studies in the hybrid OR over the next 30 minutes confirmed hemostasis. The patient was extubated in the OR, transferred to the intensive care unit for 24 hours, fully mobilized on day 3 and discharged on day 9 (NYHA class I).

\section{Follow-up}

Control fluoroscopy was performed on days 1,2 and 5 and confirmed the stable position of the two devices. The mitral valve leaflets were freely mobile. TTE showed a transvalvular gradient of $11 / 4 \mathrm{mmHg}$ (max/mean), no residual paravalvular leak, a trivial localized pericardial effusion, and a stable position of the apical device (Figure 2). 


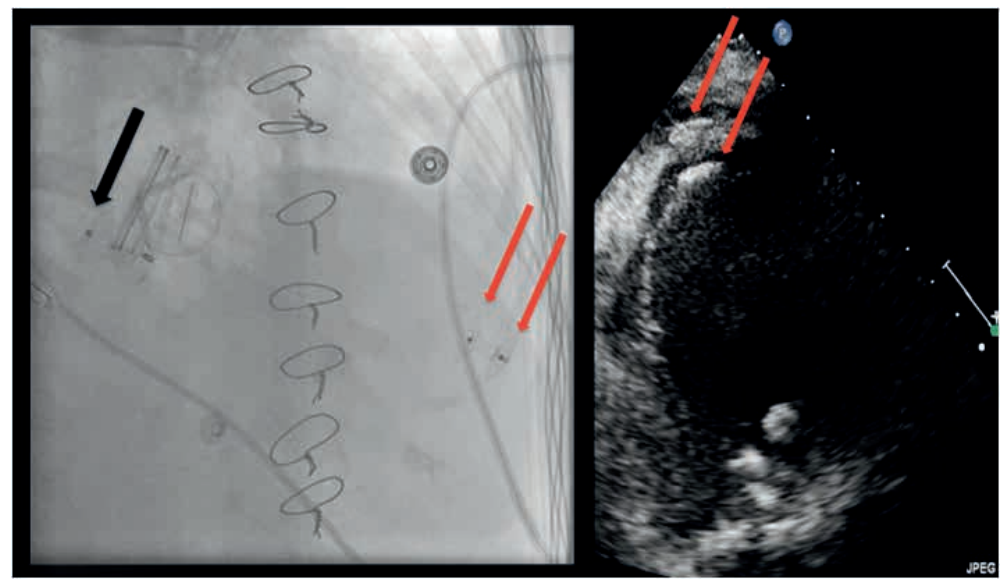

Figure 2. Left: VSD Occluder in paravalvular position (black arrow) and VSD Occluder in apical position (red arrow). Right: TTE-image showing the VSD Occluder in the left ventricular apex (red arrow). Note, the two discs of the apical device adjacent to the epi- and pericardium.

The hemoglobin rose to $104 \mathrm{~g} / \mathrm{l}$, haptoglobin to $0.22 \mathrm{~g} / \mathrm{l}$, while the LDH fell to 309 $\mathrm{U} / \mathrm{l}$. Systolic pulmonary arterial pressure fell from $76 \mathrm{mmHg}$ before the intervention to $33 \mathrm{mmHg}$ at discharge.

One month following the procedure the patient was doing well and remained in NYHA class I heart failure. TTE revealed no residual mitral PVL, no pericardial effusion and a stable position of the ventricular apical device.

\section{Discussion}

We described the procedural steps of ventricular apical access closure using an Amplatzer Muscular VSD Occluder. Only recently have a series of successful device closures of the apical access site using predominantly Amplatzer Duct Occluders been published ${ }^{2}$. We believe that direct transapical access facilitates a variety of structural heart procedures and that device closure of the access site enhances the safety of this technique. This may be particularly pertinent in patients with friable myocardial tissue as in our patient.

Whether this technique may play a role in transapical transcatheter aortic valve replacement ${ }^{3}$ merits further investigation.

\section{References}

1. Nietlispach F, Johnson M, Moss RR, Wijesinghe N, Gurvitch R, Tay EL, Thompson C, Webb JG. Transcatheter Closure of Paravalvular Defects Using a Purpose-Specific Occluder. JACC CardiovasC Interv. 2010;3:759-765. 
2. Jelnin V, Dudiy Y, Einhorn BN, Kronzon I, Cohen HA, Ruiz CE. Clinical experience with percutaneous left ventricular transapical access for interventions in structural heart defects a safe access and secure exit. JACC Cardiovasc Interv. 2011;4:868-874.

3. Smith CR, Leon MB, Mack MJ, Miller DC, Moses JW, Svensson LG, Tuzcu EM, Webb JG, Fontana GP, Makkar RR, Williams M, Dewey T, Kapadia S, Babaliaros V, Thourani VH, Corso P, Pichard AD, Bavaria JE, Herrmann HC, Akin JJ, Anderson WN, Wang D, Pocock SJ. Transcatheter versus surgical aorticvalve replacement in high-risk patients. $N$ Engl J Med. 2011;364:2187-2198. 


\subsubsection{Transapical Access Closure - The TA PLUG Device}

Henriette Brinks+, Fabian Nietlispach+, Volkhard Göber, Lars Englberger, Peter Wenaweser, Bernhard Meier, Thierry Carrel, Christoph Huber

+ Both authors contributed equally.

Interact Cardiovasc Thorac Surg. 2013;17(5):806-10 


\section{Abstract}

Objective. Percutaneous closure of the transapical access site for large calibre devices is an unsolved issue. We report the first experimental data of the TA PLUG device for true-percutaneous closure following large apical access for transcatheter aortic valve implantation.

Methods. The TA PLUG, a self-sealing full-core closure device, was implanted in an acute animal study in six pigs $(60.2 \pm 0.7 \mathrm{~kg})$. All pigs received $100 \mathrm{IU} / \mathrm{Kg}$ of heparin. After accessing the left ventricular apex with a 39French introducer the closure plug device was delivered with a 33French over-the-wire system under fluoroscopic guidance into the apex. Time to full haemostasis as well as rate of bleeding was recorded. Self-anchoring properties were assessed by hemodynamic push stress under adrenalin challenge. In a foregoing feasibility study including four pigs $(58.4 \pm 1.1 \mathrm{~kg})$ with full surgical exposure of the apex, device anchoring was assessed additionally by pull-force measurements with 0.5 Newton increments. All animals were electively sacrified. Post-mortem analysis of the heart was performed and the renal embolic index assessed.

Results. Of 6 apical closure devices, 5 were correctly inserted and fully deployed at the first attempt. One became blocked in the delivery system and was placed successfully at the second attempt. In all animals, complete haemostasis was immediate and no leak was recorded during the 5-hour observation period. Neither leak nor any device dislodgement was observed under haemodynamic push stress with repeated left ventricular peak pressure of up to $220 \mathrm{mmHg}$.

In the foregoing feasibility study assessing pull-stressing, device migration occurred at a force of $3.3 \pm 0.5 \mathrm{~N}$ corresponding to $247.5 \mathrm{mmHg}$.

Post-mortem analyses confirmed full expansion of all devices at the intended target. No macroscopic damage was identified at the surrounding myocardium. The renal embolic index was zero.

Conclusion. True-percutaneous left ventricular apex closure following large access is feasible with the self-sealing TA PLUG. The device allows for immediate haemostasis and a reliable anchoring in the acute animal setting. This is the first report of a true-percutaneous closure for large-calibre TAVI access. 


\section{Introduction}

Transapical transcatheter aortic valve implantation (TA TAVI) has gained wide popularity because of many advantages over non-antegrade access methods ${ }^{1-3}$. The short and antegrade approach allows for a precise device delivery. TA TAVI is not being dependent on good vascular access and the wire crossing of the severely stenosed aortic valve is eased and directed by the native blood flow of the ejecting heart. No crossing of the aortic arch by the valve delivery systems is required and steady wire guidance is supported by wire placement in the descending aorta. The transapical access is not only beneficial for TAVI but it might also be the most versatile access for other interventions in structural heart disease ${ }^{4-7}$ and specially well suited to access the heart for transcatheter mitral valve repair and replacement ${ }^{8}$.

Despite all the very favourable evidence, the enthusiasm for the transapical access is hampered by the mere fact that this approach requires a surgical cutdown and handling of the left ventricle.

Reliable and safe true-percutaneous entry and closure of the transapical access site are essential to further increase acceptance in the clinical routine. Similarly suture mediated and suture-less access closure has become an established routine for many femoral transcatheter techniques ${ }^{9}$.

Access closure of the apex is technically feasible. First experimental data have been reported and first clinical results are expected soon ${ }^{10}$. Nevertheless reported data do only present device based apex closure after an open surgical cut-down with active hooks or suture-based anchoring relying on the myocardial quality.

Data of true-percutaneous large calibre access closure without active hook or suture mediated anchoring has not been reported so far.

This is the first experimental study reporting successful sealing of large calibre transapical access with the TA PLUG device in a true-percutaneous method.

\section{Materials and Methods}

The sutureless TA PLUG closure device is a self-expanding and full-core device made from bio-compatible cellulose. Expanding from a crimped diameter of 27 French (F) to a fully expanded diameter of $66 \mathrm{~F}$ the device is constructed to be selfanchoring and self-sealing. The outer surface is lined with a porous polyethylene/polypropylene membrane. Integrated proximal and distal radio opaque markers define the device area to be seated in the myocardial wall. The $1.75 \mathrm{~cm}$ long closure device is delivered over the wire with a 33F delivery system (Figure 1). 


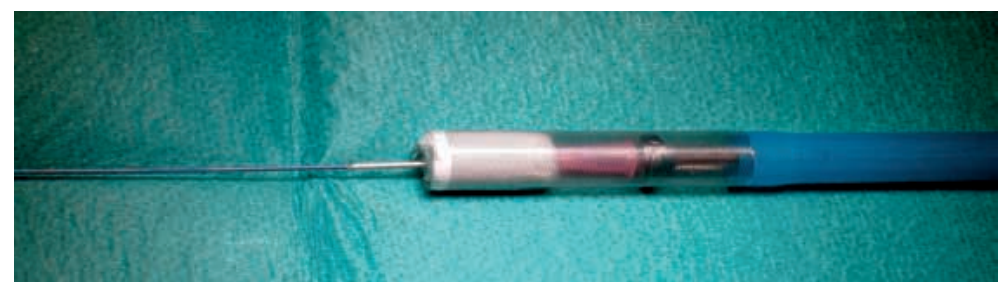

Figure 1. Over-the-wire apical closure TA PLUG loaded into the 33 French delivery system, ready for implantation.

\section{Study design and Ethics}

The study was preformed in compliance with the European Convention on Animal Care, and with permission of the national and cantonal veterinary agency including permanent on-site veterinary supervision. Experiments were performed in 6 adult pigs (mean weight $60.2 \pm 0.7 \mathrm{~kg}$, range $58-62 \mathrm{~kg}$ ). The pigs were intubated and mechanically ventilated under general anaesthesia. A $4 \mathrm{~F}$ pigtail catheter was inserted via the right carotid artery into the LV for contrast injection. Invasive haemodynamic monitoring and blood sampling were performed through the left common carotid artery and a venous infusion catheter inserted into the left brachio-cephalic vein. Continuous ECG monitoring was recorded. All animals were electively sacrified after a 5-hour observation period.

\section{Method}

True-percutaneous access to the apex of the left ventricle (LV) was gained under fluoroscopic guidance with a long biopsy needle inserted in the subxyphoid region. After wire exchange a 0.035 inch extra stiff wire was placed in the ascending aorta. A cutaneous stab incision of $0.5 \mathrm{~mm}$ was made to overcome the porcine skin resistance. Intravenous heparin $(100 \mathrm{U} / \mathrm{Kg})$ was administered only once before the procedure targeting an activated clotting time at 200s. A 39F endoscopic port access device of $12 \mathrm{~cm}$ length was subsequently inserted into the apex to create a standardized large calibre myocardial defect.

In a next step the 33F delivery system was advanced over the wire through the port access into the LV. Then the port access device was removed and the TA PLUG device placed into the created myocardial defect, aiming to align the apex wall within the radio opaque markers. Finally the closure device was released and fully deployed. After successful positioning and sealing the wire was partially pulled to reach the pericardial space and a modified pigtail catheter inserted into the pericardium to measure bleeding. To confirm stable anchoring, throughout the observation period of 5 hours the device was visualised by repeat percutaneous contrast medium injection into the device and into the LV (Figure 2). Hemodynamic stress testing with adrenalin challenges was used to simulate increased left ventricular 
pressure and provoke potential device dislodgement. Adrenalin administration was titrated to reach a systolic blood pressure of 200 to $220 \mathrm{mmHg}$ during at least 2 minutes. The Adrenalin challenges were repeated every 30 minutes throughout.

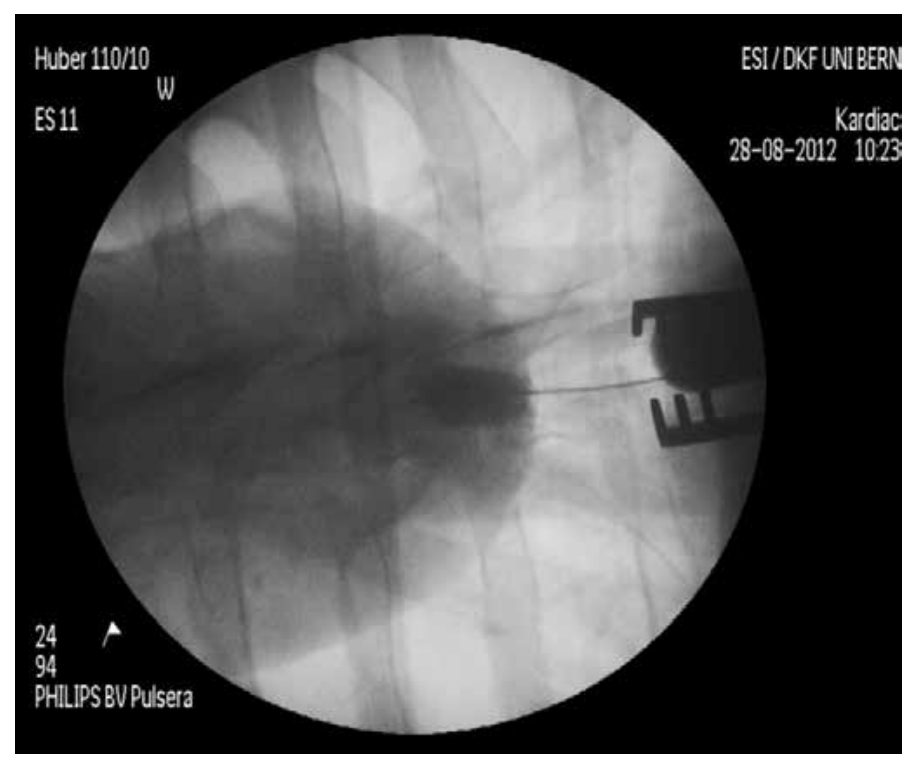

Figure 2. Angiographic view of the deployed TA PLUG after contrast medium injection into the device within the green circle. The green arrow points at the ventricular contrast markers of the device.

In forgoing feasibility experiments including 4 pigs with surgical cut-down for apex exposure and access, after a two hours observation period, additionally continuous pull-force measurements at $0.5 \mathrm{~N}$ increments were performed to measure pull-force necessary for device dislodgment. The pull-tests were not performed in the 6 pigs with true-percutaneous access and closure for technical reasons.

All animals were electively sacrified and the hearts underwent post-mortem analysis. The explanted specimens were prepared at the site of closure device implantation and inspected for macroscopic myocardial damage or clot formation at the device or the surrounding tissue.

The embolic load was assessed by means of the macroscopic embolic counts in both renal cortices. 


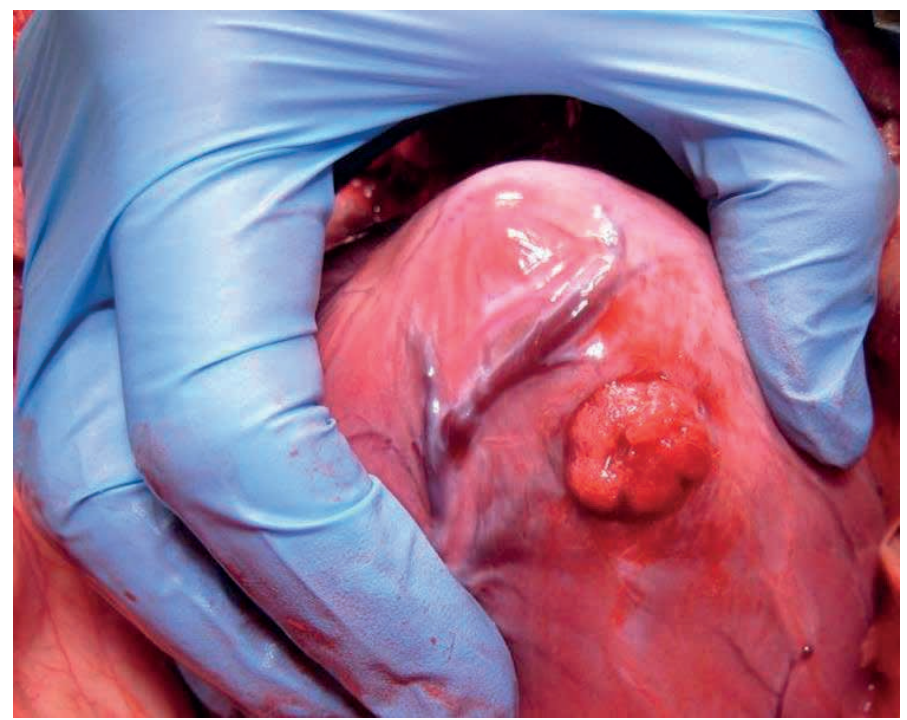

Figure 3. Intra-operative view of the pig heart. The TA PLUG device is precisely deployed and fully expanded within the myocardial wall of the left ventricle.

\section{Results}

Out of 6 true-percutaneous TA PLUG closure devices, 5 were correctly inserted and fully deployed at first attempt. Malfunction of the first generation delivery device resulted in device obstruction in the second animal. The delivery system was exchanged and a second device was loaded and delivered successfully at the second attempt. Haemostasis during the exchange of the device was achieved by temporary re-insertion of the $39 \mathrm{~F}$ port access. Device success was $100 \%$.

All implantations were performed without rapid pacing and all animals reached the 5 hours observation timeline. No major haemodynamic changes or arrhythmias were observed.

Left ventricular contrast medium injection and continuous pericardial effusion measurements revealed immediate sealing of the apex with complete haemostasis in all animals after device deployment. Because of accumulated pericardial effusion from exchanging the delivery system in the second animal $80 \mathrm{ml}$ of blood were drained fin this animal immediately after device insertion.

No device migration was observed and all devices remained safely anchored and fully expanded during the 5-hour observation period despite repeated adrenalin challenges generating prolonged periods of systolic arterial hypertension (pressures up to $220 \mathrm{mmHg}$ ). 
In-vivo pull-stress testing was performed in 4 additional animals with open surgical access to the apex. Device migration occurred at a pull force of $3.3 \pm 0.5 \mathrm{~N}$ corresponding to a left ventricular systolic pressure of $247.5 \mathrm{mmHg}$.

All devices were firmly anchored at the intended target location and fully expanded. No macroscopic damage of the myocardium surrounding the closure device was identified. Specifically neither clot formation nor haemorrhagic changes were identified and no pericardial effusion shown. The bilateral renal cortices showed zero macroscopic emboli at post-mortem.

\section{Discussion}

Transapical access to the aortic valve and to other intra-cardiac structures is the most direct and most promising route for transcatheter treatment of structural heart disease or even coronary heart disease ${ }^{11}$. For TAVI the transapical access together with the transfemoral access have become the most popular access choices. Both techniques present shortcomings.

The transfemoral technique is generally contraindicated in patients with peripheral artery disease and has been repeatedly reported to have an important local complication rate ${ }^{12,13}$. Stroke rate is reported to be higher ${ }^{14}$ in transfemoral than in transapical access TAVI patients. Despite well-engineered delivery systems with increasing miniaturisation the procedure remains retrograde and as such requires a more challenging aortic valve crossing and generates increased shear stress in the aortic arch. The longer working distance from the femoral puncture site to the target area negatively affects the precision of placement and the delivery process and might be responsible for the significant number of patients with paravalvular regurgitation ${ }^{15,16}$.

A stable guiding rail is missing as the guide wire can only be advanced into the left ventricle in a dead-end fashion and therefore cannot provide a safe and firm support. Further left ventricular guide wire perforations are repeatedly observed and reported ${ }^{17}$. Overall the transfemoral approach often represents a trade off in many respects including the mandatory lower crimping profile with increased shear forces on the device.

The main limitation of the transapical access are seen in the surgical cut-down and the direct access through the left ventricular myocardium. Creating the potential for disastrous complications. Even tough very rare reported to be below $1 \% 18,19$ when respecting some surgical rules including access planning and identification of the apex as well as its myocardial thickness by CT and TEE. Careful handling of the purse string sutures with deep intramural stiches using Teflon felt reinforcements and avoiding excessive shear forces during apex handling and delivery. Wrong judgment, insufficient training or unexpected myocardial frailty might make the apex become an unnecessary formidable surgical challenge. Save and reliable de- 
vice based apex access and closure might be the essential step for further methodical adoption of transapical transcatheter techniques.

This study is the first experimental animal trial with the TA PLUG device to demonstrate that true- percutaneous transapical TAVI becomes a reproducible reality that will challenge other TAVI access routes in the near future.

A large calibre access of 39F was repeatedly created in the left ventricle to simulate transapical aortic valve implantation. All percutaneous apex closures were successful. All animals reached the targeted 5-hour observation period. Only in the second animal the closure device remained blocked in the delivery system. A second device was loaded and successfully implanted. After modification of the delivery system with a more controlled pusher-aid no system malfunction were noted in the remaining experiments. With exception of animal two $(80 \mathrm{ml})$ no measurable blood loss was recorded throughout. No device migration was observed despite pharmacologic intervention to increase intra-ventricular pressure on the device up to $220 \mathrm{mmHg}$.

Results from a previous not reported feasibility study including 4 animals with open access to the apex confirmed the present results. In the same study the devices underwent pull-stress testing. Dislodgement was noted only above a pull-force of 3.3Newtons corresponding to a left ventricular pressure equivalent of more than $275 \mathrm{mmHg}$.

The precise deployment at the planned target location confirms the technical feasibility and ease of the device setup. The absence of myocardial damage or clots indicates good tissue tolerance and low risk of arterial embolism in the acute setting. The low thrombo-genicity of the device is also demonstrated by the absence of emboli in the renal cortices.

In contrast to previous studies ${ }^{10,20,21}$ the present closure device mechanism is free of any active stent like structures or anchoring hooks. The sealing is immediate and does not relay on haemostasis.

Given the feasibility character of the study, there are some limitations. The technical early nature of the device requires some improvements as for example a more precise delivery mechanism. The question of long-term bio-tolerance of the device core material including thrombo-genicity and inflammatory response will be evaluated in chronic animal experiments.

A true-percutaneous transapical TAVI assembles many patients' benefits including device durability, procedural handling and decreased complication profile resulting in improved overall outcomes.

The encouraging results of this relatively simple experimental setup indicate that apical closure devices are on the edge of becoming a clinical reality. Transapical TAVI may become the primary true-percutaneous access for structural heart disease in the coming year. This approach will challenge all other TAVI routes. 


\section{References}

1. Huber $\mathrm{CH}$, Nasratulla M, Augstburger M, von Segesser LK. Ultrasound navigation through the heart for off-pump aortic valved stent implantation: new tools for new goals. J Endovasc Ther. 2004 Aug;11(4):503-10.

2. Huber C. Feldmann T. Chapter 6. Access to the aortic valves, Transcatheter Valve Therapies. Informa healthcare 2009;80-100.

3. Huber $\mathrm{CH}$, Cohn LH, von Segesser LK. Direct-access valve replacement a novel approach for offpump valve implantation using valved stents. J Am Coll Cardiol. 2005 Jul 19;46(2):366-70.

4. Vassiliades TA, Block PC, Cohn LH, Adams DH, Borer JS, Feldman T, Holmes DR, Laskey WK, Lytle BW, Mack MJ, Williams DO. The clinical development of percutaneous heart valve technology. A position statement of the Society of Thoracic Surgeons (STS), the American Association for Thoracic Surgery (AATS), and the Society for Cardiovascular Angiography and Interventions (SCAI). J Am Coll Cardiol 2005;45:1554-60.

5. Said SM, Schaff HV, Abel MD, Dearani JA. Transapical approach for apical myectomy and relief of midventricular obstruction in hypertrophic cardiomyopathy. J Card Surg. 2012 Jul;27(4):443-8.

6. Hsieh $\mathrm{CH}$, Thomas SP, Ross DL. Direct transthoracic access to the left ventricle for catheter ablation of ventricular tachycardia. Circ Arrhythm Electrophysiol. 2010 Apr;3(2):178-85. Epub 2010 Feb 4. PubMed PMID: 20133932.

7. Dörr O, Möllmann H, Achenbach S, Sedding D, Basic D, Liebetrau C, Szardien S, Elsässer A, Roth P, Böning A, Hamm C, Nef HM. Transapical coronary artery intervention: "first-in-man" experience. Circ Cardiovasc Interv. 2012 Jun;5(3):446-7.

8. Ma L, Tozzi P, Huber CH, Taub S, Gerelle G, von Segesser LK. Double-crowned valved stents for offpump mitral valve replacement. Eur J Cardiothorac Surg. 2005 Aug;28(2):194-8; discussion 198-9.

9. Van Mieghem NM, Tchetche D, Chieffo A, Dumonteil N, Messika-Zeitoun D, van der Boon RM, Vahdat O, Buchanan GL, Marcheix B, Himbert D, Serruys PW, Fajadet J, Colombo A, Carrié D, Vahanian A, de Jaegere PP. Incidence, predictors, andimplications of access site complications with transfemoral transcatheter aortic valve implantation. Am J Cardiol. 2012 Nov 1;110(9):1361-7.

10. Blumenstein J, Van Linden A, Arsalan M, Voss S, Moellmann H, Liebetrau C, Thourani VH, Walther T, Kempfert J. Experimental evaluation of a new apical access and closure device. Ann Thorac Surg. 2012 Nov;94(5):1706-9.

11. Jelnin V, Dudiy Y, Einhorn BN, Kronzon I, Cohen HA, Ruiz CE. Clinical experience with percutaneous left ventricular transapical access for interventions in structural heart defects a safe access and secure exit. JACC Cardiovasc Interv. 2011 Aug;4(8):868-74.

12. Wenaweser P, Pilgrim T, Roth N, Kadner A, Stortecky S, Kalesan B, Meuli F, Büllesfeld L, Khattab AA, Huber C, Eberle B, Erdös G, Meier B, Jüni P, Carrel T, Windecker S. Clinical outcome and predictors for adverse events after transcatheter aortic valve implantation with the use of different devices and access routes. Am Heart J. 2011 Jun;161(6):1114-24.

13. Stortecky S, Wenaweser P, Diehm N, Pilgrim T, Huber C, Rosskopf AB, Khattab AA, Buellesfeld L, Gloekler S, Eberle B, Schmidli J, Carrel T, Meier B, Windecker S. Percutaneous management of vascular complications in patients undergoing transcatheter aortic valve implantation. JACC Cardiovasc Interv. 2012 May;5(5):515-24.

14. Eggebrecht H, Schmermund A, Voigtländer T, Kahlert P, Erbel R, Mehta RH. Risk of stroke after transcatheter aortic valve implantation (TAVI): a meta-analysis of 10,037 published patients. EuroIntervention. 2012 May 15;8(1):129-38.

15. Gilard M, Eltchaninoff $H$, Iung B, Donzeau-Gouge $P$, Chevreul K, Fajadet J, Leprince $P$, Leguerrier A, Lievre M, Prat A, Teiger E, Lefevre T, Himbert D, Tchetche D, Carrié D, Albat B, Cribier A, Rioufol G, Sudre A, Blanchard D, Collet F, Dos Santos P, Meneveau N, Tirouvanziam A, Caussin C, Guyon P, Boschat J, Le Breton H, Collart F, Houel R, Delpine S, Souteyrand G, Favereau X, Ohlmann P, Doisy V, Grollier G, Gommeaux A, Claudel JP, Bourlon F, Bertrand B, Van Belle E, Laskar M; FRANCE 2 Investigators. Registry of transcatheter aortic-valve implantation in high-risk patients. N Engl J Med. 2012 May 3;366(18):1705-15. 
16. Eric Van Belle; Francis Juthier; Jean - Luc Auffray; Marc Laskar; Alain Leguerrier; Bernard Lung; Martine Gilard; Helene Eltchaninoff; Carlo Banfi; Jean Fajadet; Pascal Leprince; Alain Prat; Emmanuel Teiger. TCT-91 Peri-valvular Aortic Regurgitation in Balloon-expendable and Self-expendable TAVI procedures: Predictors and Impact on clinical outcome - Insights from the FRANCE2 Registry. J Am Coll Cardiol. 2012;60.

17. Bhatia $V$, Left ventricular perforation during cardiac catheterization in a case of severe calcific aortic stenosis. Should we cross the valve?, International Journal of Cardiology, Volume 116, Issue 3, April 2007, e80-e81.

18. Unbehaun A, Pasic M, Dreysse S, Drews T, Kukucka M, Mladenow A, Ivanitskaja-Kühn E, Hetzer R, Buz S. Transapical aortic valve implantation: incidence and predictors of paravalvular leakage and transvalvular regurgitation in a series of 358 patients. J Am Coll Cardiol. 2012 Jan 17;59(3):211-21.

19. Thomas M, Schymik G, Walther T, Himbert D, Lefèvre T, Treede H, Eggebrecht H, Rubino $P$, Colombo A, Lange R, Schwarz RR, Wendler O. One-year outcomes of cohort 1 in the Edwards SAPIEN Aortic Bioprosthesis European Outcome (SOURCE) registry: the European registry of transcatheter aortic valve implantation using the Edwards SAPIEN valve. Circulation. 2011 Jul 26;124(4):425-33.

20. Barbash IM, Saikus CE, Faranesh AZ, Ratnayaka K, Kocaturk O, Chen MY, Bell JA, Virmani R, Schenke WH, Hansen MS, Slack MC, Lederman RJ. Direct percutaneous left ventricular access and port closure: pre-clinical feasibility. JACC Cardiovasc Interv. 2011 Dec;4(12):1318-25.

21. Tozzi P, Pawelec-Wojtalic M, Bukowska D, Argitis V, von Segesser LK. Endoscopic off-pump aortic valve replacement: does the pericardial cuff improve the sutureless closure of left ventricular access? Eur J Cardiothorac Surg. 2007 Jan;31(1):22-5. 


\section{Part 2}

\section{Current problems and unsolved issues}

\subsection{Pathology of Transcatheter Valve Therapy}

Fabian Nietlispach MD, John G. Webb, MD, Jian Ye, MD, Anson Cheung, MD, Samuel V. Lichtenstein, MD PhD, Ronald G. Carere, MD, Ronen Gurvitch, MB BS, Christopher R. Thompson, MD, Avi J. Ostry, MD, Lise Matzke, MSc, Michael Allard, MD

J Am Col Cardiol Intv 2012;5:582-90 


\section{Abstract}

Objectives. To report on the pathology of transcatheter aortic valves explanted at early and late time points after transcatheter aortic valve implantation (TAVI).

Background. Information on pathological findings following TAVI is scarce, particularly late after TAVI.

Methods. Twenty patients (13 male, median age 80 (IQR 72-84 years) with previous TAVI with a valve explanted at autopsy $(n=17)$ or surgery $(n=3)$ were included (10 transapical and 10 transfemoral procedures).

Results. Structural degeneration of transcatheter aortic valves was not seen, although fibrous tissue ingrowth was observed at later time points with minimal effects on cusp mobility in one case. Minor alterations in valve configuration or placement were observed in up to $50 \%$ of cases, but were not associated with substantial changes in function of the valves. Vascular or myocardial injury was common, especially within 30 days of TAVI (9/13 of cases), with the latter associated with left coronary ostial occlusion by calcified native aortic valve tissue in two. Myocardial amyloidosis was present in nearly 33\%, of cases, ranged from mild to severe, and likely played a role in the poor outcome of 3 patients. Endocarditis, migration of the valve, and embolization during the procedure led to surgical valve removal.

Conclusions. Structural degeneration was not seen and minor alterations of valve configuration or placement did not affect valve function and were not reliably caused by chest compressions. Vascular or myocardial injury is very common early after TAVI and myocardial amyloidosis represents a relatively frequent potentially significant co-morbid condition.

\footnotetext{
Abbreviations.

TAVI=transcatheter aortic valve implantation

$\mathrm{IQR}=$ interquartile range

$\mathrm{CPR}=$ cardiopulmonary resuscitation
} 


\section{Introduction}

Transcatheter aortic valve implantation (TAVI) has been established as an effective treatment for patients with severe aortic valve stenosis that are either not suitable for open-heart surgery (1), or as an alternative treatment to open-heart surgery in high-risk patients (2).

Mortality occurring less than 30 days after TAVI reflects mostly procedurerelated mortality $(3,4)$, while later mortality occurring from 30 days to 1year after TAVI is mostly caused by either progression of heart failure or the natural course of co-morbid conditions $(5)(3,6)$. Procedure-related mortality decreases with increasing operator and centre experience (3). Later mortality, on the other hand, decreases by performing the procedure in lower risk populations with less comorbid conditions (5).

Very little information is currently available on the pathological findings following TAVI (7). Post-mortem studies in humans consist of two case reports $(8,9)$ and a single series of 7 post-mortem cases (10). These prior reports primarily demonstrate findings early after valve implantation with only one reported case with late follow up at 425 days (9). In this report, we describe pathologic findings in 20 valves explanted at early, intermediate, and late time points following TAVI.

\section{Methods}

\section{Patients}

All patients with prior TAVI who died and underwent a post-mortem examination or who had a valve surgically explanted at our institution were reviewed. Written permission for pathologic examination was obtained in each case.

\section{Valves and Procedural Approach}

The Cribier Edwards ${ }^{\mathrm{TM}}$ valve (Edwards Lifesciences, Irvine, CA), the prototypic balloon-expandable prosthetic implant (11), is constructed of a stainless steel frame with attached equine pericardial leaflets and a fabric-sealing cuff. This was subsequently replaced with the Edwards SAPIEN valve with bovine pericardial leaflets and a longer fabric sealing cuff (12). The prosthetic valve is crimped onto a balloon catheter and introduced through a large sheath in the femoral artery (transarterial) (13) or directly through the left ventricular apex utilizing an intercostal incision (transapical) (14). The prosthesis is placed inside the diseased native aortic valve and balloon expanded displacing the native cusps. 


\section{Pathologic Analysis}

Entire hearts (in case of an autopsy) or the explanted transcatheter valves (in case of surgical removal) were fixed in $10 \%$ buffered formalin and examined by a cardiovascular pathologist (MFA). Autopsy hearts were examined by a step-wise approach to identify and evaluate structural and non-structural changes in the prosthesis, changes associated with the prosthesis or the procedure, and other cardiac or vascular findings, in accordance with accepted approaches for traditional prosthetic valves (15) or recommendations for transcatheter valves (16). Surgically excised transcatheter valves were examined in a similar fashion.

For microscopic analysis, paraffin-embedded myocardium was section at $4 \mu \mathrm{m}$ and stained with hematoxylin and eosin, Masson's trichrome (to identify fibrosis), Prussian blue (to identify iron), and Congo red and sulphated Alcian blue (to identify amyloid). In selected patients with relevant rhythm disturbances and/or unexplained death, the region of the atrioventricular node and the bundle branches within the interventricular septum were microscopically examined. Valve cusps, when examined, were sectioned as above and stained with hematoxylin and eosin, Movat's pentachrome, and microbiological stains, if appropriate.

\section{Statistics}

Statistical analyses were done using R Statistical Computing for Mac OS. Data are presented as median and interquartile ranges (IQR), unless otherwise indicated. For each valve and cardiac findings groups (structural and non-structural changes/dysfunction; prosthesis/procedure-related changes; and other cardiac changes) group comparison was performed using Kruskal-Willis test. Significance was taken at $\mathrm{p}=0.05$ level for all analyses.

\section{Results}

\section{Patient Characteristics}

A total of 17 valves were examined at autopsy (median age 78 years, 10 male), including 6 Cribier-Edwards valves and 11 Edwards SAPIEN valves. Access for implantation was equivalently either apical $(n=9)$ or transarterial $(n=8)$ for the entire group. Three valves were removed from patients at the time of open-heart surgery (median age 82 years, all males).

\section{Time After Implantation and Cause of Death}

Of the 17 autopsy patients, median post-procedural survival was five days (IQR 225 days, range 0-943 days). Patients were stratified into three temporal categories 
$(16,17)$ : Immediate-Early ( $<7$ days), Intermediate (7-29 days), and Late ( $\geq 30$ days). Death occurred in nine patients less than seven days after implantation and was due to cardiac causes (heart failure, major arrhythmia, rupture of adjacent structures, left main occlusion) in five, cerebrovascular accident in one, major bleeding in two, and sepsis in one. In the intermediate group, cause of death was cardiac in three and sepsis in one. After 30 days, one patient died as a consequence of an intra-cerebral bleed (on warfarin for atrial fibrillation) and progressive heart and renal failure in three. All three surgically excised transcatheter valves were removed more than 30 days after implantation, ranging from 108 to 336 days after implantation (Table 1).

Table 1. Patient Characteristics and Pathologic Findings of autopsy cases. Sixteen cases showed some degree of coronary artery disease (mild - severe); 13 cases had mitral annular calcification; all 17 cases showed myocardial hypertrophy.

\begin{tabular}{|c|c|c|c|}
\hline Age (years) & $\begin{array}{l}\text { Time to death } \\
\text { after implant }\end{array}$ & Pathologic Findings & $\begin{array}{l}\text { Access } \\
\text { Route }\end{array}$ \\
\hline 78 & 3 days & $\begin{array}{l}\text { Recent myocardial Injury } \\
\text { Recent brain injury }\end{array}$ & Apical \\
\hline 87 & 5 days & $\begin{array}{l}\text { Coronary ostial occlusion } \\
\text { Recent myocardial Injury }\end{array}$ & Arterial \\
\hline 57 & 5 days & $\begin{array}{l}\text { Heavily calcified bicuspid aortic valve } \\
\text { Recent brain injury }\end{array}$ & Apical \\
\hline 65 & 5 days & $\begin{array}{l}\text { Cuspal thrombosis } \\
\text { Recent myocardial injury }\end{array}$ & Arterial \\
\hline 80 & 6 days & $\begin{array}{l}\text { Recent myocardial injury } \\
\text { Recent brain injury }\end{array}$ & Apical \\
\hline 76 & 2 weeks & Amyloidosis & Arterial \\
\hline 77 & 28 days & Possible hypertrophic cardiomyopathy & Apical \\
\hline 73 & 1 month & & Arterial \\
\hline 89 & 20 months & $\begin{array}{l}\text { Fibrous tissue ingrowth } \\
\text { Amyloidosis }\end{array}$ & Arterial \\
\hline 85 & 24 months & $\begin{array}{l}\text { Fibrous tissue ingrowth } \\
\text { Recent brain injury }\end{array}$ & Arterial \\
\hline 84 & $<1$ days & $\begin{array}{l}\text { Vascular injury } \\
\text { Recent myocardial injury }\end{array}$ & Apical \\
\hline 58 & $<1$ days & $\begin{array}{l}\text { Vascular injury } \\
\text { Recent myocardial injury }\end{array}$ & Apical \\
\hline 81 & $<1$ days & $\begin{array}{l}\text { Partial coronary ostial occlusion } \\
\text { Recent myocardial injury }\end{array}$ & Apical \\
\hline 80 & 5 days & $\begin{array}{l}\text { Recent myocardial injury } \\
\text { Amyloidosis }\end{array}$ & Apical \\
\hline 71 & 10 days & $\begin{array}{l}\text { Recent myocardial injury } \\
\text { Ischemic bowel }\end{array}$ & Apical \\
\hline 81 & 6 weeks & Amyloidosis & Apical \\
\hline 99 & 30 months & $\begin{array}{l}\text { Fibrous tissue ingrowth } \\
\text { Amyloidosis }\end{array}$ & Arterial \\
\hline
\end{tabular}




\section{Structural and Non-Structural Prosthesis Changes}

The most common structural change observed was a less than round configuration that ranged from slightly oval to almost D-shaped (Figure 1 and 2). This finding occurred across all temporal categories and, in some instances, was accompanied by an apparent mal-alignment or mal-apposition of valve cusps (cuspal tautness, laxity and/or poor coaptation). There were no macroscopic signs of cuspal degeneration (calcifications or cuspal tears), or any evidence of fracture or disruption of the metallic stent in any valve.

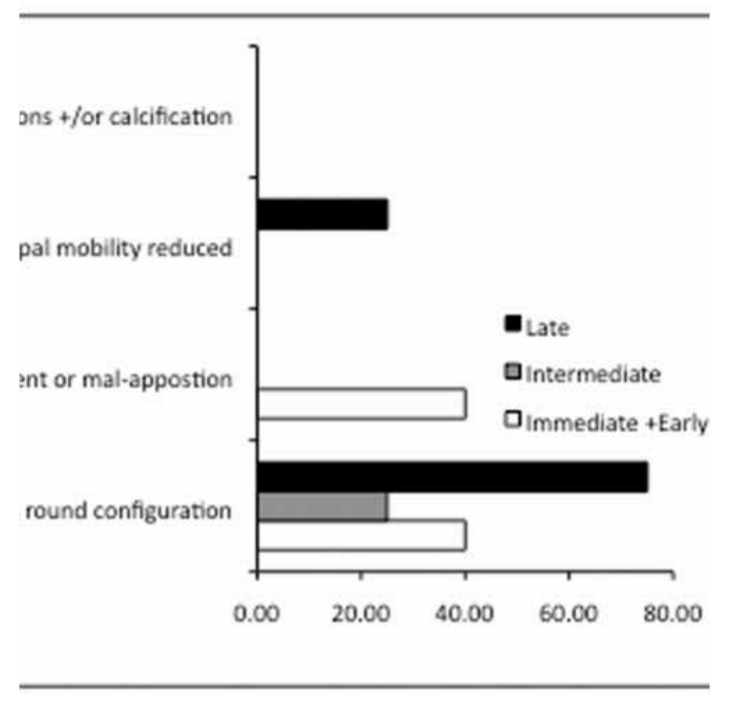

Figure 1. Bar graph illustrating relative frequency of structural prosthesis changes according to time after implantation. Expressed as \%. $\mathrm{N}=4$ to 9 per group. 

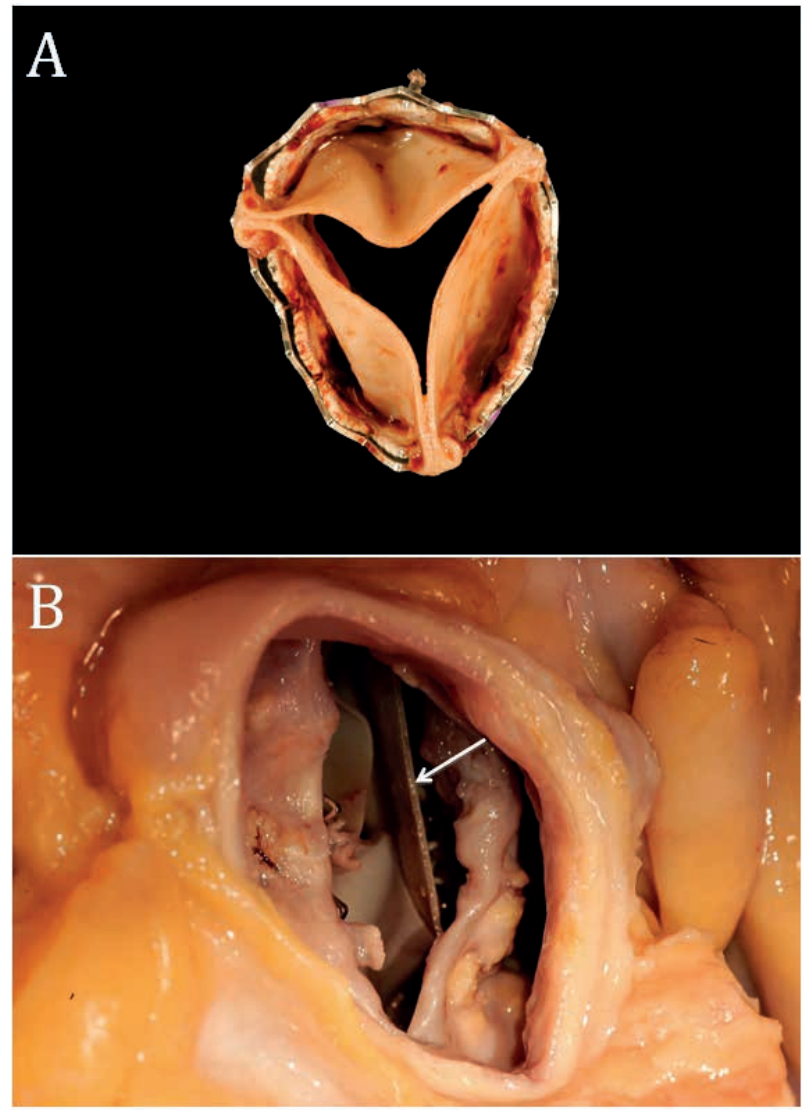

Figure 2. Non-circular configuration of a transcatheter valve removed from the heart at autopsy (A) and cuspal mal-alignment (tautness of one cusp, arrow) in a transcatheter valve with dramatic alterations in configuration (B).

Fibrous tissue ingrowth was found in valves from patients dying Late after TAVI (Figure 3) and ranged from minimal to extensive where a thin layer of filmy fibrous tissue covered approximately 80 to $90 \%$ of the inner aspect of the metallic stent (Figure 4). Localized fibrous tissue ingrowth onto the basal aspects of the cusps mildly reduced cuspal mobility in one case (Figure 1). 


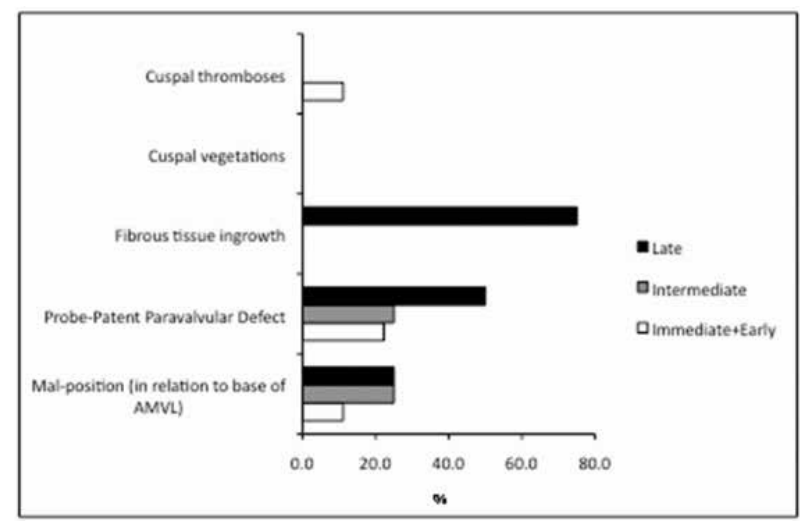

Figure 3. Bar graph illustrating relative frequency of non-structural prosthesis changes according to time after implantation. Expressed as $\%$. $\mathrm{N}=4$ to 9 per group.

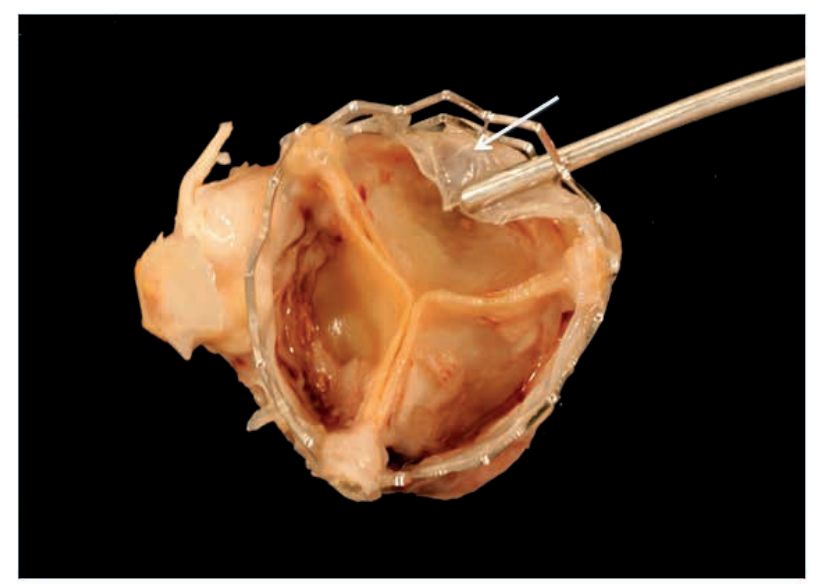

Figure 4. Photograph showing fibrous tissue ingrowth on the stent frame of a transcatheter valve (arrow).

A probe-patent paravalvular defect was another relatively frequent observation that spanned all temporal categories (Figure 3). Minor degrees of prosthesis malposition, using relation of the inferior aspect of the prosthesis stent frame to the insertion of the anterior leaflet of the mitral valve as a guide, were also observed in several cases.

Small amounts of recent thrombotic material on the ventricular and aortic aspects of the cusps (preferentially near the commissural regions) and metallic stent were found in one case in the Immediate-Early group. Histologically, the thrombotic material was comprised largely of fibrin and platelets. Notably, echocardiography at the time of valve implantation suggested thrombus on the guidewire and possibly on the valve despite heparinization. There was no evidence of thromboembo- 
lism at the time of autopsy, however. Vegetations were not seen in any of the prostheses from cases examined at autopsy.

\section{Functional Consequences of Structural and Non-Structural Prosthesis Changes}

The majority of patients demonstrated paravalvular aortic regurgitation, as assessed by echocardiography, ranging from trivial to moderate in severity. Structural and non-structural prosthesis changes do not readily explain the paravalvular regurgitation observed. Transvalvular aortic regurgitation was not seen in the valve with fibrous tissue ingrowth that mildly reduced cuspal mobility. Based upon cases with well-documented use of chest compressions during CPR $(n=8)$, an equal number of cases with chest compressions were found to be associated with altered valve shape $(n=4)$ as compared to those that were not $(n=4)$. However, dramatic changes in shape that were accompanied by tautness of one valve cusp and laxity of others (Figure 2b) did not demonstrate significant alterations in valve function during life.

\section{Prosthesis- or Procedure-Associated Changes}

The majority of these findings occurred primarily in Immediate-Early or Intermediate periods after implantation with a more frequent occurrence in the ImmediateEarly time frame (Figure 5) $(\mathrm{p}=0.03)$. Myocardial injury in the form of contraction band change in isolated or clusters of cardiac myocytes or areas of coagulative necrosis of myocardium was observed in more than $50 \%$ of all cases with the greatest frequency of occurrence seen in patients dying in the Immediate-Early period (Figure 5). In select cases, acute injury of the conducting myocardium, especially the left bundle branch, was observed with evidence that both ischemic and direct traumatic injury played a role. Most likely any injuries observed arose from the valve or delivery system rather than the guidewire.

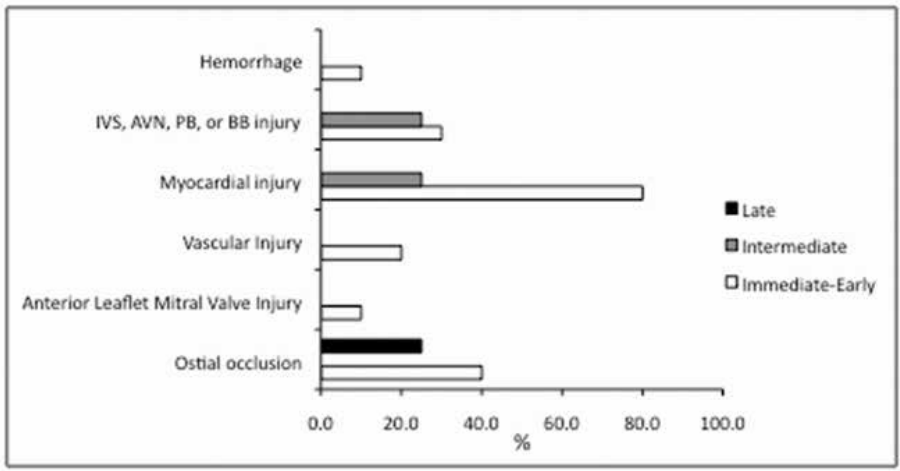

Figure 5. Bar graph illustrating relative frequency of procedure-associated changes according to time after implantation. Expressed as \%. $\mathrm{N}=4$ to 9 per group. 
Sections of healing transapical access sites showed evidence of injured myocytes, accumulation of mesenchymal cellular elements, haemorrhage, and small amounts of fibrous connective tissue deposition.

Apparent obstruction of coronary ostia was observed relatively frequently at autopsy examination providing an explanation for some of the myocardial injury observed (Figure 5). The most severe obstruction was observed in two cases when a calcified and thickened native aortic valve cusp caused complete or near complete obstruction of the left coronary ostium. This was accompanied by hypotension and showed significant ischemic myocardial injury in both. The distance from the aortic annulus to the left coronary ostium was relatively short in both patients: 8.5 and $9.5 \mathrm{~mm}$, respectively. The left sinuses of Valsalva were of normal size and not particularly shallow.

Procedurally related injury to vascular or other cardiac structures were seen in a small number of cases (Figure 5) that when present resulted in catastrophic effects and rapidly led to very poor outcomes. Traumatic disruption of the annular region of the aorta occurred in one patient where the smallest available prosthesis (23 $\mathrm{mm}$ diameter) was significantly larger than the relatively small (18 $\mathrm{mm}$ ) and heavily calcified annulus. In a second patient with severe mitral annular calcification and substantially reduced leaflet mobility, a $2 \mathrm{~cm}$ tear involving the basal aspects of the anterior mitral leaflet and adjacent outflow tract (Figure 6) was created during the procedure that resulted in communication between the left ventricle and atrium and hemodynamic collapse. Transapical access was associated with massive bleeding followed by death due to multi-organ failure at day 5 in another patient.

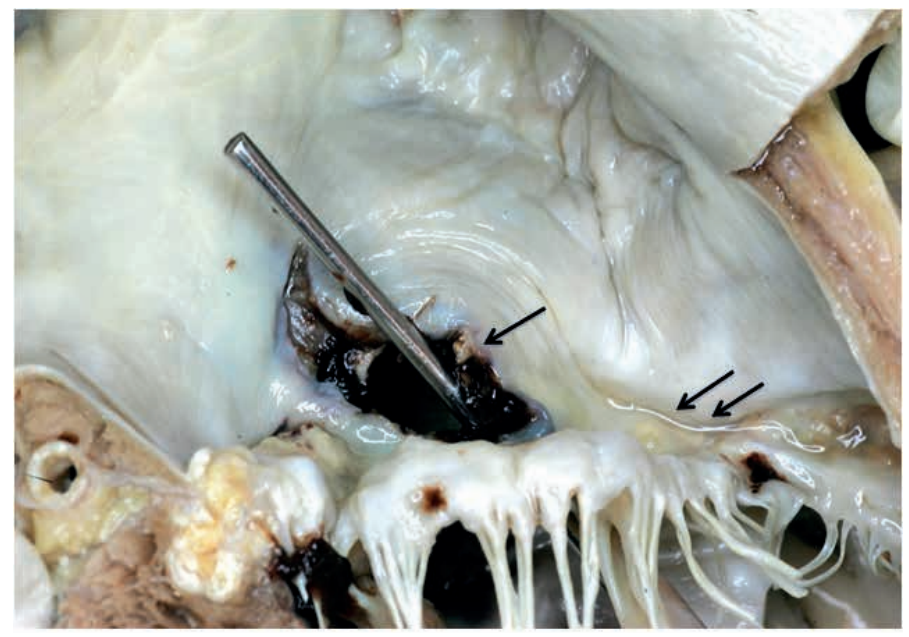

Figure 6. Defect (arrow) in the anterior leaflet of a mitral valve with severe calcification of its annulus (double arrow) that led to a communication between the left ventricle and the left atrium. 
Other Cardiac and Vascular Findings

All patients had evidence of increased cardiac mass or hypertrophy. Many patients also had coronary atherosclerosis and its manifestations including healed myocardial infarction and procedures such coronary artery bypass surgery and/or percutaneous coronary intervention. Mitral annular calcification was also a common finding whose severity potentially played a role in some of the deleterious outcomes described above. Myocardial amyloidosis was present in nearly a third of all autopsy cases ( 5 cases, ages 60 to 99 years) and ranged in severity from relatively mild to extensive and severe. Less severe involvement by amyloid was likely an incidental finding in 2 patients but where severe may have contributed to death due to progressive heart failure leading to death at 40,608 and 943 days after surgery.

\section{Findings in Surgically Excised Transcatheter Valves}

Reasons for surgical valve explantation were embolization at the time of the procedure with the valve deployment in the aortic arch and definitive surgical openheart aortic valve replacement with explantation of the embolized valve (at day 108), low implantation with gradual migration to the left ventricular outflow tract resulting in severe aortic regurgitation (at day 109), and endocarditis (at 336 days). In the latter case, the patient developed Streptococcus angiosus endocarditis of mitral and transcatheter aortic valves 6 weeks after a dental procedure that took place without endocarditis prophylaxis. The endocarditis spread to the mitral valve at the contact point of the aortic valve prosthesis with the anterior mitral leaflet leading to a perforation and regurgitation.

\section{Discussion}

As a relatively new interventional procedure, detailed pathologic examination of autopsy or surgical material from patients undergoing transcatheter implantation is critical to the on-going evolution and improvement of this approach to treatment of aortic valve disease. Results of the present investigation provide important insights into the changes in the transcatheter valves, mechanisms and functional consequences of changes observed in the prostheses, emphasize key pathologies related to the transcatheter valve implantation procedure, and serve to highlight the potential significance of co-morbidities in this patient population.

\section{Structural and Non-Structural Prosthesis Changes}

Current surgical bioprostheses are relatively durable, although structural degeneration and failure can be anticipated to occur 5 to 20 years after implantation 
$(18,19)$ with minimal histological degeneration seen up to 6 years post implantation (20). In surgical bioprostheses, the major cause of failure is related to calcification and tears of valve cusps, resulting in regurgitation or stenosis (21) (15). It is reassuring that we did not observe significant structural valve failure in any case, even up to 943 days after implantation. Variable degrees of fibrous tissue ingrowth was observed late after implantation with some localized involvement of valve cusps resulting in a mild reduction in cuspal mobility but had no impact on measureable valve function. Given its well-recognized occurrence in surgical bioprosthesis (15), it is highly likely that more extensive fibrous tissue ingrowth will occur over time in some prostheses and lead to prosthesis dysfunction, which most likely can be treated by valve-in-valve implantation (22).

A less than round configuration of the stent frame was a relatively common observation and the degree of non-circular configuration varied substantially. We cannot speculate on the reason for stent eccentricity, except for Cardiopulmonary resuscitation (CPR) with chest compressions as one possible explanation in patients dying after transcatheter valve implantation. However, a consistent and significant relationship between a non-circular configuration of the stent frame and CPR with chest compressions was not observed. This doesn't rule out the possibility that CPR with chest compressions may cause deformation in selected patients. The finding of deformed stent frames in this postmortem study stands in contrast to our finding on CT scans 3 years or more after transcatheter valve implantation, where circular stents were found (23). Chest compressions during CPR might explain this discrepancy in part but only in selected cases. Whether such deformed stent frames, even with mild, increase shear stress, thereby accelerate structural valve degeneration needs further investigation (24) (25).

Thrombosis and thromboembolic complications occur less often in association with bioprostheses as compared to mechanical valves (26). Thrombus was uncommon in our series, with significant thrombus evident in only one patient in whom intra-procedural heparinization may have been subtherapeutic. Nevertheless post-procedural thromboembolic stroke remains a concern and most groups utilize long term aspirin and clopidogrel for 1 to 6 months (27). The ideal antithrombotic regimen is yet to be determined (28).

Surgical bioprostheses are said to be associated with a 4\% 10-year risk for endocarditis (29). Mechanical valves are most often associated with localization of infection at the sewing ring, while infection of bioprosthetic valves is more often localized on the valve cusps (15). Infection of our single transcatheter valve was rather diffuse, involving the sewing skirt as well as the valve cusps and was accompanied by infection and perforation of the mitral leaflet (30). Piazza et al reported a similar case in a low implanted CoreValve prosthesis (31). 
Functional Consequence of Prosthesis Changes

Mild to moderate paravalvular aortic regurgitation after transcatheter aortic valve implantation is common, as was observed in patients in our study, although the clinical relevance of this degree of paravalvular regurgitation is uncertain (32-34). Despite a significantly higher incidence of trivial to moderate paravalvular leaks in patients after transcatheter valve implantation as compared to surgical patients, transcatheter valve patients have significantly better hemodynamics and improvement of left ventricular function (35-37). Whether paravalvular leaks after TAVI result in (clinically relevant) hemolysis (as described from surgical collectives (38)) needs further investigation.

Of interest is the finding that the presence of a non-circular shape of the stent frame, mild degrees of mal-alignment or mal-position of the transcatheter valve, or presence of a probe patent paravalvular defect had no significant or consistent association with severity of transvalvular or paravalvular aortic regurgitation during life. Thus, mild alterations in configuration or placement of transcatheter prosthetic aortic valves, as observed at autopsy, do not appear to adversely affect function.

\section{Prosthesis and Procedure Associated Findings}

Recent myocardial injury was a relatively frequent observation in our series of patients, especially in those dying in the Immediate-Early time period after implantation. Left coronary ostial obstruction was likely causative in two patients and was associated with low origins of the left coronary artery and bulky, calcified native cusps in both cases (Figure 7). Another known risk factor for coronary ostial obstruction is a narrow aortic root with shallow aortic sinuses (39). This complication has been described in $0.6 \%$ of cases in a recent large registry (27), suggesting that multimodality screening (40) may be important. Obstruction of coronary arteries can be predicted during balloon valvuloplasty with aortography during balloon inflation. If coronary obstruction occurs during implantation, early clinical signs include hypotension and severe hypokinesis on echocardiography (41). Management includes prompt cardiopulmonary support, coronary angiography, and, in most cases, urgent coronary revascularization $(39,42,43)$. 


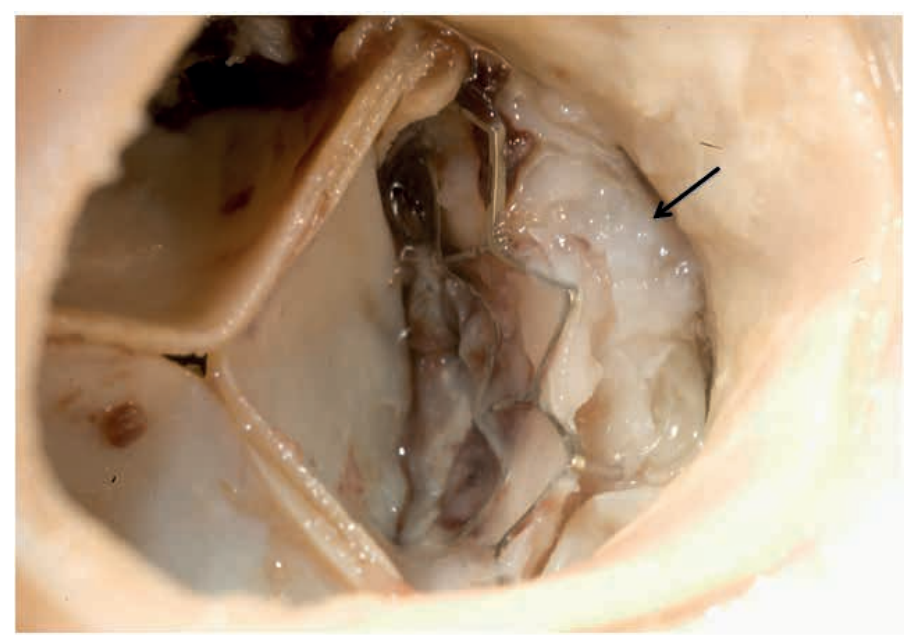

Figure 7. Photograph showing a bulky, calcified native valve cusp filling the sinus region of the aorta (arrow) to cause obstruction left coronary ostium.

New onset of heart block can occur following transcatheter valve implantation. The incidence of heart block is reportedly lower with the balloon-expandable Edwards valve, utilized in this series, as compared to the self-expanding CoreValve $(3,27,44)$. Based upon findings in select cases where the conduction system was examined, it appears that a combination of direct traumatic effects to the bundle branch system and ischemic injury occurring because of pressure-induced alterations of flow in coronary septal arteries in the interventricular septum are potential contributing factors.

\section{Other Cardiac and Vascular Findings}

One accompanying finding that warrants special mention is myocardial amyloidosis, which occurred in nearly one-third of all cases studied. Senile Systemic Amyloidosis is very common in the elderly, reportedly present in $25 \%$ of individuals over the age of 80 years, and often goes unrecognized (45). While patients with cardiac amyloidosis can successfully undergo surgical procedures, operative and postoperative problems associated with anesthesia are well described (46-48). As such, recognition of the possible presence of the condition and involvement of anesthetists familiar with cardiac anesthesia in this setting are important. Moreover, the transcatheter valve approach, as compared to open-heart valvular replacement with cardiopulmonary bypass, may be the technique of choice in this patient population. 


\section{Conclusions}

Significant structural degeneration of transcatheter valves does not occur up to 30 months after implantation and minor alterations in valve configuration or placement do not appear to be associated with substantial changes in function of the valves during life when assessed by echocardiography. Chest compressions during CPR may cause alterations in configuration of valves but only in a minority of cases. Myocardial injury is common early after the implantation procedure with coronary ostial obstruction by a thick, calcified native aortic valve cusp in the setting of a shallow coronary sinus, narrow aortic root, and/or low origin of the ostium likely a causative factor in some. Finally, myocardial amyloidosis is common in this patient population and warrants recognition because of its potential to have deleterious effects.

\section{References}

1. Leon MB, Smith CR, Mack M et al. Transcatheter aortic-valve implantation for aortic stenosis in patients who cannot undergo surgery. N Engl J Med 2010;363:1597-607.

2. Smith CR, Leon MB, Mack MJ et al. Transcatheter versus surgical aortic-valve replacement in highrisk patients. N Engl J Med 2011;364:2187-98.

3. Webb JG, Altwegg L, Boone RH et al. Transcatheter aortic valve implantation: impact on clinical and valve-related outcomes. Circulation 2009;119:3009-16.

4. Eltchaninoff $\mathrm{H}$, Prat A, Gilard $\mathrm{M}$ et al. Transcatheter aortic valve implantation: early results of the FRANCE (FRench Aortic National CoreValve and Edwards) registry. Eur Heart J 2011;32:191-7.

5. Thomas M, Schymik G, Walther T et al. One-year outcomes of cohort 1 in the Edwards SAPIEN Aortic Bioprosthesis European Outcome (SOURCE) registry: the European registry of transcatheter aortic valve implantation using the Edwards SAPIEN valve. Circulation 2011;124:425-33.

6. Ye J, Cheung A, Lichtenstein SV et al. Transapical transcatheter aortic valve implantation: follow-up to 3 years. J Thorac Cardiovasc Surg 2010;139:1107-13, 1113 e1.

7. Eltchaninoff H, Nusimovici-Avadis D, Babaliaros V, Spenser B, Felsen B, Cribier A. Five month study of percutaneous heart valves in the systemic circulation of sheep using a novel model of aortic insufficiency. EuroIntervention 2006;1:438-44.

8. Noble S, Asgar A, Cartier R, Virmani R, Bonan R. Anatomo-pathological analysis after CoreValve Revalving system implantation. EuroIntervention 2009;5:78-85.

9. Linke A, Hollriegel R, Walther T et al. Ingrowths of a percutaneously implanted aortic valve prosthesis (corevalve) in a patient with severe aortic stenosis. Circ Cardiovasc Interv. 2008;1:155-8.

10. Serruys PW, Webb J, Laborde J, Piazza N, P.D. J. Transcatheter Aortic Valve Implantation: Tips and Tricks to Avoid Failure.: Informa Healthcare 2009.

11. Cribier A, Eltchaninoff $\mathrm{H}$, Bash A et al. Percutaneous transcatheter implantation of an aortic valve prosthesis for calcific aortic stenosis: first human case description. Circulation 2002;106:3006-8.

12. Webb JG, Altwegg L, Masson JB, Al Bugami S, Al Ali A, Boone RA. A new transcatheter aortic valve and percutaneous valve delivery system. J Am Coll Card 2009;53:1855-8.

13. Webb JG, Chandavimol M, Thompson CR et al. Percutaneous aortic valve implantation retrograde from the femoral artery. Circulation 2006;113:842-50.

14. Lichtenstein SV, Cheung A, Ye J et al. Transapical transcatheter aortic valve implantation in humans: initial clinical experience. Circulation 2006;114:591-6.

15. Butany J, Allard M. The Canadian journal of cardiology 2004;20 Suppl E:74E-79E. 
16. Leon MB, Piazza N, Nikolsky E et al. Standardized endpoint definitions for Transcatheter Aortic Valve Implantation clinical trials: a consensus report from the Valve Academic Research Consortium. J Am Coll Card 2011;57:253-69.

17. Jamieson WR, Cartier PC, Allard M et al. Surgical management of valvular heart disease 2004. Can J Cardiol 2004;20 Suppl E:7E-120E.

18. Ionescu MI, Tandon AP, Chidambaram M, Yakirevich VS, Silverton NP. Durability of the pericardial valve. Eur Heart J 1984;5 Suppl D:101-6.

19. Puvimanasinghe JP, Takkenberg JJ, Eijkemans MJ et al. Comparison of Carpentier-Edwards pericardial and supraannular bioprostheses in aortic valve replacement. Eur J Cardiothorac Surg 2006;29:374-9.

20. Butany J, Collins MJ, Nair V et al. Morphological findings in explanted Toronto stentless porcine valves. Cardiovasc Pathol 2006;15:41-8.

21. Schoen FJ, Levy RJ. Pathology of substitute heart valves: new concepts and developments. J Card Surg 1994;9:222-7.

22. Webb JG, Wood DA, Ye J et al. Transcatheter valve-in-valve implantation for failed bioprosthetic heart valves. Circulation 2010;121:1848-57.

23. Gurvitch R, Wood DA, Tay EL et al. Transcatheter aortic valve implantation: durability of clinical and hemodynamic outcomes beyond 3 years in a large patient cohort. Circulation 2010;122:1319-27.

24. Roberts WC. The structure of the aortic valve in clinically isolated aortic stenosis: an autopsy study of 162 patients over 15 years of age. Circulation 1970;42:91-7.

25. Levy RJ, Schoen FJ, Levy JT, Nelson AC, Howard SL, Oshry LJ. Biologic determinants of dystrophic calcification and osteocalcin deposition in glutaraldehyde-preserved porcine aortic valve leaflets implanted subcutaneously in rats. The Am J Pathol 1983;113:143-55.

26. Schoen FJ. Surgical pathology of removed natural and prosthetic heart valves. Hum Pathol 1987;18:558-67.

27. Thomas M, Schymik G, Walther T et al. Thirty-day results of the SAPIEN aortic Bioprosthesis European Outcome (SOURCE) Registry: A European registry of transcatheter aortic valve implantation using the Edwards SAPIEN valve. Circulation 2010;122:62-9.

28. Stinson EB, Griepp RB, Oyer PE, Shumway NE. Long-term experience with porcine aortic valve xenografts. J Thorac Cardiovasc Surg 1977;73:54-63.

29. Kulik A, Bedard P, Lam BK et al. Mechanical versus bioprosthetic valve replacement in middle-aged patients. Eur J Cardiothorac Surg 2006;30:485-91.

30. Wong DR, Boone RH, Thompson CR et al. Mitral valve injury late after transcatheter aortic valve implantation. J Thorac Cardiovasc Surg. 2009;137:1547-9.

31. Piazza N, Marra S, Webb J et al. Two cases of aneurysm of the anterior mitral valve leaflet associated with transcatheter aortic valve endocarditis: a mere coincidence? J Thorac Cardiovasc Surg 2010;140:e36-8.

32. Yan TD, Cao C, Martens-Nielsen J et al. Transcatheter aortic valve implantation for high-risk patients with severe aortic stenosis: A systematic review. J Thorac Cardiovasc Surg 2010;139:1519-28.

33. Azadani AN, Jaussaud N, Matthews PB et al. Energy loss due to paravalvular leak with transcatheter aortic valve implantation. Ann Thorac Surg. 2009;88:1857-63.

34. Gotzmann M, Lindstaedt M, Bojara W, Mugge A, Germing A. Hemodynamic results and changes in myocardial function after transcatheter aortic valve implantation. Am Heart J. 2010;159:926-32.

35. Giannini C, Petronio AS, Nardi C et al. Left ventricular reverse remodeling in percutaneous and surgical aortic bioprostheses: an echocardiographic study. J Am Soc Echocardiogr. 2011;24:28-36.

36. Sherif MA, Abdel-Wahab M, Awad 0 et al. Early hemodynamic and neurohormonal response after transcatheter aortic valve implantation. Am Heart J 2010;160:862-9.

37. Clavel MA, Webb JG, Rodes-Cabau J et al. Comparison between transcatheter and surgical prosthetic valve implantation in patients with severe aortic stenosis and reduced left ventricular ejection fraction. Circulation 2010;122:1928-36.

38. Shapira Y, Vaturi M, Sagie A. Hemolysis associated with prosthetic heart valves: a review. Cardiol Rev 2009; 17:121-4. 
39. Webb JG. Coronary obstruction due to transcatheter valve implantation. Catheter Cardiovasc Interv. 2009;73:973.

40. Leipsic J, Wood D, Manders D et al. The evolving role of MDCT in transcatheter aortic valve replacement: a radiologists' perspective. AJR Am J Roentgenol. 2009;193:W214-9.

41. Moss RR, Ivens E, Pasupati $S$ et al. Role of echocardiography in percutaneous aortic valve implantation. JACC Cardiovasc Imaging 2008;1:15-24.

42. Gogas BD, Zacharoulis AA, Antoniadis AG. Acute coronary occlusion following TAVI. Catheter Cardiovasc Interv. 2011;77:435-8.

43. Stabile E, Sorropago G, Cioppa A et al. Acute left main obstructions following TAVI. EuroIntervention 2010;6:100-5.

44. Piazza N, Grube E, Gerckens U et al. Procedural and 30-day outcomes following transcatheter aortic valve implantation using the third generation (18 Fr) corevalve revalving system: results from the multicentre, expanded evaluation registry 1-year following CE mark approval. EuroIntervention 2008;4:242-9.

45. Shah KB, Inoue Y, Mehra MR. Amyloidosis and the heart: a comprehensive review. Arch Intern Med. 2006;166:1805-13.

46. Zacek P, Medilek K, Lonsky V, Laco J, Nova M, Dominik J. Cardiac amyloidosis in the cardiosurgical operating room--a rare but fatal trap. Thorac Cardiovasc Surg. 2007;55:65-7.

47. Kotani N, Hashimoto H, Muraoka M, Kabara S, Okawa H, Matsuki A. Fatal perioperative myocardial infarction in four patients with cardiac amyloidosis. Anesthesiology 2000;92:873-5.

48. Wang MM, Pollard JB. Postoperative ventricular fibrillation and undiagnosed primary amyloidosis. Anesthesiology 2000;92:871-2. 

Part 3

Discussion 



\subsection{Current issues: wrap-up}

My research tried to focus on some current issues in structural interventional cardiology. In TAVR, moving towards lower risk patients will most likely become a reality soon. Respective randomized trials comparing TAVR versus SAVR in intermediate risk patients are currently underway (Surtavi, PARTNER 2). Irrespective of the results from these trials, we aim to reduce morbidity during/after TAVR. Left atrial appendage occlusion is an interventional approach to reduce stroke risk in patients suffering from atrial fibrillation, while at the same time reducing their bleeding risk. Long-term data are available for the Watchman device, but were missing for the Amplatzer occluder device. We filled this gap, showing good stroke prevention along with a very low bleeding rate.

Combining TAVR with LAAO might be an attractive treatment concept: for reasons not fully understood, patients in atrial fibrillation undergoing TAVR have significantly worse outcome as opposed to patients in sinus rhythm.

As encountered in trials and in our autopsy study, potential complications during or after TAVR are still numerous:

Table 1: 30-day incidence of complications in large clinical studies: PARTNER A ${ }^{1}$; FRANCE $2^{2}$; SOURCE registry ${ }^{3}$ and U.K. TAVI registry ${ }^{4}$.

\begin{tabular}{lllll}
\hline & PARTNER A & FRANCE 2 & SOURCE & UK TAVI \\
\hline Death & $3.4 \%$ & $9.7 \%$ & $8.5 \%$ & $7.1 \%$ \\
Stroke & $3.8 \%$ & $4.1 \%$ & $2.5 \%$ & $4.1 \%$ \\
Vascular Complications & $17 \%$ & $9.7 \%$ & $12.8 \%$ & $6.3 \%$ \\
Kidney injury & $4.1 \%$ & $\mathrm{~N} / \mathrm{A}$ & $4.3 \%$ & $\mathrm{~N} / \mathrm{A}$ \\
Major Bleeding & $9.3 \%$ & $4,5 \%$ & $\mathrm{~N} / \mathrm{A}$ & $\mathrm{N} / \mathrm{A}$ \\
Pacemaker & $3.8 \%$ & $15,6 \%$ & $7 \%$ & $16.3 \%$ \\
\hline
\end{tabular}

The most devastating complications are death and stroke. Survival after TAVR is not different in high-risk patients, as compared to surgical collectives. In the 'astreated' analysis of the PARTNER A ${ }^{1}$ trial, survival was even statistically better after transfemoral TAVR as compared to surgery (mortality 3.7 vs $8.2 \%, \mathrm{p}=0.05$ ). This raises the question whether access route has an influence on survival, e.g. do similar patients worse is treated with a transapical approach as compared to a transfemoral approach. This question is hard to answer, if 'transfemoral' is the default approach and transapical is only chosen in case of concomitant peripheral arterial disease (selection bias). A hint to this answer comes from the SOURCE registry 3: 1-year outcome of 1038 patients (transapical: 575 patients; transfemoral 463 patients) were reported according to the EuroSCORE. In low- (EuroSCORE $<20$ ), intermediate (EuroSCORE 20-40) and high-risk (EuroSCORE $>40$ ) patients, 1year survival was $78 \%, 73 \%$ and $59 \%$ in the transapical group, as compared to 
$81 \%, 83 \%$ and $72 \%$ in the transfemoral group. This analysis suggests that outcome in low-risk patients is comparable between the two access routes, whereas there is an advantage of a transfemoral access in intermediate and high-risk patients. This might be due the higher vulnerability of sicker patients to more invasive procedures. With the development of smaller bore devices (e.g. the new Commander delivery system of the $\mathrm{S} 3$ valve is compatible with a 14 French sheath), the percentage of patients that are treated by the transfemoral route is steadily increasing.

Besides, with these new devices, it can be anticipated that vascular complications can be even further reduced: as shown by Toggweiler 5 , introduction of smaller bore devices lead to a decrease in major vascular complications from $8 \%$ to $1 \%$ and in major bleedings $14 \%$ to $1 \%$ ( $p>0.01)$.

Should a patient with renal insufficiency rather undergo surgical valve replacement or contrast-agent dependent TAVR? We investigated this important question ${ }^{6}$ by matching 119 patients with chronic kindey disease undergoing TAVR with 104 matched patients undergoing surgical valve replacement. The incidence of acute kidney injury was significantly lower after TAVR as compared to surgical valve replacement $(9.2 \%$ vs $25.9 \%, \mathrm{p}<0.05)$. Therefore, severe kidney failure - although a marker of poorer longterm survival - can be a good argument to refer a patient to TAVR.

We learned that there are differences in terms of outcome and complications between TAVR and surgery, and that access route might play an additional role in this regard. But, are there differences between the two most commonly used valves on the market - the self-expandable CoreValve and the balloon-expandable Edwards valve? According to a recent study, comparing outcomes between CoreValve and Edwards valves ${ }^{7}$, there were no differences in hard endpoints: all-cause and cardiovascular mortality after 1 year was comparable (CoreValve $16.2 \%$ and $8.3 \%$; Edwards $12.3 \%$ and $7.4 \%$ ). The only significant difference was need for permanent pacemaker (CoreValve 22.5\%; Edwards 5.9\%). From the PARTNER A ${ }^{1}$ trial we know, that need for pacemaker is comparable after transcatheter Edwards valve implantation compared to surgical valve replacement (3.8\% vs $3.6 \%$ ). The vicinity of the intraventricular septum, the left ventricular outflow tract (LVOT) and the non-coronary cusp explain the mechanisms of new bundle branch blocks or atrioventricular blocks. In an elaborate study, Nuis et al ${ }^{8}$ analyzed continuous ECG's during implantation of the CoreValve prosthesis. They found that conduction abnormalities occurred mostly during balloon valvuloplasty, followed by 'complete CoreValve expansion', again followed by 'positioning of the CoreValve in the LVOT. Third degree atrio-ventricular blocks occurred in $15 \%$ of the patients, whereof twothirds occurred during the procedure and one-third after the valve implantation.

While conduction changes occur at different time-points when using a balloonexpandable versus a self-expandable valve, the mechanisms are most likely the same. In our post-mortem study, we found that direct injury (e.g. by direct injury on the conduction system by calcified deplaced aortic valve leaflets) as well as indirect 
injury (compression of small arteries that supply the conduction system) play a role in the pathophysiology (see below). While 'you see what you get' after implantation of a self-expanding valve (conduction disturbances can only recover when the edema is reduced over time), conduction disturbances can occur late ( $>48 \mathrm{~h}$ ) after implantation of a self-expanding valve (which keeps expanding over time). Besides the higher need for pacemaker, the fact that severe rhythm disturbances occur late after CoreValve implantation poses a problem when moving towards lower risk patients with early discharge. Currently it is our practice to monitor all patients for 72hours after CoreValve implantation.

Higher degree blocks ask for pacemaker implantation. This reliably solves the conduction block issue, but may lead to right-ventricular pacing, which is not well tolerated in some heart failure patients. Depending on the ejection-fraction, even biventricular pacing may therefore be indicated.

In the following sub-chapters, I will delve into more detailed discussion regarding issues that were specifically addressed in the previous chapters:

\subsubsection{Neurologic events}

While major strokes or the combined endpoint of death or major stroke was not different between the TAVR and the SAVR group in the PARTNER Trial ${ }^{1}$, more neurologic events occurred (TIA, minor and major strokes) in the TAVR group after one year. During longer follow-up, these differences leveled out and were no longer statistically significant ${ }^{9}$.

Several arguments exist, why the two groups (SAVR and TAVR) are not comparable with regard to neurologic events: patients were intubated for a longer period of time after SAVR. During this time period transient ischemic events or even minor strokes would go unrecognized. Furthermore, 30-day follow-up was held 30 days after randomization. Days to implant was only 10.8 days in the TAVR group, as compared to 15.6 days in the SAVR group - resulting in an about $25 \%$ shorter postprocedural 30-day follow-up in the SAVR group. Another confounder is the fact that $10 \%$ of patients randomized to SAVR did not undergo surgical valve replacement (as opposed to $1 \%$ in patients randomized to TAVR). Most frequent reasons were withdrawal of consent and refusal of SAVR in $8 \%$.

When looking at the more relevant 'as-treated analysis', numerically more major strokes occurred in the TAVR group (3.8\% vs $2.3 \%, \mathrm{p}=$ not significant). Therefore, efforts to reduce the stroke rate during/after TAVR are beneficial and welcomed. The use of cerebral protection devices is one approach to do so.

In Chapter 2.1 we show that the use of the Embrella cerebral protection device $^{10}$ is technically feasible: introduced through the right radial or brachial artery, an 'umbrella-like' device is introduced to the aortic arch, where a semipermeable mesh prevents embolization to the neck arteries, while ensuring proper blood flow to the protected areas. Although technically feasible, results from subse- 
quent studies are not very promising. In a contemporary review ${ }^{11}$ on all currently available protection devices and the respective study results, we conclude that the use of protection devices can currently not be recommended: while making the TAVR procedure more complicated, cerebral protection devices can at best reduce 30 -day stroke rate by $50 \%$, since the other half of the strokes occur from postprocedural day 2 onwards. At the same time, introduction of protection devices by itself can potentially cause harm: latest data confirm a higher rate of silent cerebral lesion when the Embrella device is used, as compared to historical data without the use of Embrella. Mechanisms may be embolization of atherosclerotic plaques from the innominate artery or the aortic arch, thrombus formation or air embolism. Developing smaller, less traumatic delivery catheters and increased operator experience will most likely more effectively reduce the occurrence of neurologic events and might even resolve 'the stroke issue'. In my opinion, cerebral protection devices will at best be used as niche products in TAVR, e.g. for selected very high-risk TAVR patients. We should, however, await results from large, randomized trials that are currently underway, before we conclusively close the books on cerebral protection devices.

Stroke prevention is an important issue in patients suffering from atrial fibrillation (AF), whether or not they undergo concommittant TAVR. The $\mathrm{CHA}_{2} \mathrm{DS}_{2}$-Vasc Score is a scoring system that allows extrapolating an individual annual stroke risk. At the same time, the risk of bleeding in a mostly elderly patient population is substantial. Left atrial appendage occlusion (LAAO) is an attractive treatment option for stroke prevention for these patients ${ }^{12} 13$. The concept of LAAO is based on pathology data from AF patients, showing that $>90 \%$ of all thrombi form in the left atrial appendage. Once the left atrial appendage is occluded, the most important source of thrombus formation is excluded from the circulation; therefore oral anticoagulation can be terminated. In Chapter 2.2 we give a review of the history of LAAO, available devices, indications and technical aspects. We further report the largest and longest (10 year) single center experience with Amplatzer devices for LAAO. In our series, stroke protection was comparable to previous reports when using oral anticoagulation, but at a much lower major bleeding rate. Since the procedure is demanding and comes along with a flat learning curve, the risk of procedural complications is, however, considerable. Most of those complications are temporary and do not result in any long-term sequelae (e.g. tamponade, air embolism). All our procedures were performed in local anaesthesia and with fluoroscopic guidance only. This allows for a patient-friendly and efficient approach - it further allows performing ad-hoc LAAO (Nietlispach et al, J Interv. Cardiology, in press). After successful LAAO the patient's benefit will increase the longer the follow-up. Even with newer, safer and more effective oral anticoagulants (rivaroxaban, apixaban and dabigatran), there is a higher annual rate of major bleeding complications (ranging from 2-3.6\%/year), as compared to patients that underwent left atrial appendage occlusion (0.7\%/year). Our data with the Amplatzer devices are sup- 
ported by recently presented long-term data from a randomized trial (PROTECT$\mathrm{AF}$ ), resulting not only in significantly less strokes, but also better overall survival when LAAO is performed (presented by Holmes at EuroPCR 2013).

Given current evidence, LAAO should not only be offered to patients with previous bleeding or at high risk for bleeding, but every patient suffering AF should be offered the procedure as an alternative to life-long oral anticoagulation. As treating physicians we have to balance the risks of the two treatment strategies against each other: oral anticoagulation with a lifelong higher bleeding risk versus left atrial appendage closure that comes along with a certain procedural risk.

While the $\mathrm{CHA}_{2} \mathrm{DS}_{2}$-Vasc score is on high in the TAVR population, the same population is typically prone to experience major bleeding complications. Combining LAAO and TAVR is an interesting approach in the TAVR-population and might help to improve TAVR outcomes in these patients (see below).

\subsubsection{Pathology findings and ischemia during TAVR}

In our postmortem study ${ }^{14}$ no valve degeneration was found in patients analyzed at least 20 months after the TAVR procedure (Chapter 2.4). Some fibrous tissue ingrowth on the stent reflects endothelialization but did not interfere with leaflet function. In one out of 20 valves, fibrous tissue ingrowth was extensive expanding to the basal part of the cusps with slight reduction in valve mobility, but not stenosis. The lack of valve degeneration is reassuring, but longer follow-up data will have to confirm this finding. Valve degeneration is of particular importance when treating lower risk populations with TAVR. Assuming durability of transcatheter valves of 10-15 years, a valve-in-valve procedure can be performed repeatedly if needed a concept that would allow treating younger low risk patients with TAVR in the future. Interestingly, a less than round configuration was a common finding, leading in some patients to mal-alignment of valve cusps, but resulting in malfunction of the valve. It can be speculated that other than round configuartion can potentially lead to earlier valve degeneration and may also be a cause of paravalvular leakage. Cardiopulmonary resuscitation (CPR) was performed in half of the patients with stent deformation - indicating that CPR can be safely performed in those patients.

Another finding of our postmortem study was the high prevalence of amyloidosis in the TAVR population. Co-existing amyloidosis could be one factor that is associated with poor functional recovery despite valve replacement - but further research is needed.

Damage to the conduction system is a more frequently encountered complication when using self-expanding valves. We found in patients strictly treated with a balloon-expandable valve, the mechanisms of new conduction disturbances to be either direct mechanical damage (by the valve and the displaced calcified native leaflets), or ischemia of the conduction cells (by mechanical obstruction of the respective arteries by the valve stent). Postinterventional rhythm monitoring allows for timely measures, such that heart block should not cause any long-term sequelae. 
Myocardial damage during TAVI can be due to coronary obstruction by displaced native valve leaflets - a complication with a high mortality rate, as we also encountered in our postmortem study. If a patient is at danger for this complication (low coronary-annular distance, shallow sinuses), the patient can either undergo SAVR, or preventive measures can be initiated prior to valve implantation (e.g. wiring the coronary artery and positioning of a angioplasty-balloon that once inflated would immediately restore coronary blood flow).

Direct injury from the delivery system or the guidewire is another mechanism causing myocardial damage. This complication occurs clinically silent in most cases. We found direct injury in our post-mortem study, mainly at the septum during transapical procedures.

Prolonged periods of hypotension usually occur during TAVR, either due to rapid pacing (for placement of self-expanding valves), relevant aortic regurgitation after balloon-valvuloplasty, vagal reactions or outflow obstruction during positioning of the prosthetic valve. These prolonged phases of hypotension could potentially cause relevant ischemia in case of concommittant coronary artery disease, thereby triggering a potentially lethal downward spiral. To avoid such complications during TAVR, revascularization of critical stenoses is non-controversial. However, it is a matter of debate whether complete revascularization of non-critical lesions prior to TAVR is beneficial. Data from surgical studies on aortic valve replacement and concomitant bypass surgery report controversial results: some showing better outcome when complete revascularisation is performed at the time of aortic valve replacement, whereas other studies cannot confirm this finding 15 .

We know that concomitant coronary artery disease is a marker of worse overall long-term outcome in TAVR patients. While in elderly patients one could argue that moderate coronary artery disease may be left alone in case the patient remains asymptomatic, a younger patient might benefit from complete revascularization. At this stage we are awaiting better data on whether complete coronary revascularization before TAVR is beneficial or not.

\subsubsection{The transapical procedure}

We learned from the European SOURCE registry ${ }^{3}$ that transapical (and transaortic) TAVR procedures might have worse outcome as compared to transfemoral TAVR, even after adjusting for patients' risk. The reasons are not fully understood. Given the more direct access to the aortic valve, it can be speculated that rather accessrelated (e.g. more invasiveness) reasons make the difference (as opposed to procedure related differences). A truly percutaneous transapical access and percutaneous access-closure have the theoretical potential to improve outcome of transapical procedures. At this stage, however, no truly percutaneous apical closure system is available for TAVR procedures. Devices for apical closure have been investigated, but currently still ask for a surgical cut-down to the apex. 
A truly percutaneous procedure through the apex with smaller bore devices is feasible as shown on a young but multi-morbid patient who underwent paravalvular leak closure ${ }^{16}$ (Chapter 2.3). This particular patient is doing very well three years after the procedure without any side effects from the apical closure device. The current transapical delivery sheaths are, however, more than 3-fold larger than the sheath used in the above mentioned patient. When thinking of using a similar, 'Amplatzer-like device' for access site closure with the large bore TAVR delivery sheaths, new problems arise: how do you prevent invagination of the left ventricular wall when placing the sheath through the skin? Is predilatation of the puncture site necessary - and if yes, how can it be serially done without substantial blood loss while exchanging the dilators? Given the larger hole in the left ventricle, one can anticipate that there might be considerable leakage through the closure device. All the questions we currently try to address in ongoing animal experiments with a modified purpose-specific device.

Besides Amplatzer-like devices, we tested the performance of a selfexpanding, cellulose-based plug ${ }^{17}$ (Chapter 2.3). In 6 animal experiments we were able to reliably close a $33 \mathrm{~F}$ hole in the apex, without residual peri-device leakage.

It is still a long way from promising initial results in animal studies to clinical use in humans, but if the concept proves to work, transapical TAVR in local anaesthesia may become a reality in the future. This is not only of interest for transapical TAVR, but the transapical access is probably the most suitable access for percutaneous mitral interventions.

\subsection{A glimpse into the future}

\subsubsection{Combined interventions}

Atrial fibrillation is a common co-morbidity in the TAVR population, affecting about one third of patients and new-onset atrial fibrillation in the postprocedural period affects another $15 \%$ of patients. Presence of atrial fibrillation negatively affects long-term prognosis and is a predictor for stroke after TAVR, particularly if no anticoagulation regimen is initiated 18,19 . The risk of major bleeding after insertion of large bore devices may explain the hesitation to initiate patients on an oral anticoagulant. Furthermore, HAS-BLED scores and $\mathrm{CHA}_{2} \mathrm{DS}_{2}$-Vasc scores are often high in this patient population, indicating a high-risk for bleeding.

Significant coronary artery disease increases procedural risk during TAVR. Addressing all patients' issues at the same sitting is feasible: TAVR combined with percutaneous coronary intervention (to treat coronary artery disease) and with left atrial appendage occlusion (to simultaneously reduce the risk of stroke and the bleeding risk) resolves the aortic stenosis, treats coronary artery disease and al- 
lows to avoid oral anticoagulation despite the presence of atrial fibrillation. It offers a patient- and resource friendly solution (see figure below). Despite the theoretically higher overall procedural risk when combining these procedures, we could show safety of such an approach, with similar in-hospital and short-term (30-day) outcome as compared to 'TAVR alone' in a preliminary analysis of 10 combined interventions (Nietlispach, presented at TVT 2013, Vancouver). With longer follow-up, patients undergoing combined interventions will profit more and more from a more complete treatment approach. Prospective data comparing a combined approach with a staged approach will be needed in the future.

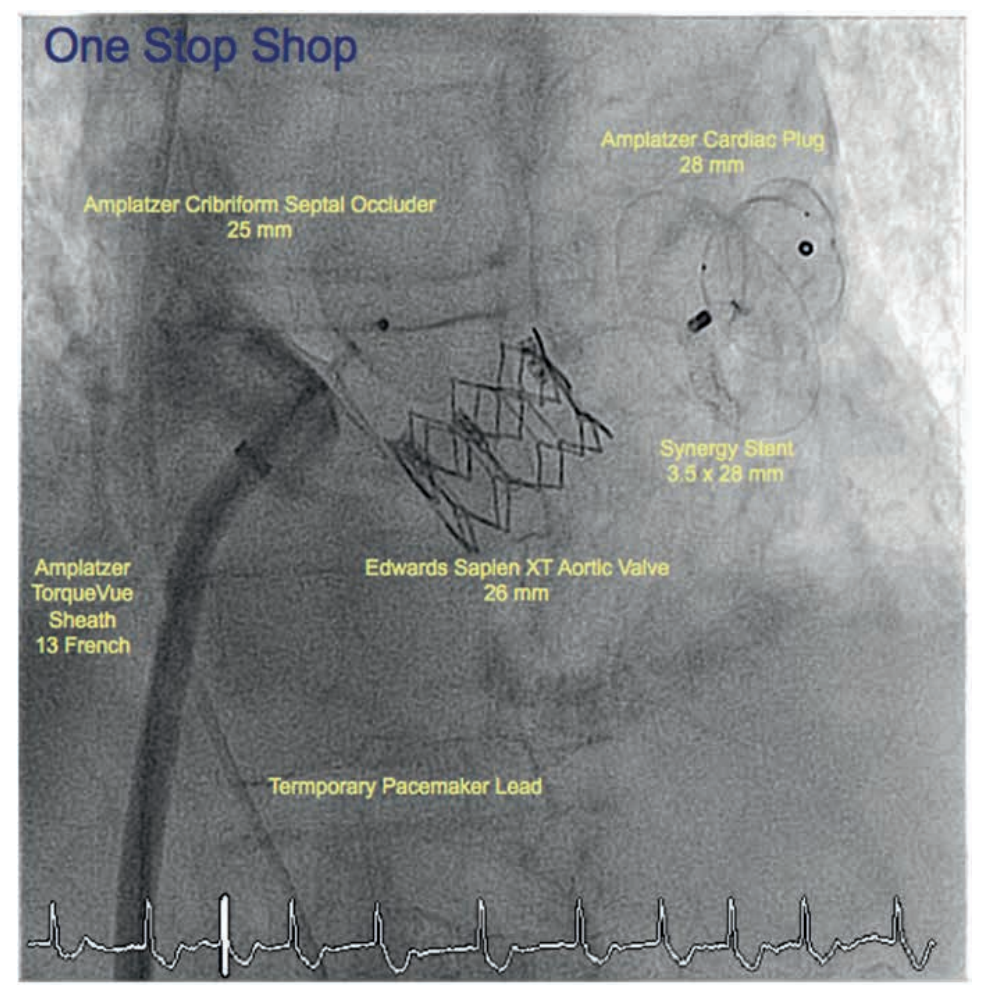

One-stop shopping: simultaneous PCI, TAVR, LAAO and PFO-closure during a single sitting

\subsubsection{Ad-hoc TAVR: the future starts now}

Pre-requisites for ad-hoc TAVR are (1) reliable fluoroscopic imaging (e.g. annular sizing, assessing peripheral arterial diameter) without the need of adjunctive imaging, (2) reliable percutaneous peripheral arterial closure, (3) fluoroscopic guidance of the procedure, (4) no need for anaesthesia.

With smaller delivery systems, the ability to perform TAVR in local anaesthesia without transesophageal echocardiographic guidance ${ }^{20}$, reliable fully percutaneous 
arterial closure (with suture based closure devices) and with the possibility to perform reliable balloon sizing of the aortic annulus ${ }^{21}$, ad-hoc TAVR has become a reality. New fully recapture- and repositionable valves that will become available shortly will further facilitate such an approach. Respective live-cases were recorded and presented by our group in June 2013 (C3 meeting Orlando, Florida, Operators F. Nietlispach and B. Meier; http://speakerready.com/C3_2013/coronary/june-202013). Avoiding anaesthesia during the procedure and avoiding costly and timeconsuming investigations during the 'work-up period', offers a frugal, patient- and resource-friendly treatment.

\section{References}

1. Smith CR, Leon MB, Mack MJ, Miller DC, Moses JW, Svensson LG, Tuzcu EM, Webb JG, Fontana GP, Makkar RR, Williams M, Dewey T, Kapadia S, Babaliaros V, Thourani VH, Corso P, Pichard AD, Bavaria JE, Herrmann HC, Akin JJ, Anderson WN, Wang D, Pocock SJ. Transcatheter versus surgical aorticvalve replacement in high-risk patients. N Engl J Med. 2011;364:2187-2198.

2. Gilard $M$, Eltchaninoff $H$, Iung $B$, Donzeau-Gouge $P$, Chevreul $K$, Fajadet J, Leprince $P$, Leguerrier $A$, Lievre M, Prat A, Teiger E, Lefevre T, Himbert D, Tchetche D, Carrie D, Albat B, Cribier A, Rioufol G, Sudre A, Blanchard D, Collet F, Dos Santos P, Meneveau N, Tirouvanziam A, Caussin C, Guyon P, Boschat J, Le Breton H, Collart F, Houel R, Delpine S, Souteyrand G, Favereau X, Ohlmann P, Doisy V, Grollier G, Gommeaux A, Claudel JP, Bourlon F, Bertrand B, Van Belle E, Laskar M. Registry of transcatheter aortic-valve implantation in high-risk patients. $N$ Engl J Med. 2012;366:1705-1715.

3. Thomas M, Schymik G, Walther T, Himbert D, Lefevre T, Treede H, Eggebrecht H, Rubino P, Colombo A, Lange R, Schwarz RR, Wendler O. One-year outcomes of cohort 1 in the Edwards SAPIEN Aortic Bioprosthesis European Outcome (SOURCE) registry: the European registry of transcatheter aortic valve implantation using the Edwards SAPIEN valve. Circulation. 2011;124:425-433.

4. Moat NE, Ludman P, de Belder MA, Bridgewater B, Cunningham AD, Young CP, Thomas M, Kovac J, Spyt T, MacCarthy PA, Wendler O, Hildick-Smith D, Davies SW, Trivedi U, Blackman DJ, Levy RD, Brecker SJ, Baumbach A, Daniel T, Gray H, Mullen MJ. Long-term outcomes after transcatheter aortic valve implantation in high-risk patients with severe aortic stenosis: the U.K. TAVI (United Kingdom Transcatheter Aortic Valve Implantation) Registry. J Am Coll Cardiol. 2011;58:2130-2138.

5. Toggweiler S, Gurvitch R, Leipsic J, Wood DA, Willson AB, Binder RK, Cheung A, Ye J, Webb JG. Percutaneous aortic valve replacement: vascular outcomes with a fully percutaneous procedure. J Am Coll Cardiol. 2012;59:113-118.

6. Bagur R, Webb JG, Nietlispach F, Dumont E, De Larochelliere R, Doyle D, Masson JB, Gutierrez MJ, Clavel MA, Bertrand OF, Pibarot P, Rodes-Cabau J. Acute kidney injury following transcatheter aortic valve implantation: predictive factors, prognostic value, and comparison with surgical aortic valve replacement. Eur Heart J. 2010;31:865-874.

7. Chieffo A, Buchanan GL, Van Mieghem NM, Tchetche D, Dumonteil N, Latib A, van der Boon RM, Vahdat O, Marcheix B, Farah B, Serruys PW, Fajadet J, Carrie D, de Jaegere PP, Colombo A. Transcatheter Aortic Valve Implantation With the Edwards SAPIEN Versus the Medtronic CoreValve Revalving System Devices: A Multicenter Collaborative Study: The PRAGMATIC Plus Initiative (Pooled-RotterdAm-Milano-Toulouse In Collaboration). J Am Coll Cardiol. 2013;61:830-836.

8. Nuis RJ, Van Mieghem NM, Schultz CJ, Tzikas A, Van der Boon RM, Maugenest AM, Cheng J, Piazza N, van Domburg RT, Serruys PW, de Jaegere PP. Timing and potential mechanisms of new conduction abnormalities during the implantation of the Medtronic CoreValve System in patients with aortic stenosis. Eur Heart J. 2011;32:2067-2074. 
9. Kodali SK, Williams MR, Smith CR, Svensson LG, Webb JG, Makkar RR, Fontana GP, Dewey TM, Thourani VH, Pichard AD, Fischbein M, Szeto WY, Lim S, Greason KL, Teirstein PS, Malaisrie SC, Douglas PS, Hahn RT, Whisenant B, Zajarias A, Wang D, Akin JJ, Anderson WN, Leon MB. Two-Year Outcomes after Transcatheter or Surgical Aortic-Valve Replacement. N Engl J Med. 2012

10. Nietlispach F, Wijesinghe N, Gurvitch R, Tay E, Carpenter JP, Burns C, Wood DA, Webb JG. An embolic deflection device for aortic valve interventions. JACC Cardiovasc Interv. 2010;3:1133-1138.

11. Praz F, Nietlispach F. Cerebral protection devices for transcatheter aortic valve implantation: is better the enemy of good? EuroIntervention. 2013;9 Suppl:S124-8.

12. Nietlispach F, Gloekler S, Krause R, Shakir S, Schmid M, Khattab AA, Wenaweser P, Windecker S, Meier B. Amplatzer left atrial appendage occlusion: Single center 10-year experience. Catheter Cardiovasc Interv. 2013

13. Reddy VY, Holmes D, Doshi SK, Neuzil P, Kar S. Safety of percutaneous left atrial appendage closure: results from the Watchman Left Atrial Appendage System for Embolic Protection in Patients with AF (PROTECT AF) clinical trial and the Continued Access Registry. Circulation. 2011;123:417-424.

14. Nietlispach F, Webb JG, Ye J, Cheung A, Lichtenstein SV, Carere RG, Gurvitch R, Thompson CR, Ostry AJ, Matzke L, Allard MF. Pathology of transcatheter valve therapy. JACC Cardiovasc Interv. 2012;5:582-590.

15. Dell'Amore A, Aquino TM, Pagliaro M, Lamarra M, Zussa C. Aortic valve replacement with and without combined coronary bypass grafts in very elderly patients: early and long-term results. Eur J Cardiothorac Surg. 2012;41:491-498.

16. Nietlispach F, Eckstein F, Seeberger M, Osswald S, Kaufmann BA, Reuthebuch O. Closure of apical access site after transapical, transcatheter paravalvular leak closure. Can J Cardiol. 2012;28:516.e5516.e7.

17. Brinks H, Nietlispach F, Gober V, Englberger L, Wenaweser P, Meier B, Carrel T, Huber C. Transapical access closure: the TA PLUG device. Interact Cardiovasc Thorac Surg. 2013;17:806-810.

18. Nombela-Franco L, Webb JG, de Jaegere PP, Toggweiler S, Nuis RJ, Dager AE, Amat-Santos IJ, Cheung A, Ye J, Binder RK, van der Boon RM, Van Mieghem N, Benitez LM, Perez S, Lopez J, San Roman JA, Doyle D, Delarochelliere R, Urena M, Leipsic J, Dumont E, Rodes-Cabau J. Timing, predictive factors, and prognostic value of cerebrovascular events in a large cohort of patients undergoing transcatheter aortic valve implantation. Circulation. 2012;126:3041-3053.

19. Stortecky S, Buellesfeld L, Wenaweser P, Heg D, Pilgrim T, Khattab AA, Gloekler S, Huber C, Nietlispach F, Meier B, Juni P, Windecker S. Atrial fibrillation and aortic stenosis: impact on clinical outcomes among patients undergoing transcatheter aortic valve implantation. Circ Cardiovasc Interv. 2013;6:77-84.

20. Durand E, Borz B, Godin M, Tron C, Litzler PY, Bessou JP, Bejar K, Fraccaro C, Sanchez-Giron C, Dacher JN, Bauer F, Cribier A, Eltchaninoff H. Transfemoral aortic valve replacement with the Edwards SAPIEN and Edwards SAPIEN XT prosthesis using exclusively local anesthesia and fluoroscopic guidance: feasibility and 30-day outcomes. JACC Cardiovasc Interv. 2012;5:461-467.

21. Babaliaros VC, Junagadhwalla Z, Lerakis S, Thourani V, Liff D, Chen E, Vassiliades T, Chappell C, Gross N, Patel A, Howell S, Green JT, Veledar E, Guyton R, Block PC. Use of balloon aortic valvuloplasty to size the aortic annulus before implantation of a balloon-expandable transcatheter heart valve. JACC Cardiovasc Interv. 2010;3:114-118. 
Part 4

Summary 



\section{Chapter 1}

Transcatheter aortic valve replacement (TAVR) is a rather young technique. In the first chapter, a historical overview, an overview of different access routes and the clinical role of TAVR are given.

It all started with a prototype transcatheter valve being successfully implanted in a pig. It was a balloon-expandable stent with a valve sutured in. Ten years later, Cribier performed the first successful transcatheter valve implantation in a human. Techniques, valves and delivery systems evolved considerably ever since the firstin-human case, making TAVR a procedure with good and reproducible outcomes. Initial TAVR patients were deemed inoperable, while later TAVR was performed in high-risk patients. Both populations were investigated in the first large randomized PARTNER trials: while TAVR significantly improved survival and also reduced symptoms as compared to medical therapy, TAVR proofed to be non-inferior as compared to surgical valve replacement (SAVR).

While transfemoral was the initial access route, peripheral arterial disease precludes transfemoral TAVR in some patients, in which case a transapical, transaortic or subclavian access can be chosen.

At the end of the chapter, current challenges are discussed which will be touched upon in the following chapters:

- In the PARTNER trial, a trend towards a higher rate of neurologic complications in the TAVR arm as compared to patients treated with SAVR was seen (Chapter 2.1).

- Of particular concern is the large subgroup of TAVR-patients suffering from atrial fibrillation: worse overall outcome and a higher stroke rate were seen in these patients as compared to patients in sinus rhythm. This is of particular concern, since about $30-40 \%$ of TAVR patients suffer from atrial fibrillation. Left atrial appendage occlusion has the potential to improve the outcomes in this subgroup of patients. (Chapter 2.2).

- Transapical TAVR seems to come along with worse overall outcomes as compared to patients treated with transfemoral access. Decreasing the invasiveness of the procedure by means of a true percutaneous approach with percutaneous apical closure may improve outcomes in patients who undergo transapical TAVR (Chapter 2.3).

- Procedural complications (e.g. left main obstruction) and long-term performance of the valve need to be better understood. Autopsy data and pathology analyses from explanted valves provide valuable information (Chapter 2.4).

\section{Chapter 2.1}

In this chapter the stroke issue is discussed: 
Several embolic protection devices were designed aiming at deflecting or capturing embolic debris during TAVR, by protecting the neck vessels. Several issues arise when temporarily implanting such devices during TAVR: (1) the device should enable sufficient blood flow to the neck vessels, (2) introduction of the device is supposed to be easy and fast in order not to considerably prolong the overall procedure time, (3) introduction of the device should not cause any harm, e.g. arterial dissection or cerebral embolization.

In the first section the first-in-human experience with the first available embolic protection device (Embrella Embolic Deflector, year 2010) is described: An umbrella-like device made out of a porous membrane is introduced via the radial or brachial artery, is deployed and is sitting at the outer curvature of the aortic arch where it deflects emboli away from the neck vessels. During the aortic valve intervention the device is sitting in place and is removed only once the TAVR procedure is terminated. In this feasibility study the device was implanted in four patients, three of them undergoing TAVR and one undergoing aortic balloon valvuloplasty. Radial access was used in all and no procedural complications occurred. No pressure difference was noted up- and downstream the device, indicating sufficient blood flow through the porous membranes. On a post-procedural cranial magnetic resonance imaging study, however, one new, clinically silent cortical infarct was noted. In conclusion we could show technical feasibility of the use of the Embrella device, with no interference of the device with the TAVR delivery system, no visible damage to the device after removal and sufficient blood-perfusion of the neck vessels. Additional median procedure time was 13 minutes from device insertion to removal. Given the low patient number, the study, does of course only allow a statement regarding feasibility, but not safety and efficacy of the device use.

In the second section, a current (year 2013) review of the pathogenesis of stroke during/after TAVR and of all currently available protection devices is given. Only half of the strokes occur during the TAVR procedure, while the other half occurs later in the course. Intraprocedural strokes are caused by embolization of mostly aortic valve and aortic wall debris. Despite the theoretical advantage when using cerebral protection devices, these devices themselves carry a risk of causing strokes by interfering with the aortic wall and/or the carotid arteries. 4 devices are currently on the market, whereof two deflect emboli away from the neck vessels, while two capture embolic material. These four devices are reviewed and the current evidence is summarized. One device is the Embrella device, a deflection device. A randomized study found new lesions on cerebral DW-MRI in all patients when the device was used, however, the volume of the lesions was overall smaller as comapred to patients where no device was used. A reduction in lesion volume without reduction in the numbers of lesions was also found for the second deflection device, the TriGuard. No data on cerebral embolism exists for the third device, the Montage Dual Filter device. A niche product is the second capture device, the Embol-X filter, which is sitting in the ascending aorta and can only be used for transaortic TAVR - no data on the efficacy of this device during TAVR procedures 
exist. The review article concludes, that at the current stage, not sufficient data exist that would justify the use of these protection devices.

\section{Chapter 2.2}

In this chapter stroke prevention by means of left atrial appendage occlusion (LAAO) is discussed:

In the first section a review article including original data is presented. The increased risk of stroke in patients suffering from atrial fibrillation is discussed, followed by a section discussing the pros and cons of the available medical therapies (oral anticoagulants). Although these medical therapies effectively reduce the stroke risk, the main drawback is the increased risk of bleeding. The rate of major bleeding with the newer and safer factor $\mathrm{X}$ and thrombin inhibitors are still in the range of 3-14\%/year. Since in atrial fibrillation, the majority of thrombi arise from the left atrial appendage, left atrial appendage occlusion (LAAO) is an attractive treatment to reduce the stroke risk without a risk of increased bleeding. The price for this advantage is procedural complications during LAAO, such as serious pericardial effusions (in about 2\%), device embolization or atrial perforation. Former and current devices are reviewed together with implantation techniques and follow-up care. At the Bern University Hospital the procedures were done in local anaesthesia and without transesophageal echocardiography guidance. Despite the fact that most LAAOs were performed in conjunction with other procedures (e.g. PFO closure, percutaneous coronary intervention), complication rate was acceptable $(6 \%)$ in the first 100 patients. No deaths or long-term disabilities occurred. The section concludes that LAAO has become an established therapy as an alternative to oral anticoagulation.

In the second section, the largest single-center experience with the longest follow-up (10-years, mean 32months) of LAAO is presented. In 152 patients LAAO was attempted with non-dedicated (32 patients; PFO-, VSD- and ASD-occluders) and dedicated (120 patients; Amplatzer Cardiac Plug) Amplatzer devices. While device-embolization was an issue with non-dedicated devices (occurring in 12\%), the incidence could be considerably reduced with the dedicated Amplatzer Cardiac Plug (incidence 2\%). During follow-up, embolic events occurred in three and major bleeding events in four patients. Reasons for LAAO were in order of their frequency: high-risk of bleeding, relevant previous bleeding, and patients' preference or high-risk of falls. The data show that with the new, dedicated devices, outcome could be considerably improved and that with these devices LAAO has become a valuable alternative to oral anticoagulation. 


\section{Chapter 2.3}

In this chapter the transapical access is discussed with a focus on percutaneous transapical access closure. If true percutaneous transpical access with percutaneous apical closure became a reality, the invasiveness of the transapical approach could be considerably reduced and outcomes potentially improved.

In the first section, a case of true percutaneous access and percutaneous closure is described. A 56-year old patient suffered from a severe paravalvular leak after repeated double-valve replacement. Percutaneous apical puncture was followed by introduction of a 9 French sheath, over which paravalvular leak closure was successfully performed. The novelty of the described technique was removal of the 9 French sheath and deployment of a $6 \mathrm{~mm}$ muscular VSD occluder at the apical entry site. Immediate and complete hemostasis was achieved and during follow-up the patient is doing well.

While this technique worked nicely for removal of a 9 French sheath, removal of larger bore devices (e.g. sheaths for transapical TAVR) may require different devices. Such a prototype device is described in the next section: in 6 acute pigs a 39 French hole in the porcine apex was completely sealed by a cellulose-based plug (device success 100\%). Repetitive contrast injections to the left ventricle and through the delivery sheath confirmed the stable position and stress testing (by adrenalin challenges to raise the left ventricular pressure $>200 \mathrm{mmHg}$ ) showed no device dislodgment. In another four pigs, a surgical cut-down was performed after device deployment and pull- and push forces were applied to document the force necessary to dislodge the device. Device dislodgment was found at forces corresponding to pressures of $247 \mathrm{mmHg}$. This study shows feasibility of closing even large bore holes in the apex. It paves the way for further research in this field.

\section{Chapter 2.4}

As compared to surgical aortic valve replacement, TAVR is still a relatively young technique and only small case series of autopsy results have been published. The next section describes the postmortem findings of a larger series of patients undergoing TAVR. Autopsy was performed in 17 patients, while three valves were removed from patients at the time of open-heart surgery. Of the 17 patients, 9 died within 7 days after TAVR, 4 died from days 7-30, while 4 died after 30 days and up to 30 months. Three valves were surgically removed after 108-336 days.

A frequent finding across all temporal categories was a less than round configuration of the valve, without any signs of enhanced valve degeneration. The same was true for dramatic changes in valve and stent deformation in a few specimens after chest compressions during resuscitation. Probe-patent paravalvular defects were commonly found, but did not correspond with the severity of paravalvular 
regurgitation during life. The same was true for other than round stent configurations or mild mal-alignments of valve-stents. Fibrous tissue ingrowth was found late after TAVR, ranging from minimal to extensive, but with interference with valve cusp mobility in only one single specimen. Another interesting finding was injury to the conduction system with evidence of direct traumatic injury (e.g. by the stent or calcified valve tissue) and ischemic injury (e.g. by stent compression of small septal arteries supplying the conduction system). Left main obstruction occurred in two patients, both with a short distance of the left main ostium to the annulus, despite normal sizes of their sinuses of Valsalva. In one patient with a small and heavily calcified annulus, an annular tear created a communication from the left ventricular outflow tract to the left atrium, also tearing the anterior mitral leaflet - this event was followed by hemodynamic collapse and death. In a third of all patients the presence of myocardial amyloidosis was noted and could have potentially contributed to progressive heart failure leading to death in three patients (after 40-943 days after TAVR).

Longer follow-up of valves may be necessary to determine the clinical significance of fibrous tissue ingrowth, which may potentially lead to valve degeneration over time. If such occurs, a repeat transcatheter procedure (valve-in-valve) could solve the problem.

\section{Chapter 3}

In this chapter, the issues of vascular complications, kidney injury and pacemaker implantation are discussed, followed by a more focused discussion on the most devastating complication after TAVR: stroke. Although initial analyses of the PARTNER trials documented more early neurologic events with TAVR as compared to surgery, the incidence leveled out over time. Methods to reduce the stroke rate after TAVR are welcomed. Cerebral protection devices are in my opinion not suited for this purpose and will not solve the problem. This is due to the preliminary findings on cerebral protection devices: equally many or even more ischemic lesions occurred when these devices were used, indicating that placement of the devices itself carries a certain risk. Furthermore, only 50\% of strokes occur intraprocedurally. There are more promising methods to reduce the rate of neurologic events: (1) reducing the size of the valve delivery systems will make the systems less traumatic, and (2) in patients suffering from atrial fibrillation the combination of left atrial appendage occlusion with TAVR is a promising way to hopefully reduce the stroke rate in this high-risk population. The subgroup of TAVR patients suffering from atrial fibrillation is not only exposed to a high thromboembolic risk, but also to a high-risk of suffering from major bleeding complications (if oral anticoagulation is prescribed). Left atrial appendage occlusion can reduce the stroke rate at least as effectively as oral anticoagulation, but at a significantly lower bleeding risk. 
Then the findings of the postmortem study are discussed. Durability of the transcatheter valves is an important issue. Even if valve degeneration occurs over time (and it will occur), the possibility of a repeat transcatheter valve-in-valve procedure still allows treating younger and lower risk patients with this new technique. Myocardial damage can occur acutely by displacement of the native valve leaflets, thereby obstruction a coronary ostium. Further, in case of coronary artery disease, even non-critical stenoses could lead to ischemia during prolonged periods of hypotension (e.g. during rapid pacing). It is still a matter of debate, if non-critical stenoses should be revascularized prior to TAVR.

An apical closure device that would enable a true percutaneous apical access (maybe even in local anaesthesia) may be less important for TAVR in the future, given the current technical developments enabling a transfemoral approach in more and more patients (with the most recent transfemoral delivery system requiring only a 14 French sheath). However, there are patients where a transfemoral access is not possible due to severe peripheral arterial disease. Also, percutaneous devices for mitral valve replacement are underway and may lead to a renaissance of the transapical access. By reducing the invasiveness of this access route, outcomes could potentially be improved in the future.

The final paragraph of this chapter focuses on the imminent clinical developments of the TAVR procedure: in my opinion, combining procedures (e.g. percutaneous coronary revascularisation, left atrial appendage occlusion and TAVR) is patient- and are resource-friendly and should be performed more often. I hope that in the near future ad-hoc TAVR will become a reality. Ad-hoc TAVR with combined procedures describes my vision on how TAVR should be performed in the near future. 
Part 4

Samenvatting (Summary in Dutch) 



\section{Hoofdstuk 1}

Transcatheter aortaklepimplantatie (TAVI) is een relatief jonge techniek. In het eerste hoofdstuk worden een historisch overzicht, een overzicht van de verschillende toegangsroutes en de klinische rol van TAVI gegeven.

De ontwikkeling van TAVI is begonnen met het implanteren van een prototype transcatheterklep die succesvol is geïmplanteerd in een varken. Dit prototype bestond uit een klep die gehecht was in een stent, die met een ballon geplaatst kon worden. Tien jaar later was Cribier de eerste die succesvol een transcatheter klepimplantatie uitvoerde bij de mens. De techniek, kleppen en implantatiesystemen zijn sterk verbeterd sinds de eerste plaatsing, waardoor TAVI nu een procedure is met goede en reproduceerbare uitkomsten. Initieel werd TAVI gebruikt voor patienten die inoperabel verklaard waren, later werden daar hoog-risicopatiënten aan toegevoegd. Beide populaties zijn onderzocht in de eerste, grote, gerandomiseerde PARTNER-trials. TAVI verbeterde de overleving en zorgde voor symptoomreductie ten opzichte van medicamenteuze therapie, waarbij bewezen werd dat TAVI noninferieur was aan chirurgische klepvervanging.

Als eerste keuze wordt voor een transfemorale toegangsweg gekozen, maar bij patiënten waarbij dat niet mogelijk is, kan gekozen worden voor transapicale, transaortale of transsubclaviale toegang.

Aan het einde van dit hoofdstuk worden de huidige uitdagingen besproken, waar verder op ingegaan zal worden in de volgende hoofdstukken:

- In de PARTNER-trial is er een trend richting meer neurologische complicaties in de TAVI-arm gevonden, vergeleken met chirurgische klepvervanging (Hoofdstuk 2.1).

- Speciale aandacht verdient de subgroep van TAVI-patiënten die lijden aan atriumfibrilleren: zij hebben een slechter resultaat en hogere kans op cerebrovasculaire accidenten vergeleken met patiënten in sinusritme. Dit is des te meer van belang omdat $30-40 \%$ van de TAVI-patiënten lijdt aan atriumfibrilleren. Afsluiting van het linker hartoor kan mogelijk het resultaat in deze subgroep van patiënten verbeteren (Hoofdstuk 2.2).

- Transapicale TAVI lijkt slechtere uitkomsten te geven vergeleken met een transfemorale benadering. Door de transapicale TAVI minder invasief te maken door een volledig percutane benadering met percutane apicale sluiting, kunnen mogelijk de uitkomsten verbeterd worden (Hoofdstuk 2.3).

- Er is meer informatie nodig over procedurele complicaties (zoals hoofdstamafsluiting) en het functioneren van de klep op lange termijn. Data verkregen na obductie en pathologisch onderzoek van geëxplanteerde kleppen leveren waardevolle informatie (Hoofdstuk 2.4). 


\section{Hoofdstuk 2.1}

In dit hoofdstuk wordt gesproken over cerebrovasculaire accidenten (CVA).

Er zijn verschillende devices ontwikkeld om tijdens TAVI embolisch débris af te buigen of af te vangen door de halsvaten te beschermen. Er zijn diverse overwegingen waar rekening mee gehouden moet worden bij het implanteren van dergelijke devices tijdens TAVI: (1) er moet voldoende bloeddoorstroming mogelijk blijven door de halsvaten, (2) het device moet gemakkelijk en snel in te brengen zijn om de procedurele tijd niet te veel te verlengen en (3) het device moet geen schade aanrichten, met name geen arteriële dissectie of cerebrale embolisatie.

In het eerste gedeelte wordt de eerste ervaring in de mens met het eerste beschikbare device dat beschermt tegen embolisatie beschreven (Embrella Embolic Deflector, jaar 2010). Dit is een op een paraplu gelijkend device dat gemaakt wordt van een poreus membraan en dat wordt ingebracht via de arteria radialis of brachialis. Het wordt ontvouwen en steunt tegen de bocht van de aortaboog, waar het embolieën wegvoert van de halsvaten. Het device blijft in situ gedurende de gehele TAVI-procedure en wordt na afloop verwijderd. In dit haalbaarheidsonderzoek is het device geïmplanteerd in vier patiënten, drie patiënten ondergingen TAVI en één een ballondilatatie van de aortaklep. Toegang via de arteria radialis werd gebruikt in alle patiënten en er traden geen complicaties op. Er was geen drukverschil vóór en na het device, wat aangeeft dat voldoende bloedstroom door het poreuze membraan mogelijk was. Op een post-procedurele MRI van de hersenen bleek er bij één patiënt een klinisch niet opgemerkt corticaal infarct aanwezig te zijn. Concluderend konden wij de haalbaarheid van het gebruik van het Embrella-device aantonen, waarbij er geen interferentie was met het gebruik van het TAVI-systeem, geen zichtbare schade aan het device na afloop en voldoende perfusie van de halsvaten. Additionele proceduretijd was 13 minuten van insertie tot verwijdering van het device. Gezien het kleine aantal patiënten in de studie kunnen er uit deze studie alleen conclusies getrokken worden aangaande haalbaarheid, en niet over veiligheid of effectiviteit van het device.

In het tweede gedeelte wordt een overzicht gegeven van de huidige stand van zaken (jaar 2013) betreffende pathogenese van CVA gedurende en na TAVI met alle beschikbare beschermingsdevices. Niet meer dan de helft van de CVA's vindt plaats gedurende de TAVI, de rest erna. Intraprocedurele CVA's worden meestal veroorzaakt door embolisatie van de aortaklep en débris uit de aortawand. Hoewel de cerebrale beschermingsdevices een theoretisch voordeel bieden, leiden deze devices ook tot een risico op CVA's door manipulatie van de aortawand en/of de halsarteriën. Er zijn op dit moment vier devices op de markt, waarvan er twee embolieën afbuigen van de halsvaten en twee devices het embolische materiaal afvangen. Deze vier devices worden besproken en het beschikbare bewijs wordt samengevat. Een van deze devices is het Embrella-device. Een gerandomiseerde studie toonde nieuwe laesies op cerebrale MRI in alle patiënten waarbij het device gebruikt werd, hoewel het volume van de laesies kleiner was dan die van patiënten waarbij geen 
device werd gebruikt. Een reductie in het volume van de laesies zonder reductie in het aantal laesies werd ook gevonden voor het tweede device dat embolieën afbuigt, de TriGuard. Er is geen data beschikbaar over cerebrale embolieën voor het derde device, het Montage Dual Filter-device. Een nicheproduct is het tweede device dat embolieën afvangt, het Embol-X filter, dat geplaatst wordt in de aorta ascendens en alleen gebruikt kan worden voor transaortale TAVI - er is geen data beschikbaar over de effectiviteit van dit device gedurende TAVI-procedures. Het overzichtsartikel concludeert dat er op dit moment niet voldoende data beschikbaar is om het gebruik van deze devices te rechtvaardigen.

\section{Hoofdstuk 2.2}

In dit hoofdstuk wordt preventie van CVA door afsluiting van het linker hartoor (LAAO) besproken.

In het eerste gedeelte wordt een overzichtsartikel, inclusief originele data, gepresenteerd. Het toegenomen risico op CVA in patiënten met atriumfibrilleren wordt besproken, gevolgd door een gedeelte waar de voor- en nadelen van de beschikbare medicamenteuze therapieën besproken worden (orale anticoagulantia). Hoewel deze medicamenteuze therapieën effectief het risico op ischemisch CVA verlagen, leiden ze tegelijkertijd tot een verhoogd risico op bloedingen. Bij het gebruik van de nieuwere en veiligere factor $\mathrm{X}$ - en thrombine-inhibitoren ligt het risico op belangrijke bloedingen nog steeds op $3-14 \% /$ jaar. Omdat in atriumfibrilleren de meeste embolieën ontstaan in het linker hartoor, is afsluiting hiervan (LAAO) een aantrekkelijke behandeling om het risico op CVA te verminderen zonder de verhoogde kans op bloedingen. De prijs die hiervoor betaald moet worden zijn de intraprocedurele complicaties gedurende LAAO, zoals ernstige pericardeffusie (in $2 \%$ ) en embolisatie of perforatie van het atrium. Er wordt een overzicht gegeven van oudere en huidige devices voor LAAO, tezamen met implantatietechnieken en nazorg. In het universitaire ziekenhuis van Bern werd de procedure uitgevoerd onder lokale anesthesie en zonder transoesofageale echogeleiding. Hoewel de LAAO-procedure vaak tegelijk gedaan werd met andere ingrepen (PFO-sluiting, percutane coronaire interventie), was het aantal complicaties acceptabel (6\%) in de eerste 100 patiënten. Er waren geen sterfgevallen of gevallen van langdurige beperkingen. Dit gedeelte concludeert dat LAAO een gevestigde therapie geworden is als een alternatief voor orale anticoagulantia.

In het tweede gedeelte wordt de grootste patiëntengroep die LAAO heeft ondergaan gepresenteerd die in één centrum behandeld is, met de langst bekende follow-up (10 jaar, gemiddeld 32 maanden). In 152 patiënten werd LAAO uitgevoerd, met niet-specifieke devices (32 patiënten; PFO-, VSD- en ASD-occluders) en specifieke devices (120 patiënten; Amplatzer Cardiac Plug). Hoewel deviceembolisatie een probleem was in niet-specifieke devices (12\% van de gevallen), werd de incidentie hiervan sterk gereduceerd door het gebruik van de Amplatzer 
Cardiac Plug (incidentie 2\%). Gedurende follow-up waren er trombo-embolische events in 3 patiënten en belangrijke bloedingen in vier patiënten. De indicatie voor LAAO was, in volgorde van frequentie: hoog bloedingsrisico, belangrijke bloeding in de voorgeschiedenis, patiëntenvoorkeur of een hoog valrisico. De data laten zien dat met de nieuwe, specifieke devices de uitkomsten duidelijk verbeterd zijn en dat met deze devices LAAO een waardevol alternatief is voor orale anticoagulantia.

\section{Hoofdstuk 2.3}

In dit hoofdstuk wordt de transapicale toegang besproken, met de focus op percutane sluiting van de transapicale toegang. Als volledig percutane transapicale toegang met percutane sluiting hiervan realiteit zou worden, zou de transapicale toegang veel minder invasief zijn en de uitkomsten hiervan mogelijk verbeterd kunnen worden.

In het eerste gedeelte wordt een casus van volledig percutane toegang met percutane sluiting beschreven. Een 56-jarige patiënt leed aan ernstige paravalvulaire lekkage na herhaalde dubbele klepvervanging. Na percutane apicale punctie werd een 9 French sheath ingebracht, waarover sluiting van het paravalvulaire lek succesvol werd uitgevoerd. De noviteit van de beschreven techniek bestond uit het verwijderen van de 9 French sheath en het inbrengen van een $6 \mathrm{~mm}$ musculair VSDoccluder op de plaats van de apicale toegang. Onmiddellijke en volledige hemostase werd bereikt en het gaat goed met de patiënt gedurende follow-up.

Hoewel deze techniek goed werkt na verwijdering van een 9 French sheath, vereist verwijdering van grotere devices (zoals sheaths voor transapicale TAVI) mogelijk een ander device. Een prototype hiervan wordt beschreven in het volgende gedeelte: in 6 varkens werd een 39 French opening in het apicale gedeelte van het varkenshart gesloten met een cellulose-plug (succespercentage 100\%). Herhaaldelijke contrastinjecties in het linkerventrikel en door de sheath bevestigden de stabiele positie van de plug en stress tests (adrenaline-injecties om de linkerventrikeldruk te verhogen tot $>200 \mathrm{mmHg}$ ) toonden geen dislocatie van het device. In vier andere varkens werd na chirurgische excisie gekeken hoeveel duw- en trekkracht nodig was om het device te dislokeren. Dislocatie van de device werd gevonden bij het toedienen van krachten die passen bij drukken van $247 \mathrm{mmHg}$. Deze studie toont de haalbaarheid van het sluiten van zelfs grotere gaten in de apex. Het opent mogelijkheden voor verder onderzoek in dit veld.

\section{Hoofdstuk 2.4}

Vergeleken met chirurgische aortaklepvervanging is TAVI nog een relatief jonge techniek en alleen kleine series van obductie-resultaten zijn gepubliceerd. Het vol- 
gende gedeelte beschrijft de postmortem bevindingen van een grotere groep patienten die TAVI ondergaan hebben. Obductie werd uitgevoerd in 17 patiënten, 3 kleppen werden verwijderd bij patiënten tijdens open-hart chirurgie. Van de 17 patiënten stierven er 9 binnen 7 dagen na TAVI, 4 tussen dag 7 en 30, en 4 gedurende de periode tussen 30 dagen en 30 maanden. Drie kleppen werden chirurgisch verwijderd na 108 - 336 dagen.

Een frequent voorkomende bevinding was een niet-ronde vorm van de klep, zonder tekenen van verhoogde klepdegeneratie. Hetzelfde werd gezien in dramatische klep- en stentdeformatie in een aantal casussen na borstcompressies gedurende reanimatie. Paravalvulaire defecten werden veel gevonden, maar correspondeerden niet met paravalvulaire regurgitatie tijdens het leven. Hetzelfde gold voor niet-ronde stentconfiguraties of milde onjuiste uitlijning van de klep-stents. Ingroei van fibreus weefsel werd laat na TAVI gevonden, variërend van mild tot uitgebreid, maar leidde maar bij één geval tot interferentie met mobiliteit van een klepblad. Een andere interessante vondst was schade aan het geleidingssysteem door directe traumatische schade (zoals door de stent of gecalcificeerd klepweefsel) en ischemische schade (zoals door compressie door de stent van kleine septale arteriën die het geleidingssysteem van bloed voorzien). Hoofdstamobstructie vond plaats in twee patiënten, beiden met een korte afstand tussen het ostium van de linker coronairarterie en de annulus, ondanks de normale grootte van de sinus van Valsalva. In een patiënt met een kleine en ernstig gecalcificeerde annulus ontstond een annulaire scheur waardoor communicatie tussen de linkerventrikel uitstroomtraject en het atrium ontstond, met daarbij ruptuur van het anterieure blad van de mitralisklep dit leidde dit hemodynamische collaps en dood. In een derde van de patiënten was myocardiale amyloïdose te zien, wat bijgedragen kan hebben aan progressief hartfalen, leidend tot de dood bij 3 patiënten (na 40-493 dagen na TAVI).

Langere follow-up van de kleppen kan nodig zijn om de klinische relevantie van ingroei van fibreus weefsel te bepalen, dat mogelijk kan leiden tot klepdegeneratie op de langere termijn. In dat geval kan een herhaalde transcatheter procedure (klep-in-klep) het probleem verhelpen.

\section{Hoofdstuk 3}

In dit hoofdstuk worden vasculaire complicaties, nierschade en pacemakerimplantatie besproken, gevolgd door een discussie gefocust op de meeste ernstige complicatie na TAVI: het cerebrovasculaire accident.

Hoewel initiële analyses van de PARTNER-trials meer vroege neurologische complicaties toonde voor TAVI vergeleken met chirurgie, trokken de incidenties steeds verder naar elkaar toe. Methoden om het aantal CVA's na TAVI te verminderen zijn welkom, maar de beschermingsdevices zijn naar mijn mening niet geschikt hiervoor en zullen het probleem niet oplossen. Dit is gebaseerd op vroege bevindingen over deze devices: er ontstonden even veel of zelfs meer ischemische laesies 
bij het gebruik van deze devices, wat impliceert dat het plaatsen van deze devices met risico's gepaard gaat. Daarbij vindt maar 50\% van de CVA's intraprocedureel plaats. Er zijn meer veelbelovende methoden die de prevalentie van neurologische complicaties kunnen verminderen: (1) verminderen van de grootte van de implantatiesystemenkunnen kan deze systemen minder traumatisch maken en (2) in patienten met atriumfibrilleren kan simultane afsluiting van het linker hartoor de prevalentie verminderen. De subgroep van TAVI-patiënten met atriumfibrilleren heeft niet alleen een hoog risico op trombo-embolieën, maar ook op ernstige bloedingen (als orale anticoagulantia worden voorgeschreven). Afsluiting van het linker hartoor is even effectief voor wat betreft het voorkomen van CVA, maar kent een significant lager risico op bloeding.

Hierna worden de bevindingen van de postmortem studie bediscussieerd. Levensduur van de transcatheterkleppen is een belangrijke kwestie. Zelfs als er klepdegeneratie is na verloop van tijd (wat valt te verwachten), maakt de mogelijkheid tot een herhaalde transcatheter klep-in-klep procedure het mogelijk jongere en laag-risicopatiënten te behandelen met deze nieuwe techniek. Schade aan het myocard kan acuut ontstaan door verplaatsing van de native klepbladen, waardoor het ostium van een coronair geobstrueerd kan worden. Daarbij, in het geval van coronarialijden, kunnen zelfs niet-significante stenoses leiden tot ischemie bij langere periodes van hypotensie (bijvoorbeeld tijdens snelle pacing). Het is nog steeds onderwerp van discussie of niet-significante stenoses gerevasculariseerd zouden moeten worden vóór TAVI.

Een apicaal sluitingsdevice die een volledig percutane apicale toegang mogelijk maakt (mogelijk zelfs onder lokale anesthesie) wordt mogelijk minder belangrijk voor TAVI in de toekomst, gezien de huidige technische ontwikkelingen waardoor een transfemorale benadering in steeds meer patiënten mogelijk wordt (waarbij het meest recente implantatiesysteem maar een 14 French sheath nodig heeft). Er blijven echter patiënten waarbij transfemorale toegang niet mogelijk is wegens perifeer vaatlijden. Daarbij zijn er ook devices in ontwikkeling voor percutane mitralisklepvervanging, wat kan leiden tot opleving van de transapicale toegangsweg. Door deze toegangsweg minder invasief te maken, kunnen uitkomsten mogelijk verbeterd worden in de toekomst.

De laatste paragraaf van dit hoofdstuk focust op de aankomende klinische ontwikkelingen van de TAVI-procedure: naar mijn mening is het combineren van procedures (bijvoorbeeld percutane coronaire revascularisatie, afsluiting van het linker hartoor en TAVI) patiënt- en kostenvriendelijk en zou dat vaker moeten plaatsvinden. Ik hoop dat ad-hoc TAVI in de toekomst werkelijkheid wordt. Ad-hoc TAVI met gecombineerde procedures beschrijven mijn visie op hoe TAVI in de toekomst uitgevoerd zou moeten worden. 
Part 5

Acknowledgment 

The heart is not an ordinary organ: it contracts every second, every day, for an entire lifetime - an incredible performance. Besides the scientific fascination, there is another fascinating aspect of heart: the heart is associated with emotions, such as love, generosity, kindness and life in general. A diseased heart is potentially life threatening - a broken heart, too. As cardiologists, we are experts on the medical aspect of treating diseased hearts, but we are always also exposed to the emotional connotation of the heart.

During my education and professional career, there were many people who accompanied me, helped me, from whom I learned, with whom I shared. I would like to take the opportunity to thank a few of them in chronological order - making no claim to be complete: Andreas Flammer with whom I went through all the up's and down's during medical school and with whom I only lately started working together at the same hospital again. Igal Moarof with whom I not only share my passion for interventional cardiology, but in whom I also found a friend to share a passion for good food and wine. Hanspeter Brunner - La Rocca who introduced me to clinical research and clinical cardiology, a tutor and friend who had a big impact on my career. John Webb, my mentor and friend from whom I learned interventional cardiology and who introduced me to the field of structural interventions. Last but not least, Bernhard Meier, a role model and friend, from whom I learned a lot, from whom I got my vision on how to practice interventional cardiology and who encouraged me to stay on the treaded path despite potential obstacles. Francesco Maisano a truly unusual heart surgeon with whom I work closely together at the University Hospital Zurich, who inspires me with his pioneering spirit and who became a good friend. I am honoured and thankful to having met these people during my professional career.

Besides, there are many best friends and family who allowed me to become who I am - personally and professionally. I would like to particularly thank my parents Erna und Peter Nietlispach; my sister Barbara Nietlispach with her husband Christoph and her children Noah, Julian and Florin; my good friends Brigitte Steiger, Jean-Daniel Schlegel, Philipp Schuetz, Sabina Hunziker, Joerg Brunner, Gaby LaRocca, Esther and Lars De Bekker, Sandrine Zweifel, Philipp and Antoinette Hediger, Jeff Vopni, Erin Garrity, Jennifer Webb, Ron Carere, Pascal Haegeli, Lisa Ochowycz, Christoph Graeni and Sam D'Cruz and many more.

And my very special thanks go to Heidi Adler. 

Part 6

Curriculum Vitae and Publication List 

Fabian Nietlispach was born in Zug, Switzerland. After high-school, travels and curiousness made him spend 5 months in Malibu, California where he attended classes at Pepperdine University. He graduated Medicine at the University of Basel and completed his Cardiology residency in Switzerland, besides a rotation in Valladolid, Spain.

A cornerstone of his professional development was a two year fellowship

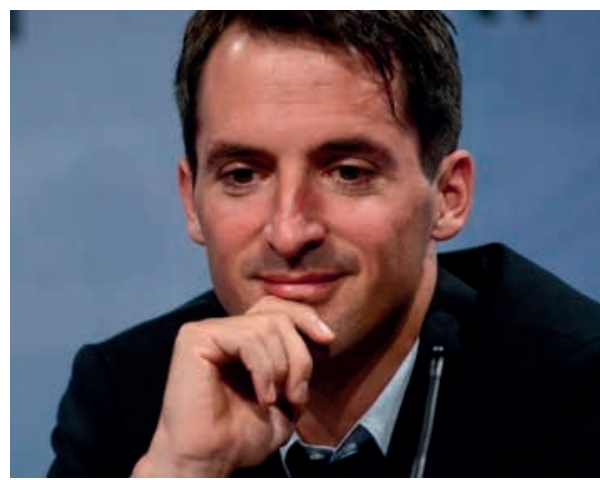
at the University of British Columbia, where he specialized in Interventional Cardiology and was trained in structural interventions by Dr. John Webb, the pioneer of transcatheter valve implantation. Back in Switzerland he worked as an attending physician in Basel, followed by a staff position in Bernhard Meier's Team at the University Hospital Bern. His current position is Head Transcatheter Aortic Valve Implantation at the Andreas Gruentzig Laboratories at the University Hospital Zurich. His special interests comprise Transcatheter Aortic Valve Implantation (TAVI), left atrial appendage occlusion (LAAO) and percutaneous perivalvular leak closures.

Besides a fascination for structural interventions, Fabian Nietlispach loves to travel the world with extended trips to the US, Canada, Mexico, Guatemala, Costa Rica, Belize, Thailand, Vietnam, Indonesia, Israel and many destinations in Europe. Being a proctor for Edwards Lifesciences for TAVI and for St. Jude Medical for LAAO enables him to combine work with his affection for travelling.

In the spirit of 'mens sana in corpore sano', Fabian completed marathons, worked as a swim- and ski-instructor and also practises snowboarding, wind- and kite-surfing, tennis and scuba diving. 


\section{Original Publications:}

Amplatzer left atrial appendage occlusion through a patent foramen ovale.

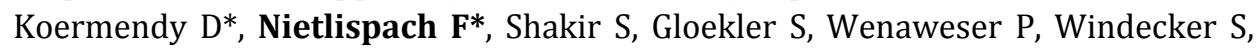
Khattab AA, Meier B.

Catheter Cardiovasc Interv. 2014 Jan 8. doi: 10.1002/ccd.25354. [Epub ahead of print]

*shared first authorship

Long-Term Results of Intensified, N-Terminal-Pro-B-Type Natriuretic PeptideGuided Versus Symptom-Guided Treatment in Elderly Patients With Heart Failure: Five-Year Follow-Up From TIME-CHF.

Sanders-van Wijk S, Maeder MT, Nietlispach F, Rickli H, Estlinbaum W, Erne P, Rickenbacher P, Peter M, Pfisterer MP, Brunner-La Rocca HP; TIME-CHF Investigators.

Circ Heart Fail. 2014 Jan 1;7(1):131-9.

Biomarkers in outpatient heart failure management; Are they correlated to and do they influence clinical judgment?

Peeters JM, Sanders-van Wijk S, Bektas S, Knackstedt C, Rickenbacher P, Nietlispach F, Handschin R, Maeder MT, Muzzarelli SF, Pfisterer ME, Brunner-La Rocca HP.

Neth Heart J. 2013 Dec 14. [Epub ahead of print]

Ad hoc percutaneous left atrial appendage closure.

Nietlispach F, Krause R, Khattab A, Gloekler S, Schmid M, Wenaweser P, Windecker $\mathrm{S}$, Meier B.

J Invasive Cardiol. 2013 Dec;25(12):683-6.

Clinical outcomes of patients with low-flow, low-gradient, severe aortic stenosis and either preserved or reduced ejection fraction undergoing transcatheter aortic valve implantation.

O'Sullivan CJ, Stortecky S, Heg D, Pilgrim T, Hosek N, Buellesfeld L, Khattab AA, Nietlispach F, Moschovitis A, Zanchin T, Meier B, Windecker S, Wenaweser P.

Eur Heart J. 2013 Nov;34(44):3437-50.

Transapical access closure: the TA PLUG device.

Brinks H*, Nietlispach F*, Göber V, Englberger L, Wenaweser P, Meier B, Carrel T, Huber C.

Interact Cardiovasc Thorac Surg. 2013;17(5):806-10

*shared first authorship 
Transcatheter left atrial appendage closure in patients with atrial fibrillation

Schmid M, Gloekler S, Saguner AM, Wahl A, Fischer U, Arnold M, Khattab AA, Nietlispach F, Guerios E, Wenaweser M, Windecker S, Meier B

Cardiovascular Medicine 2013;16(4):123-130

Amplatzer left atrial appendage occlusion: Single center 10-year experience.

Nietlispach F, Gloekler S, Krause R, Shakir S, Schmid M, Khattab AA, Wenaweser P, Windecker S, Meier B.

Catheter Cardiovasc Interv. 2013;82(2):283-9

Customized Covered Stent Graft for Percutaneous Closure of Fontan Baffle Leak Binder RK, Nietlispach F, Carere RG.

J Invasive Cardiol 2013, 2013 May;25(5):E118-22

Aortic root dimensions among patients with severe aortic stenosis undergoing transcatheter aortic valve replacement.

Buellesfeld L, Stortecky S, Kalesan B, Gloekler S, Khattab AA, Nietlispach F, Delfine V, Huber C, Eberle B, Meier B, Wenaweser P, Windecker S.

JACC Cardiovasc Interv. 2013 Jan;6(1):72-83

Pathology of Transcatheter Valve Therapy

Nietlispach F, Webb JG, Ye J, Cheung A, Lichtenstein SV, Carere RG, Gurvitch R, Thompson CR, Ostry AJ, Matzke L, Allard M.

JACC Cardiovasc Interv. 2012 May;5(5):582-90.

Cerebrovascular accidents complicating transcatheter aortic valve implantation: frequency, timing and impact on outcomes.

Stortecky S, Windecker S, Pilgrim T, Heg D, Buellesfeld L, Khattab AA, Huber C, Gloekler S, Nietlispach F, Mattle H, Jüni P, Wenaweser P.

EuroIntervention. 2012 May 15;8(1):62-70.

A high-risk period for cerebrovascular events exists after transcatheter aortic valve implantation.

Tay EL, Gurvitch R, Wijesinghe N, Nietlispach F, Wood D, Cheung A, Ye J, Lichtenstein SV, Carere R, Thompson C, Webb JG.

JACC Cardiovasc Interv. 2011 Dec;4(12):1290-7.

Frequency and Predictors of Hyperkalemia in Patients $\geq 60$ Years of Age With Heart Failure Undergoing Intense Medical Therapy.

Muzzarelli S, Maeder MT, Toggweiler S, Rickli H, Nietlispach F, Julius B, Burkard T, Pfisterer ME, Brunner-La Rocca HP; TIME-CHF Investigators.

Am J Cardiol. 2012 Mar 1;109(5):693-8 
Transcatheter aortic valve implantation: Lessons from the learning curve of the first 270 high-risk patients.

Gurvitch R, Tay EL, Wijesinghe N, Ye J, Nietlispach F, Wood DA, Lichtenstein S, Cheung A, Webb JG.

Catheter Cardiovasc Interv. 2011 Dec 1;78(7):977-8.

Valve thrombosis after transcatheter heart valve implantation.

Tay EL, Gurvitch R, Wijeysinghe N, Nietlispach F, Wood D, Allard M, Munt B, Cheung A, Webb JG.

EuroIntervention. 2011 May;7(1):170-1.

Outcome of patients after transcatheter aortic valve embolization.

Tay EL, Gurvitch R, Wijeysinghe N, Nietlispach F, Leipsic J, Wood DA, Yong G, Cheung A, Ye J, Lichtenstein SV, Carere R, Thompson C, Webb JG.

JACC Cardiovasc Interv. 2011 Feb;4(2):228-34.

An embolic deflection device for aortic valve interventions.

Nietlispach F, Wijesinghe N, Gurvitch R, Tay E, Carpenter JP, Burns C, Wood DA, Webb JG.

JACC Cardiovasc Interv. 2010 Nov;3(11):1133-8.

Multislice computed tomography for prediction of optimal angiographic deployment projections during transcatheter aortic valve implantation.

Gurvitch R, Wood DA, Leipsic J, Tay E, Johnson M, Ye J, Nietlispach F, Wijesinghe N, Cheung A, Webb JG.

JACC Cardiovasc Interv. 2010 Nov;3(11):1157-65.

Transcatheter aortic valve implantation in patients with bicuspid aortic valve stenosis.

Wijesinghe N, Ye J, Rodés-Cabau J, Cheung A, Velianou JL, Natarajan MK, Dumont E, Nietlispach F, Gurvitch R, Wood DA, Tay E, Webb JG.

JACC Cardiovasc Interv. 2010 Nov;3(11):1122-5.

Transcatheter aortic valve implantation: durability of clinical and hemodynamic outcomes beyond 3 years in a large patient cohort.

Gurvitch R, Wood DA, Tay EL, Leipsic J, Ye J, Lichtenstein SV, Thompson CR, Carere RG, Wijesinghe N, Nietlispach F, Boone RH, Lauck S, Cheung A, Webb JG.

Circulation. 2010 Sep 28;122(13):1319-27..

Impact of coronary artery disease on outcomes after transcatheter aortic valve implantation.

Masson JB, Lee M, Boone RH, Al Ali A, Al Bugami S, Hamburger J, John Mancini GB, Ye J, Cheung A, Humphries KH, Wood D, Nietlispach F, Webb JG. 
Catheter Cardiovasc Interv. 2010 Aug 1;76(2):165-73.

Transcatheter closure of paravalvular defects using a purpose-specific occluder.

Nietlispach F, Johnson M, Moss RR, Wijesinghe N, Gurvitch R, Tay EL, Thompson C, Webb JG.

JACC Cardiovasc Interv. 2010 Jul;3(7):759-65.

First-in-man use of a tapered endovascular stent graft for treatment of aneurysm after coarctation repair.

Nietlispach F, Leipsic J, Wijesinghe N, Webb JG, Carere RG.

Catheter Cardiovasc Interv. 2010 Dec 1;76(7):1035-40.

Role of RAS inhibition in the regulation of $\mathrm{Cu} / \mathrm{Zn}-\mathrm{SOD}$ in the cardiac and peripheral arterial beds in humans.

Kuster GM, Nietlispach F*, Kiowski W, Schindler R, Bernheim A, Schuetz P, Mueller B, Morgenthaler NG, Rüter F, Riesen W, Rickli H, Brunner-La Rocca HP.

Clin Pharmacol Ther. 2010 Jun;87(6):686-92.

*shared first authorship

Transapical transcatheter aortic valve implantation: follow-up to 3 years.

Ye J, Cheung A, Lichtenstein SV, Nietlispach F, Albugami S, Masson JB, Thompson CR, Munt B, Moss R, Carere RG, Jamieson WR, Webb JG.

J Thorac Cardiovasc Surg. 2010 May;139(5):1107-13, 1113.e1. 
Transcatheter valve-in-valve implantation for failed bioprosthetic heart valves.

Webb JG, Wood DA, Ye J, Gurvitch R, Masson JB, Rodés-Cabau J, Osten M, Horlick E, Wendler O, Dumont E, Carere RG, Wijesinghe N, Nietlispach F, Johnson M, Thompson CR, Moss R, Leipsic J, Munt B, Lichtenstein SV, Cheung A.

Circulation. 2010 Apr 27;121(16):1848-57.

Transcatheter aortic valve implantation for the treatment of severe symptomatic aortic stenosis in patients at very high or prohibitive surgical risk: acute and late outcomes of the multicenter Canadian experience.

Rodés-Cabau J, Webb JG, Cheung A, Ye J, Dumont E, Feindel CM, Osten M, Natarajan MK, Velianou JL, Martucci G, DeVarennes B, Chisholm R, Peterson MD, Lichtenstein SV, Nietlispach F, Doyle D, DeLarochellière R, Teoh K, Chu V, Dancea A, Lachapelle $\mathrm{K}$, Cheema A, Latter D, Horlick E.

J Am Coll Cardiol. 2010 Mar 16;55(11):1080-90.

Acute kidney injury following transcatheter aortic valve implantation: predictive factors, prognostic value, and comparison with surgical aortic valve replacement.

Bagur R, Webb JG, Nietlispach F, Dumont E, De Larochellière R, Doyle D, Masson JB, Gutiérrez MJ, Clavel MA, Bertrand OF, Pibarot P, Rodés-Cabau J.

Eur Heart J. 2010 Apr;31(7):865-74.

Current balloon-expandable transcatheter heart valve and delivery systems.

Nietlispach F, Wijesinghe N, Wood D, Carere RG, Webb JG.

Catheter Cardiovasc Interv. 2010 Feb 1;75(2):295-300.

CT of the ilio-femoral arteries using direct aortic contrast injection: proof of feasibility in patients screened towards percutaneous aortic valve replacement.

Nietlispach F, Leipsic J, Al-Bugami S, Masson JB, Carere RG, Webb JG.

Swiss Med Wkly. 2009 Aug 8;139(31-32):458-62.

Stent thrombosis up to 3 years after stenting for ST-segment elevation myocardial infarction versus for stable angina--comparison of the effects of drug-eluting versus bare-metal stents.

Leibundgut G, Nietlispach F*, Pittl U, Brunner-La Rocca H, Kaiser CA, Pfisterer ME. Am Heart J. 2009 Aug;158(2):271-6.

\section{*shared first authorship}

Transcatheter aortic valve implantation: impact on clinical and valve-related outcomes.

Webb JG, Altwegg L, Boone RH, Cheung A, Ye J, Lichtenstein S, Lee M, Masson JB, Thompson C, Moss R, Carere R, Munt B, Nietlispach F, Humphries K.

Circulation. 2009 Jun 16;119(23):3009-16. 
BNP-guided vs symptom-guided heart failure therapy: the Trial of Intensified vs Standard Medical Therapy in Elderly Patients With Congestive Heart Failure (TIMECHF) randomized trial.

Pfisterer M, Buser P, Rickli H, Gutmann M, Erne P, Rickenbacher P, Vuillomenet A, Jeker U, Dubach P, Beer H, Yoon SI, Suter T, Osterhues HH, Schieber MM, Hilti P, Schindler R, Brunner-La Rocca HP; TIME-CHF Investigators.

JAMA. 2009 Jan 28;301(4):383-92.

Long-term benefit-risk balance of drug-eluting vs. bare-metal stents in daily practice: does stent diameter matter? Three-year follow-up of BASKET.

Pfisterer M, Brunner-La Rocca HP, Rickenbacher P, Hunziker P, Mueller C, Nietlispach F, Leibundgut G, Bader F, Kaiser C; BASKET.

Eur Heart J. 2009 Jan;30(1):16-24.

Long-term outcomes after intracoronary Beta-irradiation for in-stent restenosis in bare-metal stents.

Maeder MT, Pfisterer ME, Buser PT, Roser HW, Roth J, Weilenmann D, Nietlispach FP, Zellweger MJ, Amsler B, Kaiser CA.

J Invasive Cardiol. 2008 Apr;20(4):179-84.

Influence of acute and chronic mineralocorticoid excess on endothelial function in healthy men.

Nietlispach F, Julius B, Schindler R, Bernheim A, Binkert C, Kiowski W, Brunner-La Rocca HP.

Hypertension. 2007 Jul;50(1):82-8.

Echocardiographic quantification of atherosclerosis leads to cost-effective treatment with statins.

Nietlispach F, Hug B, Jansen C, Barbosa V, Keller D, Buser PT, Siegemund M, Marsch S, Hunziker PR.

Swiss Med Wkly. 2005 Jan 22;135(3-4):62-8.

Bedside quantification of atherosclerosis severity for cardiovascular risk stratification: a prospective cohort study.

Hunziker PR, Imsand C, Keller D, Hess N, Barbosa V, Nietlispach F, Liel-Cohen N, Weyman AE, Pfisterer M, Buser P.

J Am Coll Cardiol. 2002 Feb 20;39(4):702-9.

\section{Reviews:}

Cerebral protection devices for transcatheter aortic valve implantation: is better the enemy of good? 
Praz F, Nietlispach F.

EuroIntervention, 2013;9Suppl.;S124-8

Transcatheter Aortic Valve Implantation - an attractive treatment option

Nietlispach F., Meier B.

Eur Geriatr Med., 2013;4:260-265

Cerebral protection devices for transcatheter aortic valve implantation

Nietlispach $\mathbf{F}$.

Cardiovascular Medicine 2012;15(10):287-92

Percutaneous Left Atrial Appendage Closure

Nietlispach F, Gloekler S, Khattab A, Pilgrim T, Schmid M, Wenaweser P, Windecker S, Meier B.

Eur Geriatr Med. 2012;3(5):308-311

Transcatheter aortic valve implantation : What do anesthetists need to know?.

Riediger C, Nietlispach F, Rüter F, Fassl J.

Anaesthesist. 2011 Dec;60(12):1095-108.

Drug-eluting coronary stents in clinical practice: lessons from the «BAsel Stent Kosten-Effektivitäts Trials» (BASKET).

Pfisterer M, Nietlispach F, Jeger R, Kaiser C.

Swiss Med Wkly. 2011 Aug 31;141

The evolving role of MDCT in transcatheter aortic valve replacement: a radiologists' perspective.

Leipsic J, Wood D, Manders D, Nietlispach F, Masson JB, Mayo J, Al-Bugami S, Webb $\mathrm{JG}$.

Am J Roentgenol. 2009 Sep;193(3):W214-9.

Antiplatelet Therapy: what do you do if the patient with a drug-eluting stent needs elective noncardiac surgery?

Pfisterer M, Zellweger MJ, Filipovic M, Nietlispach F

Dialogues Cardiovasc Med 2008;13:262-6

Praktische Probleme bei älteren Patienten mit Herzinsuffizienz (,Clinical problems of elderly patients with heart failure')

Nietlispach F, Pfisterer M

Swiss Medical Forum, 2003 Dec 10;50:1237-40 


\section{Case reports:}

Catch me if you can

Attinger A, Landmesser U, Luscher TF, Nietlispach F

Eur Heart J., in press

Closure of apical access site after transapical, transcatheter paravavlular leak closure.

Nietlispach F, Eckstein F, Seeberger M, Osswald S, Kaufmann BA, Reuthebuch 0 Can J Cardiol. 2012 Jul-Aug;28(4):516.e5-7.

\section{Book chapters:}

\section{Nietlispach F, Meier B}

Amplatzer Cardiac Plug

In: Percutaneous Interventions in Structural, Valvular and Congenital Heart Disease, Second edition; Sievert H, Qureshi SA, Wilson N, Hijazi ZM

Webb JG, Nietlispach F

Transcatheter Aortic Valve Replacement

In: Oxford Textbook of Interventional Cardiology

Nietlispach F, Webb JG.

Implantation of the Edwards SAPIEN valve.

In: Serruys PW CA, Webb J, Laborde JC, Piazza N, de Jaegere P, ed. Percutaneous implantation of the aortic valve - tips and tricks to avoid failure: Informa; 2009 